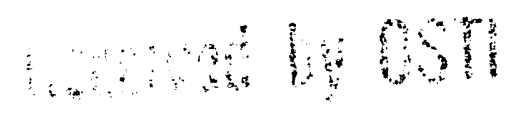

OCT 231991

NUREG/GR-0003

\section{تffect of Prior Deformation}

on Sensitization Development

n Stainless Steel During

Jontinuous Cooling

:epared by

W. Simmons

epartment of Materials Science and Engineering

regon Graduate Institute of Science and Technology

repared for

.S. Nuclear Regulatory Commission 


\section{NOTICE}

This document was prepared with the support of the U.S. Nuclear Regulatory Commission (NRC) Grant Program. The purpose of the NRC Grant Program is to support basic, advanced, and developmental scientific research for a public purpose in areas relating to nuclear safety. The nature of NRC's Grant Program is such that the grantee bears prime responsibility for the conduct of the research and exercises judgement and original thought toward attaining the scientific goals. The opinions, findings, conclusions and recommendations expressed herein are therefore those of the author(s) and do not necessarily reflect the views of the NRC.

Available from

Superintendent of Documents

U.S. Government Printing Office

P.C. Box 37082

Washington, DC 20013-7082

and

National Technical Information Service

Springfield, VA 22161 
NUREG/GR--0003

TI92 001770

\section{Effect of Prior Deformation on Sensitization Development in Stainless Steel During Continuous Cooling}

Manuscript Completed: September 1991

Date Published: September 1991

Prepared by

J. W. Simmons

Contributing Authors:

D. G. Atteridge, S. M. Bruemmer*

Department of Materials Science and Engineering Oregon Graduate Institute of Science and Technology Beaverton, OR 97006-1999

Prepared for

Division of Engineering Office of Nuclear Regulatory Research

U.S. Ruclear Regulatory Commission

Washington, DC 20555

iNRC FIN G1107

Under Grant No. NRC-G-04-87-105

*Pacific Northwest Laboratory

Richland, WA 99352

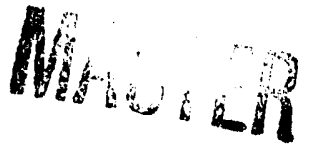




\section{ABSTRACT}

Continuous cooling sensitization (CCS) occurs in austenitic stainless steel (SS) weldment HAZs where the material is subjected to weld-induced plastic deformation, and non-linear heating and cooling cycles. The primary purpose of this investigation was to quantitatively determine the effects of prior deformation on CCS. In addition, these results were used to develop a CCS data base for comparison to a recently published sensitization prediction model (SSDOS). ${ }^{1}$

Continuous cooling thermal cycling of specimens from high-carbon Type 316 SSs was performed in a computer-controlled Gleeble thermal simulator. The degree of sensitization (DOS) of thermally treated specimens was quantitatively measured using the electrochemical potentiokinetic reactivation (EPR) test. Sensitization values for the thermal cycles employed in the investigation were predicted using the SSDOS sensitization prediction model.

Prior deformation significantly enhanced the rate of CCS development in the Type 316 SS material. The DOS increased with increasing amounts of prior strain and decreasing cooling rates. Sensitization response was also sensitive to peak cycle temperatures. Continuous cooling sensitization development occurred primarily in the critical temperature range between about 900 and $750^{\circ} \mathrm{C}$. Peak cycle temperatures of 1000 and $1050^{\circ} \mathrm{C}$ retarded sensitization development during subsequent continuous cooling. Strain recovery at elevated temperatures played an important role in reducing the effectiveness of prior deformation in accelerating sensitization kinetics. Due to the effects of recovery, in certain cases, prior strain values of $20 \%$ were only as effective as $10 \%$ in increasing the rate of sensitization development. Limited transoranular carbide precipitation was observed in $20 \%$ prior strain samples depending on specific thermal cycle parameters but was not a significant factor in the present work. The SSDOS model consistently overpredicted the CCS development in both heats of 316 SS studied, regardless of material condition (i.e. mill-annealed, solution-annealed, and pre-strained materials). The exact reason for this is not known. However, the results indicate that carbide nucleation characteristics are important in CCS and need to be considered for sensitization modeling.

\footnotetext{
'S.M. Bruemmer, CORROSION/89, Paper No. 561, National Association of Corrosion Engineers (1989).
} 


\section{CONTENTS}

ABSTRACT $\ldots \ldots \ldots \ldots \ldots \ldots \ldots \ldots \ldots \ldots \ldots \ldots \ldots \ldots \ldots \ldots \ldots \ldots \ldots \ldots \ldots$

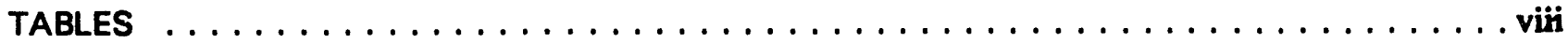

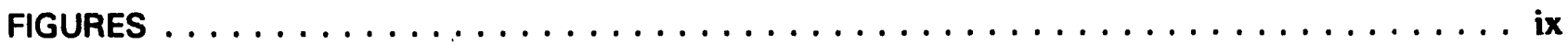

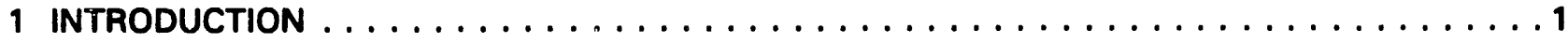

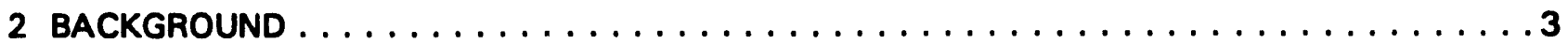

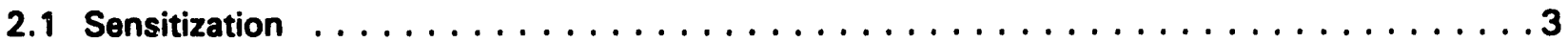

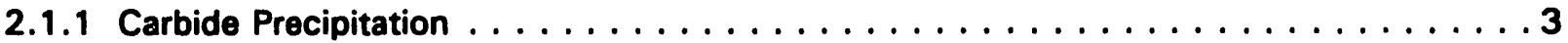

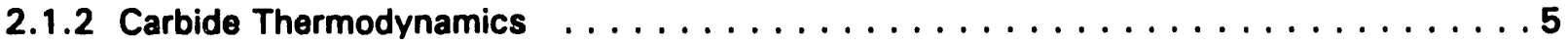

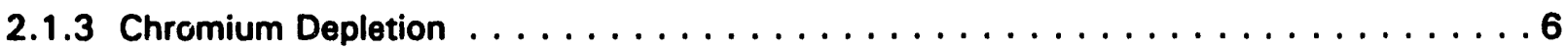

2.2 Desensitization (Self-Healing) $\ldots \ldots \ldots \ldots \ldots \ldots \ldots \ldots \ldots \ldots \ldots \ldots \ldots$

2.3 Effects of Alloying Elements on Sensitization. $\ldots \ldots \ldots \ldots \ldots \ldots \ldots \ldots \ldots$

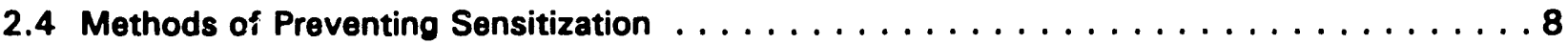

2.5 Measurement of the Degree of Sensitization (DOS) $\ldots \ldots \ldots \ldots \ldots \ldots \ldots$

2.5.1 Oxalic Acid Test (ASTM A 262, Practice A) . . . . . . . . . . . . . . 9

2.5.2 Modified Strauss Test (ASTM A 262, Practice E) $\ldots \ldots \ldots \ldots \ldots \ldots$

2.5.3 Electrochemical Potentiokinetic Reactivation (EPR) Test $\ldots \ldots \ldots \ldots \ldots \ldots$

2.5.4 Direct Measurement of Chromium Depletion $\ldots \ldots \ldots \ldots \ldots \ldots \ldots \ldots$

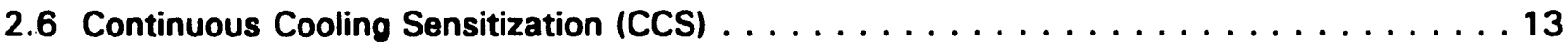

2.7 Effects of Strain on Carbide Precipitation and Sensitization $\ldots \ldots \ldots \ldots \ldots \ldots$

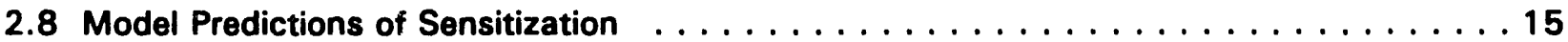

3 EXPERIMENTAL PROCEDURES $\ldots \ldots \ldots \ldots \ldots \ldots \ldots \ldots \ldots \ldots \ldots \ldots \ldots$

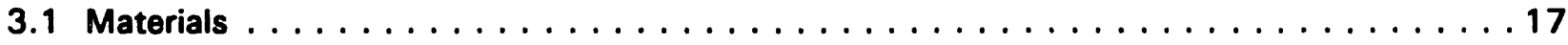

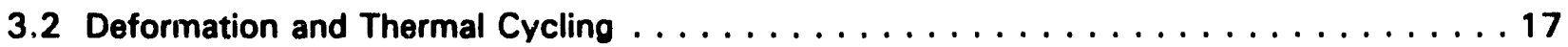

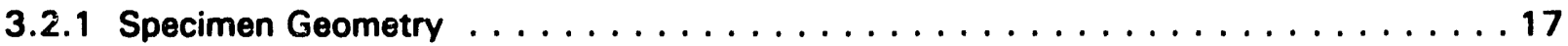

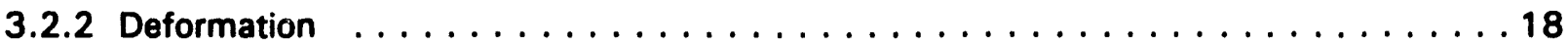


3.2.3 Continuous Cooling Thermal Cycling $\ldots \ldots \ldots \ldots \ldots \ldots \ldots \ldots \ldots \ldots \ldots \ldots \ldots \ldots \ldots$

3.3 CCS of Mill-Annealed and Solution-Annealed Materials $\ldots \ldots \ldots \ldots \ldots \ldots$

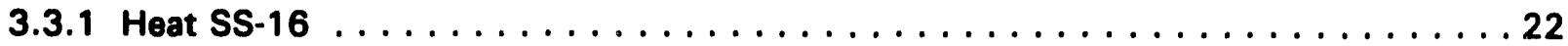

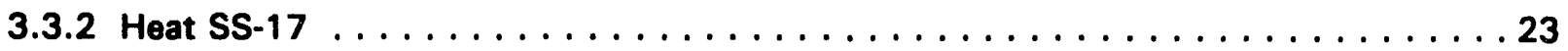

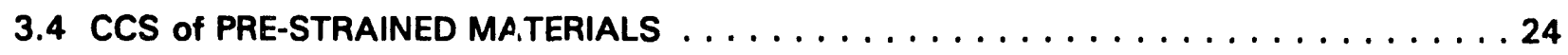

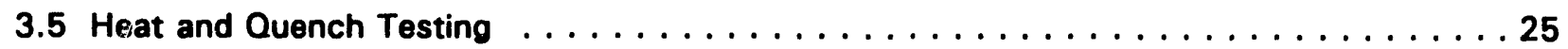

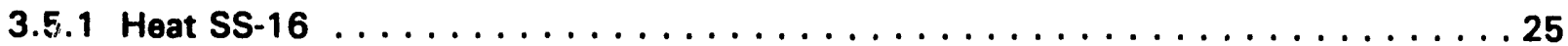

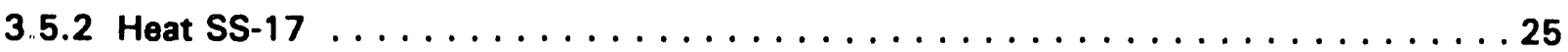

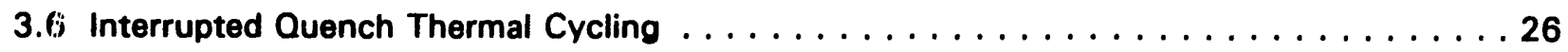

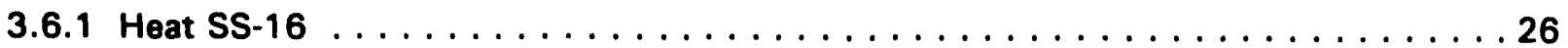

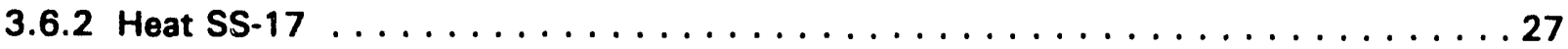

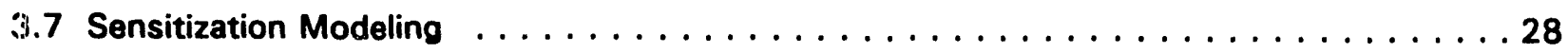

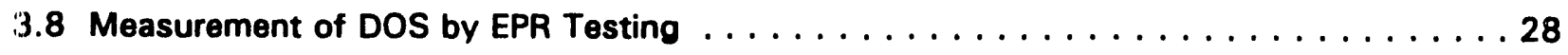

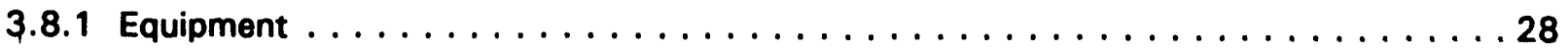

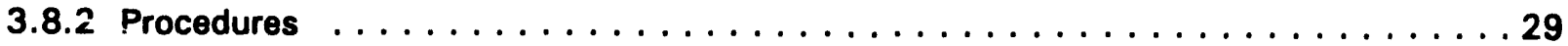

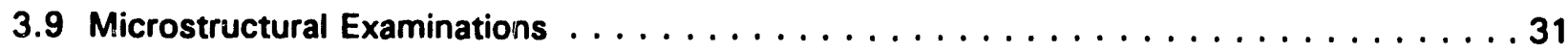

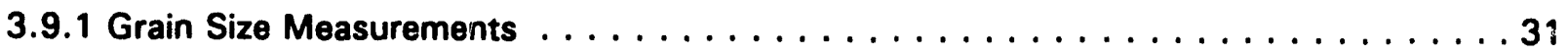

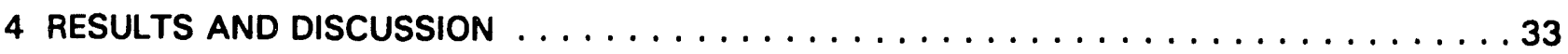

41 CCS of Mill-Annealed and Solution-Annealed Materials $\ldots \ldots \ldots \ldots \ldots$

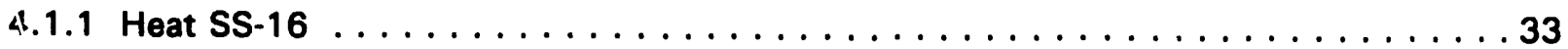

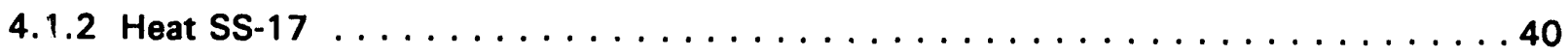

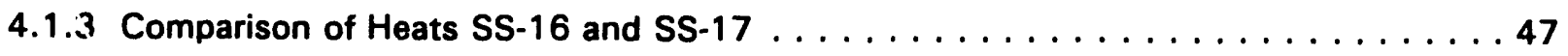

4.2 Effects of Prior Deformation on CCS Development $\ldots \ldots \ldots \ldots \ldots \ldots$

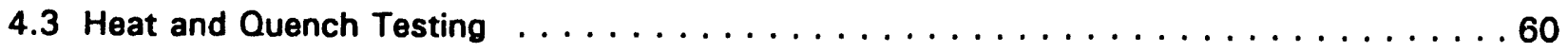

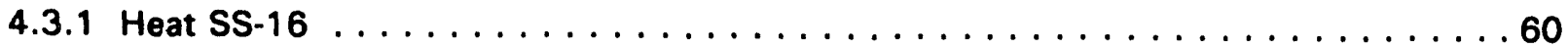

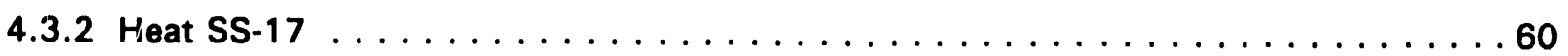


4.4 Interrupted-Quench Thermal Cycling $\ldots \ldots \ldots \ldots \ldots \ldots \ldots$

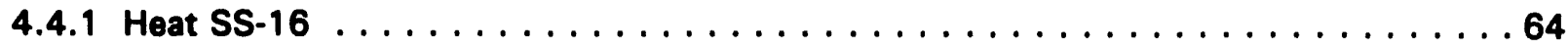

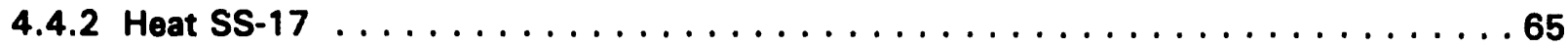

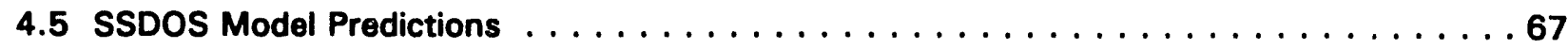

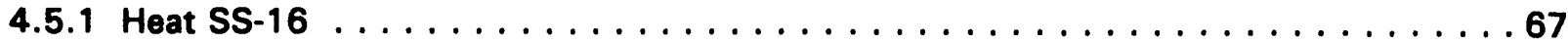

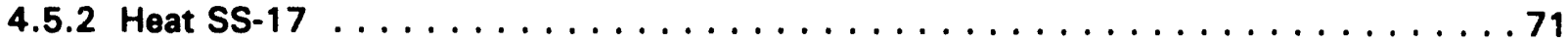

4.5.3 Comparisons with Other CCS Investigations $\ldots \ldots \ldots \ldots \ldots \ldots$

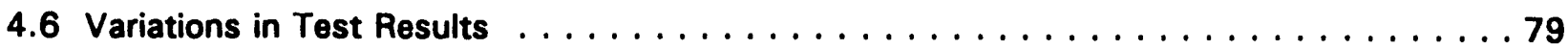

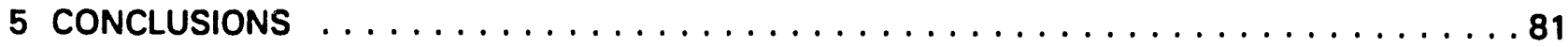

6 FUTURE WORK RECOMMENDATIONS $\ldots \ldots \ldots \ldots \ldots \ldots$

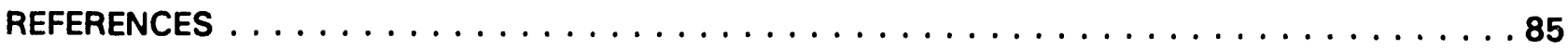

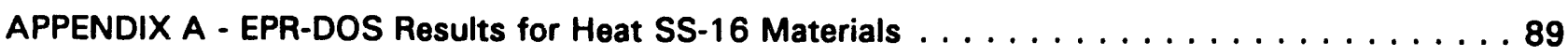

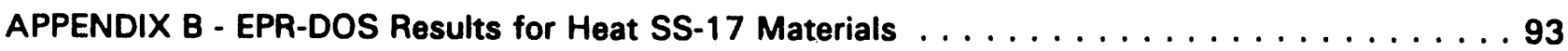




\section{TABLES}

1. Bulk Compositions of AISI Typo 316 SS Heats $\ldots \ldots \ldots \ldots \ldots \ldots \ldots \ldots \ldots$

2. Test Matrix for SS-16 MA and SA Materials $\ldots \ldots \ldots \ldots \ldots \ldots \ldots \ldots \ldots \ldots$

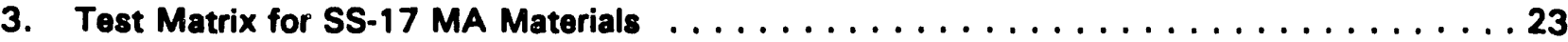

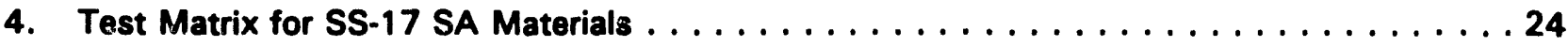

5. Test Matrix for SS-17 Pre-Strained Materials $\ldots \ldots \ldots \ldots \ldots \ldots \ldots \ldots$

6. Heat and Quench Matrix for ss-16 Materials $\ldots \ldots \ldots \ldots \ldots \ldots$

7. Heat and Quench Matrix for SS-17 Materials $\ldots \ldots \ldots \ldots \ldots \ldots \ldots \ldots \ldots \ldots \ldots \ldots$

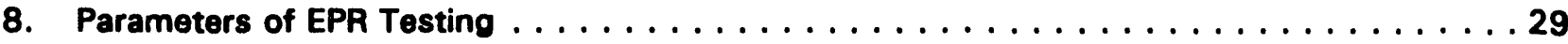

9. Results for SS-16 Heat and Quench Samples $\ldots \ldots \ldots \ldots \ldots \ldots$

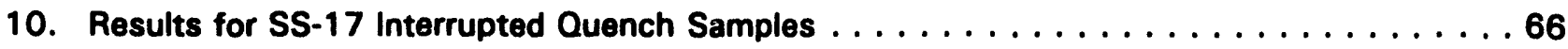

\section{APPENDIX TABLES}

A1. EPR-DOS Results for Heat SS-16 MA Material $\ldots \ldots \ldots \ldots \ldots \ldots \ldots \ldots \ldots \ldots$

A2. EPR-DOS Results for Heat SS-16 SA Material $\ldots \ldots \ldots \ldots \ldots \ldots \ldots \ldots$

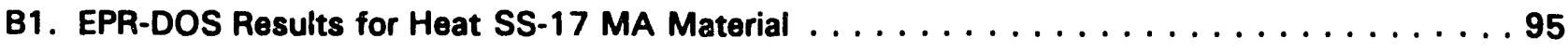

B2. Results for Heat SS-17 MA $+5 \%$ PS Material $\ldots \ldots \ldots \ldots \ldots \ldots$

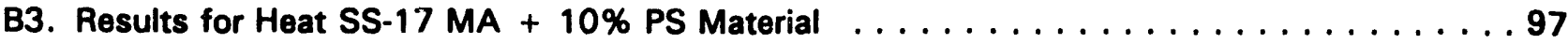

B4. Results for Heat SS-17 MA $+20 \%$ PS Material $\ldots \ldots \ldots \ldots \ldots \ldots \ldots$

B5. EPR-DOS for Heat SS-17 Heat and Quench Matrix $\ldots \ldots \ldots \ldots \ldots$

B6. SSDOS Predictions for Heat and Quench Matrix $\ldots \ldots \ldots \ldots \ldots$ 


\section{FIGURES}

1. Variation of Carbon Solubility as a Function of Temperature

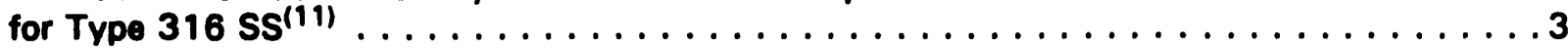

2. Time-Temperature-Precipitation (TTP) Diagram for Type 316

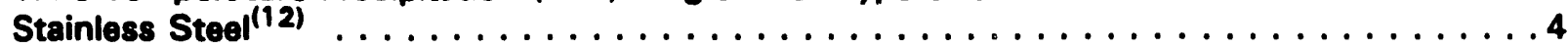

3. Time-Temperature-Sensitization (TTS) Curves Determined by Electrochemical Potentiokinetic Reactivation (EPR) Tests on Type 304 SS Alloys of Variable

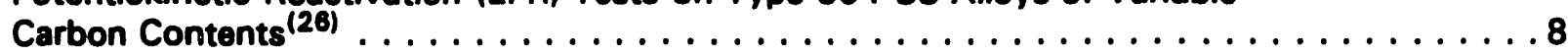

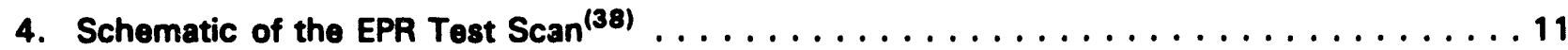

5. Illustration of Chromium Depletion Profile Normal to Grain Boundary in a

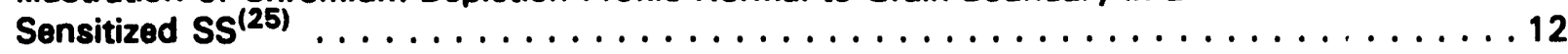

6. Non-Linear Heating and Cooling Cycle Typical of One Point in the HAZ

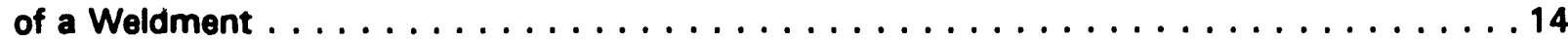

7. Schematic of Specimen Configurations for Gleeble and EPR Testing $\ldots \ldots \ldots \ldots \ldots$

8. Illustration of Test Specimen in Jaws of the Gleeble Thermal Simulator Showing

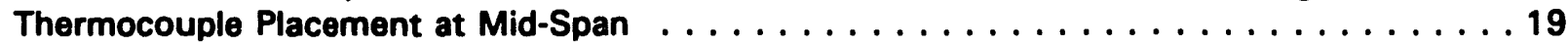

9. Thermal Gradient Profile from the Center of the $13 \mathrm{~cm}$ Gleeble Specimen . . . . . . . . . . 20

10. Thermal Gradient Profile from the Center of the $10 \mathrm{~cm}$ Gleeble Specimen . . . . . . . . . 21

11. Typical Continuous Cooling Gleeble Thermal Cycle Utilized in the Current Work . . . . . . . 22

12. Complex Continuous Cooling Thermal Cycle Used for Interrupted-Quench Testing . . . . . 27

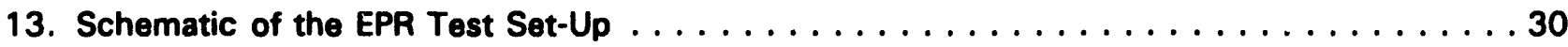

14. Optical Micrographs of Heat SS-16 (a) Mill-Annealed and (b) Solution-Annealed

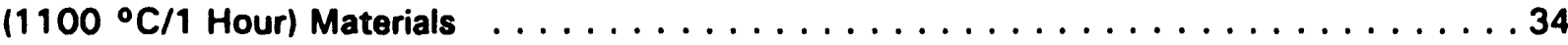

15. Continuous Cooling Sensitization Behavior of the MA Material from Heat SS-16 as a Function of Peak Cycle Temparature and Cooling Rate . . . . . . . . . . . . . 35

16. Continuous Cooling Sonsitization Behavior of the SA Materia! from Heat SS-16 as

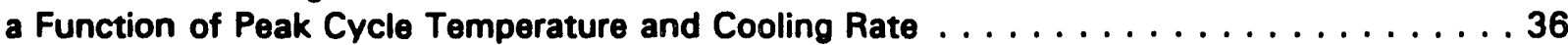

17. Comparison of the CCS Behavior of the MA and SA Materials from Heat SS-16 as a Function of Peak Cycle Temperature for a Cooling Rate of $0.05^{\circ} \mathrm{C} / \mathrm{sec} \ldots \ldots . \ldots 37$

18. Comparison of the CCS Behavior of the MA and SA Materials from Heat SS-16 as a Function of Peak Cycle Temperature for a Cooling Rate of $0.10^{\circ} \mathrm{C} / \mathrm{sec}$ 38 
19. Comparison of the CCS Behavior of the MA and SA Materials from Heat SS-16 as

a Function of Peak Cycle Temperature for a Cooling Rate of $1.0^{\circ} \mathrm{C} / \mathrm{sec} \ldots \ldots \ldots$

20. Optical Micrograph of Heat SS-17 Mill-Annealed Material $\ldots \ldots \ldots \ldots \ldots \ldots$

21. Optical Micrographs of Heat SS-17 Samples Solution Annealed at Temperatures

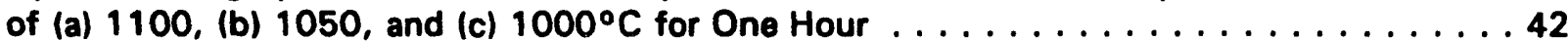

22. Continuous Cooling Sensitization Behavior of the MA Material from Heat SS-17

as a Function of Peak Cycle Temperature and Cooling Rate . . . . . . . . . . . . 44

23. Effects of Solution Annealing Temperature on the CCS Behavior of Heat SS-17 as a Function of Peak Cycle Temperature for a Cooling Rate of $0.10^{\circ} \mathrm{C} / \mathrm{sec} \ldots \ldots 45$

24. Effects of Solution Annealing Temperature on the CCS Behavior of Heat SS-17 . . . . . 46

25. Comparison of the CCS Development of the MA Materials from Heats SS-16 and SS-17 as a Function of Peak Cycle Temperature for a Cooling Rate

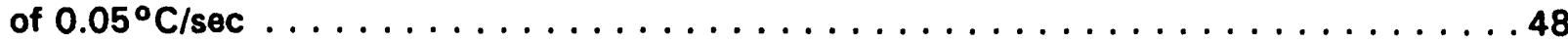

26. Comparison of the CCS Development of the MA Materials from Heats SS-16 and SS-17 as a Function of Peak Cycle Temperature for a Cooling Rate

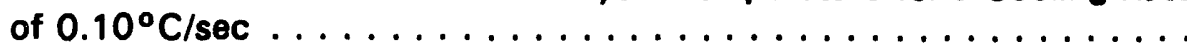

27. Comparison of the CCS Development of the SA Materials $\left(1100^{\circ} \mathrm{C} / 1\right.$ Hour $)$ from Heats SS-16 and SS-17 as a Function of Peak Cycle Temperature

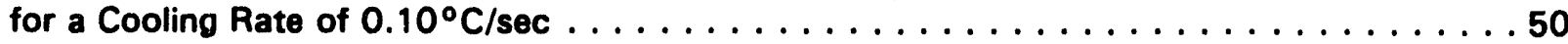

28. Prior Strain Effects on the CCS Development of the MA Material from Heat SS-17 as a Function of Peak Cycle Temperature for a Cooling Rate

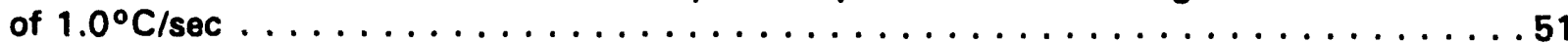

29. Prior Strain Effects on the CCS Development of the MA Material from Heat SS-17 as a Function of Peak Cycle Temperature for a Cooling Rate

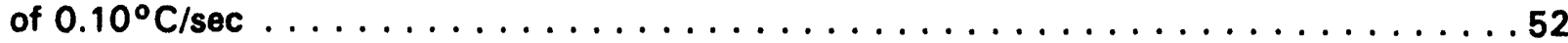

30. Prior Strain Effects on the CCS Development of the MA Material from Heat SS-17 as a Function of Peak Cycle Temperature for a Cooling Rate

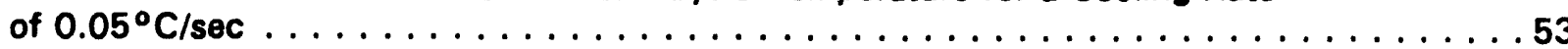

31. Optical Micrographs Showing the Amount of Transgranular Attack, After EPR Testing, in 20\% Prior Strain Specimens Heated to Peak Temperatures of (a) $900^{\circ} \mathrm{C}$ and (b) $950^{\circ} \mathrm{C}$ and Cooled at a Rate of $0.05^{\circ} \mathrm{C} / \mathrm{sec}$

32. Deformation Effects on the CCS Development of the MA Material from Heat SS-17 as a Function of Prior Strain for a Cooling Rate of $1.0^{\circ} \mathrm{C} / \mathrm{sec}$ 
33. Deformation Effects on the CCS Development of the MA Material from Heat SS-17 as a Function of Prior Strain for a Cooling Rate

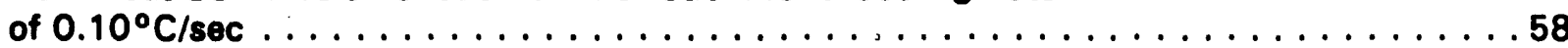

34. Deformation Effects on the CCS Development of the MA Material from Heat SS-17 as a Function of Prior Strain for a Cooling Rate

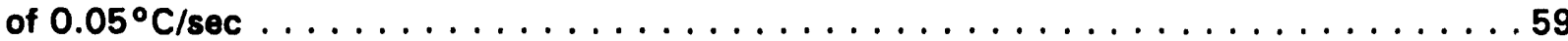

35. CCS Development of Heat SS-17 MA Material as a Function of the Minimum Temperature Reached During Slow Cooling, Prior to Quenching. The Dotted Line Represents the EPR-DOS Value for a Specimen Continuously Cooled Down

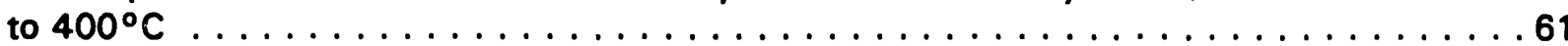

36. Deformation Effects on the CCS Development of Heat SS-17 MA Material as a Function of the Minimum Temperature Reached During Slow Cooling, Prior to Quenching. The Dotted and Solid Horizontal Lines Represent the EPR-DOS Values for Specimens Continuously Cooled Down to $400^{\circ} \mathrm{C}$

37. CCS Development of Heat SS-17 MA Material as a Function of the Minimum Temperature Reached During Slow Cooling, Prior to Quenching. The Dotted Line Represents the EPR-DOS Value for a Specimen Continuously Cooled Down

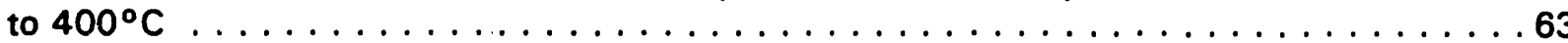

38. Comparisons of SMA SSDOS Predictions with Experimental CCS Results for MA and SA Materials from Heat SS-16 for a Cooling Rate of $0.05^{\circ} \mathrm{C} / \mathrm{sec} \ldots \ldots \ldots 6$

39. Comparisons of SMA SSDOS Predictions with Experimental CCS Results for MA and SA Materials from Heat SS-16 for a Cooling Rate of $0.10^{\circ} \mathrm{C} / \mathrm{sec} \ldots \ldots \ldots \ldots$

40. Comparisons of SMA SSDOS Predictions with Experimental CCS Results for MA and SA Materials from Heat SS-16 for a Cooling Rate of $1.0^{\circ} \mathrm{C} / \mathrm{sec} \ldots \ldots \ldots \ldots$

41. Comparisons, on a One-To-One Correlation Basis, of SMA SSDOS Predictions with Experimental CCS Results for MA and SA Materials from Heat SS-16

42. Comparisons, on a One-To-One Correlation Basis, of SMA SSDOS Predictions with Experimental CCS Results frr MA and Pre-Strained MA Materials from Heat SS-17

43. Comparisons of SMA SSDOS Predictions and HO Results for Heat SS-17 MA Materials (Peak Temperature of $950^{\circ} \mathrm{C}$ ) as a Function of Minimum Cycle Temperature and (a) EPR-DOS, and (b) Percentage EPR-DOS Development $\ldots \ldots \ldots \ldots \ldots \ldots \ldots$

44. Comparisons of SMA SSDOS Predictions and HQ Results for Heat SS-17 Materials with $10 \%$ PS (Peak Temperature of $950^{\circ} \mathrm{C}$, as a Function of Minimum Cycle Temperature and (a) EPR-DOS, and (b) Percentage EPR-DOS Development

45. Comparisons of SMA SSDOS Predictions for CCS of Heat SS-16 MA Materials with Experimental Results of Simmons and Bruemmer ${ }^{(8)}$ for a Cooling Rate of $0.05^{\circ} \mathrm{C} / \mathrm{sec}$. Bruemmer's Results are for Furnace Cooled Specimens . . . . . . . . . . . . . . . . . . 76 
46. Same Comparisons of SMA SSDOS Predictions with Experimental Results for CCS of Heat SS-16 MA Materials as Figure 45 with Cedeno' $\mathbf{s}^{(56)}$ Gleeble and Furnace Cooled Results Added

47. Comparisons of SMA SSDOS Predictions for CCS of Heat SS-17 MA Materials with Experimental Results of Simmons, Bruemmer, ${ }^{(8)}$ and Cedeno ${ }^{(56)}$ for a Cooling Rate of $0.05^{\circ} \mathrm{C} / \mathrm{sec}$. Bruemmer's and Cedeno's Results are for Furnace Cooled Specimens 


\section{EFFECTS OF PRIOR DEFORMATION CONTINUOUS COOLING OF TYPE 316 AUSTENITIC STAINLESS STEEL}

\section{INTRODUCTION}

Intergranular stress corrosion cracking (IGSCC) of AISI Types 304 and 316 austenitic stainless steals (SSs) in the recirculation piping of boiling water reactors (BWRs) has impacted the reliability of nuclear plant operations for many years. The IGSCC cracking of these materials occurs predominantly in sensitized regions of weld heat affected zones (HAZs). ${ }^{(1-4)}$

A material is referred to as being sensitized when chromium-rich carbides precipitate at grain boundaries (GBs) and cause an IG chromium depleted region in the adjacent matrix. ${ }^{(5-7)}$ Austenitic SSs can become sensitized when subjected to an isothermal heat treatment within, or continuous cooling (CC) through, the temperature regime in which the precipitation of these chromium-rich carbides $\left(\mathrm{M}_{23} \mathrm{C}_{6}\right)$ takes place (approximately $600-950^{\circ} \mathrm{C}$ for a high-carbon $316 \mathrm{SS}$ ).

Quantification of sensitization has primarily been studied using isothermal heat treatments which are not always relevant to "real world" applications of the materials. In many industrial applications, SSs are continuously heated or cooled through the sensitization temperature range. In addition, materials often contain deformation from prior thermomechanical processing or are strained during thermal cycling. Non-isothermal exposures can result from welding, thermomechanical processing of the materials, or temperature excursions into the sensitization regime during service.

Continuous cooling sensitization (CCS) occurs in weldment HAZs where materials are subjected to weld-induced plastic deformation, non-linear heating and cooling cycles, and higher temperatures than are generally associated with isothermal exposures. Modeling and prediction of the very complicated weld-induced sensitization phenomenon is desirable for industrial applications. However, the accurate modeling and prediction of linear CCS is a necessary step in the progression towards quantitative understanding of weld-induced sensitization.

Isothermal sensitization modeling capabilities currently exist and they are relatively successful. Isothermally-based sensitization models have been applied to CCS, but an adequate CCS data base for validation of the results is not currently available. ${ }^{(8-10)}$

In the present research, the following areas have been studied in order to provide greater quantification and understanding of prior strain effects on the CCS of austenitic SSs:

(1) Effects of initial material condition on CCS behavior as a function of maximum temperature and cooling rate during the thermal cycle. Specifically, comparisons of CCS development in mill-annealed (MA) and solution-annealed (SA) materials.

(2) Quantification of prior strain effects on CCS development in 316 SS using the electrochemical potentiokinetic reactivation (EPR) test.

(3) Comparisons of the experimental CCS results obtained in the current work with predictions from a recently published sensitization prediction model $\left(\right.$ SSDOS). ${ }^{(8,10)}$ 


\section{BACKGROUND}

\subsection{Sensitization}

\subsubsection{Carbide Precipitation}

The precipitation of $\mathrm{Cr}$-rich $\mathrm{M}_{23} \mathrm{C}_{6}$ carbides is dependent upon carbide formation being thermodynamically favorable and requires the supersaturation of carbon in austenite. Deighton(11) characterized the solubility of carbon in 316 SS using the following equation:

$$
\text { Log }[C \mathrm{ppm}]=7.771-6272 / \mathrm{T}\left(\mathrm{T} \text { in }{ }^{\circ} \mathrm{K}\right)
$$

The temperature dependence of the carbon solubility in austenite for 316 SS is illustrated in Figure 1. Carbon solubility can be seen to be very low $(<0.03 \mathrm{wt} \%)$ at temperatures below $900^{\circ} \mathrm{C}$.

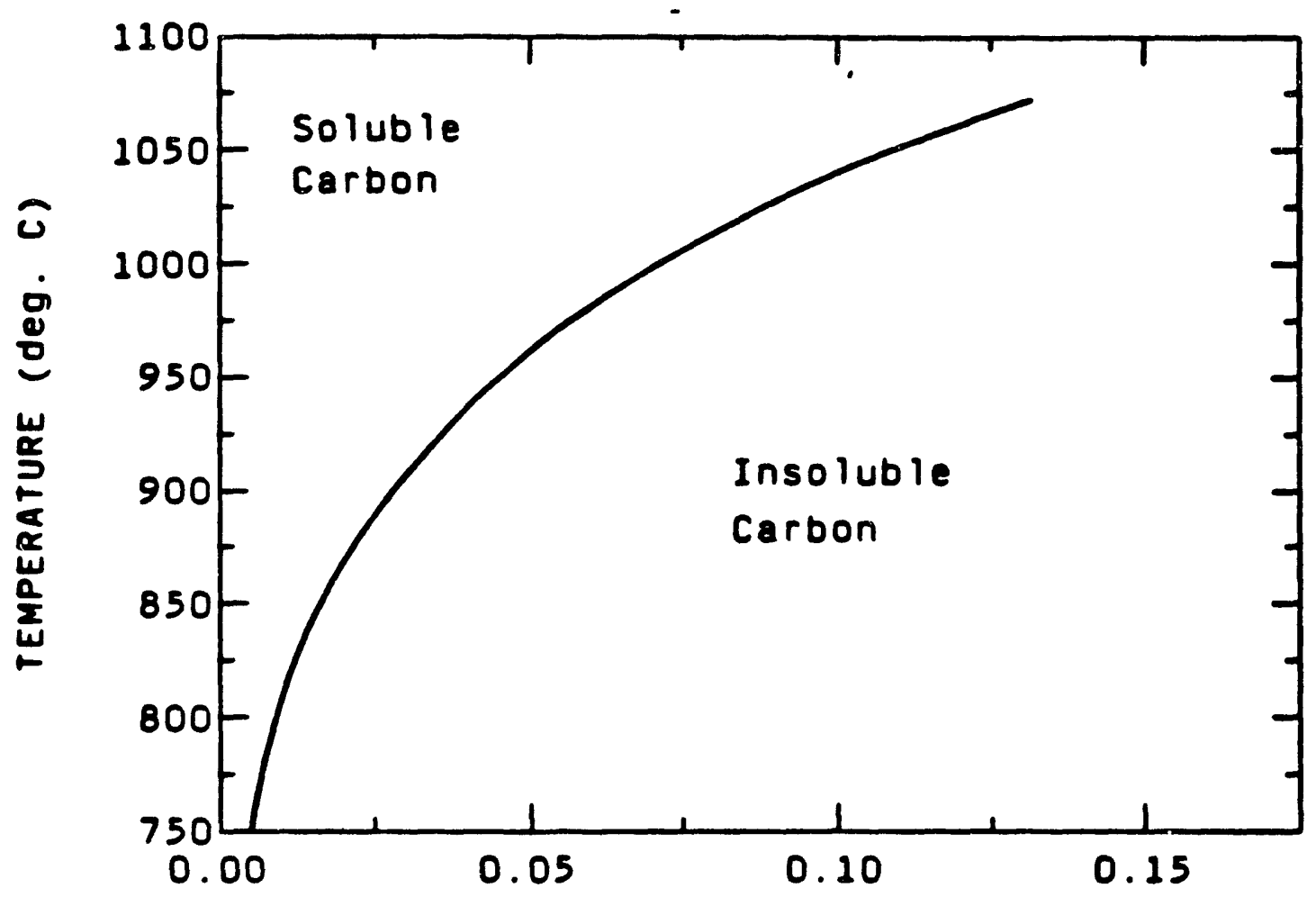

CARBON SOLUBILITY (wt\%)

Figure 1. Variation of Carbon Solubility as a Function of Temperature for Type $316 \mathrm{SS}^{(11)}$ 
Carbide nucleation and growth is typical of many solid state reactions in that the precipitation reaction is controlled by diffusion kinetics (chromium) at lower temperatures and precipitation thermodynamics at higher temperatures. This results in a time-temperature-precipitation (TTP) diagram in the shape of a C-curve, characteristic of such reactions, as shown in Figure 2.

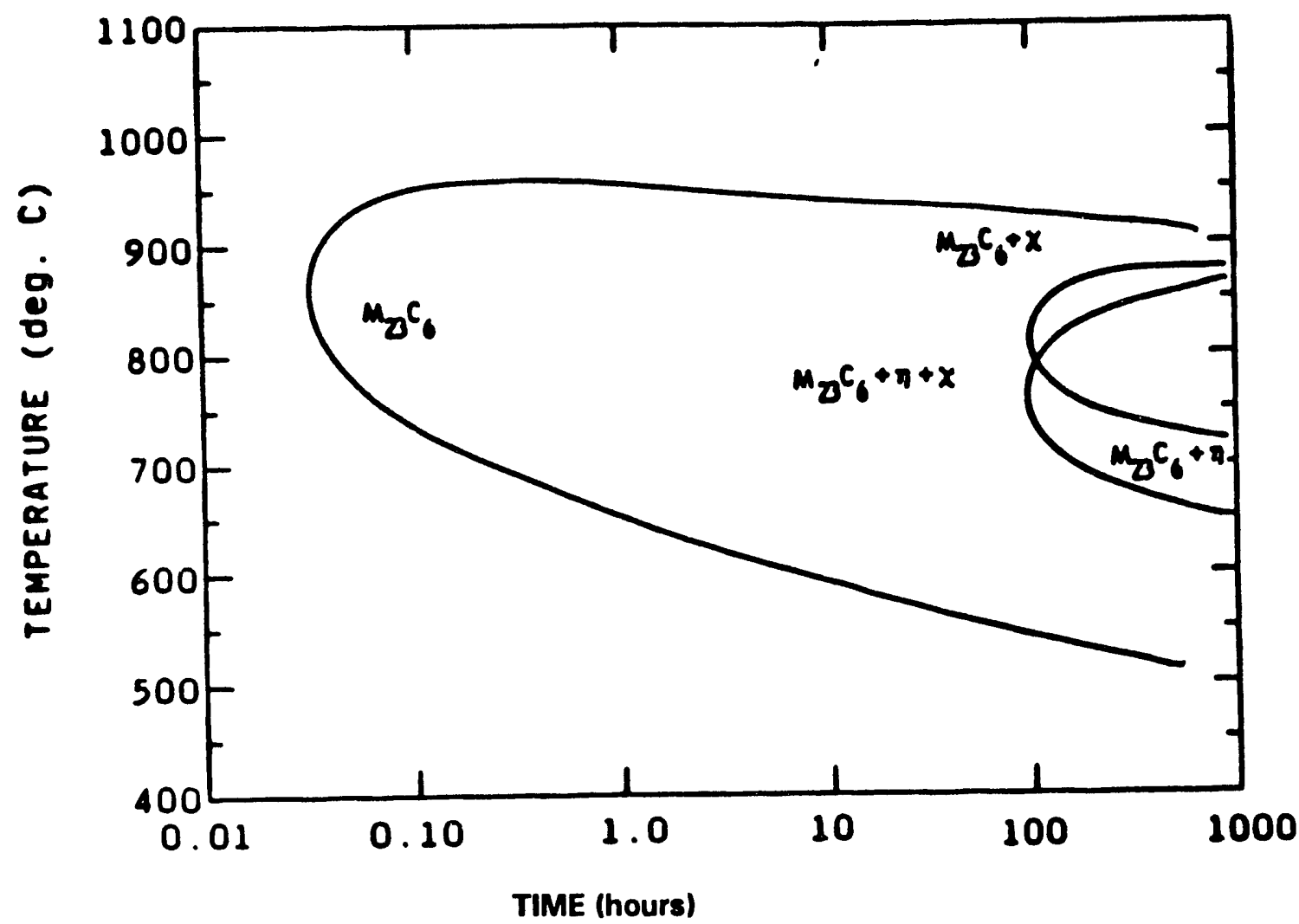

Figure 2. Time-Temperature-Precipitation (TTP) Diagram for Type 316 Stainless Steel $^{(12)}$

Weiss and Stickler ${ }^{(12)}$ determined TTP curves for second phase reactions in 316 SS (Figure 2). For all aging temperatures below $900^{\circ} \mathrm{C}$, the first detectable precipitate consisted of $\mathrm{M}_{23} \mathrm{C}_{6}$ carbides followed at longer aging times by the precipitation of intermetallic chi $(x)$, laves $(n)$, and sigma $(\sigma)$ phases. The general precipitation sequence for $\mathrm{M}_{23} \mathrm{C}_{6}$ is grain boundary carbides, the formation of carbides on incoherent and coherent twin boundaries, and intragranular carbides. The precipitation of intermetallic $\sigma$ phase was observed at longer aging times (over 1000 hours longer) than the $x$ and $\eta$ phases. Of course, these precipitation reactions depend upon the chemical composition of the SS (particularly carbon), aging temperature, and prior thermomechanical processing of the material. Several investigators have reported that increasing carbon contents retard the formation of these intermetallic phases and enhance the precipitation of $M_{23} C_{6}$ carbides. ${ }^{(12-14)}$ 
The composition of carbides extracted from a Type 316 SS has been reported to be $\mathrm{Cr}_{16} \mathrm{Fe}_{5} \mathrm{MO}_{2} \mathrm{C}_{6}$, and in Type 304 to be $\mathrm{Cr}_{16} \mathrm{Fe}_{7} \mathrm{C}_{6}$. ${ }^{(12,15)}$ Carbides have been reported to be ironrich at early growth stages, with the $\mathrm{Cr}$ : $\mathrm{Fe}$ ratio increasing with time at temperature during aging. The $\mathrm{Cr}$ : $\mathrm{Fe}$ ratio in the carbides seems to approach a different final value at each isothermal aging temperature. This reflects the temperature dependence of the equilibrium of iron in the $\mathrm{M}_{23} \mathrm{C}_{6}$ lattice. The rate of $\mathrm{Cr}$ transfer into the carbide lattice, replacing $\mathrm{Fe}$, increases with increasing temperature. ${ }^{(16)}$

\subsubsection{Carbide Thermodynamics}

In order to quantitatively characterize the degree of chromium depletion at grain boundaries in SSs, thermodynamic models of carbide precipitation have been developed and utilized by several researchers. ${ }^{16,7,17,18)}$ Thermodynamic models have been used to determine the minimum chromium concentration in equilibrium with the carbide at the carbide-matrix interface. This approach, combined with diffusion kinetics, has led to the modeling of the $\mathrm{Cr}$-depletion profile that exists in the matrix adjacent to the growing carbide (i.e. normal to the GB), and the Cr-depletion profile that may also exist along a GB between adjacent carbides. ${ }^{(6,7,17,18)}$

The assumption is generally made that the carbide is simply $\mathrm{Cr}_{23} \mathrm{C}_{6}$. This results in the equilibrium reaction between the matrix and the carbide shown below:

$$
\begin{aligned}
& 6 \mathrm{C}+23 \mathrm{Cr} \Leftrightarrow \mathrm{Cr}_{23} \mathrm{C}_{6} \text { where } \\
& \Delta G=-R T \ln K_{\text {oq }} \text { and } \\
& K_{o q}=1 /\left(a_{c r}\right)^{23}\left(a_{c}\right)^{6} \\
& K_{o q}=1 /\left(r_{C_{r}}[C r]\right)^{23}\left(a_{c}\right)^{6}
\end{aligned}
$$

$\mathrm{K}_{\mathrm{eq}}$ is the equilibrium constant for the reaction, $\mathrm{a}_{\mathrm{C}}$ and $\mathrm{a}_{\mathrm{Cr}}$ are the activities of carbon and chromium in equilibrium with the carbide, $[\mathrm{Cr}]$ is the matrix chromium concentration in equilibrium with the carbide, and $\gamma_{\mathrm{Cr}}$ is the activity coefficient of $\mathrm{Cr}$ in the matrix. The activity of the $\mathrm{Cr}_{23} \mathrm{C}_{6}$ carbide is assumed to be unity in this equation. Two standard assumptions are normally made when determining $a_{c} ;(1)$ that the carbon has a constant activity from the carbide-matrix interface out into the matrix, and $(2)$ that carbon is not significantly depleted below its bulk value. ${ }^{(6,7,17,18)}$

The equilibrium (minimum) $\mathrm{Cr}$ concentration at the GB depends upon the composition of the steel (primarily carbon content for 304 and 316 SSs) and temperature. The chromium concen-tration in equilibrium with the carbide increases with increasing temperatures and decreasing carbon contents in the matrix. ${ }^{(8,7)}$

It becomes obvious that the assumption that the $\mathrm{Cr}$-carbide is simply $\mathrm{Cr}_{23} \mathrm{C}_{6}$ is not correct when experimental results of carbide compositions are considered. However, the simplification has generally been used for thermodynamic modeling of the carbide-matrix equilibrium. The presence of additional carbide-forming elements in complex carbides may have a significant effect on carbon and chromium activities. The presence of elements within the carbide, besides carbon and chromium, should therefore affect quantification of the sensitization phenomena. Fullman ${ }^{(18)}$ applied the thermodynamics of carbioc formation to predict the influence of metallic elements on the susceptibility of SSs to IG corrosion (IGC) and IGSCC. This concept has led to the creation of 
an effective bulk chromium concentration which has been used to incorporate the effects of molybdenum on sensitization development into a sensitization prediction model for Type 316 SSs. ${ }^{(8,10)}$

\subsubsection{Chromium Depletion}

The importance of $\mathrm{Cr}$-rich carbide precipitation at grain boundaries and the presence of a Cr-depletion region in the adjacent matrix in reducing the resistance of austenitic SSs to IGC was first proposed by Bain and his co-workers. ${ }^{(5)}$ The existence of a Cr-depletion zone in sensitized austenitic SSs has been experimentally confirmed by numerous investigators. ${ }^{(8,17,19-21)}$ Development of the Cr-depleted zone was treated theoretically in a more quantitative manner by Strawstrom and Hillert, ${ }^{(6)}$ and by Tedmon et al. ${ }^{(7)}$ using carbide thermodynamics and diffusion kinetics.

The slow lattice diffusion rate of chromium compared to that of carbon in austenite is responsible for the formation of the Cr-depletion zone. Chromium and carbon diffusivity equations which have been reported for 316 SS are shown below: ${ }^{(8,22)}$

$$
\begin{aligned}
& D_{C_{r}}=0.334 \exp [-63,900 / R T] \\
& D_{C}=0.190 \exp [-18,820 / R T]
\end{aligned}
$$

For sensitization it is required that the equilibrium chromium concentration at the carbide-matrix interface be below a critical value and that a suificiently wide $\mathrm{Cr}$-depletion zone exist in the matrix adjacent to GBs. Strawstrom and Hillert ${ }^{(8)}$ concluded that stainless steels are sensitive to IGC only when there is a Cr-depletion zone with a minimum chromium content at the GBs of about $13 \mathrm{wt} \% \mathrm{Cr}$ and a width greater than about 20 nanometers $(\mathrm{nm})$. . Bruemmer ${ }^{(8)}$ concluded that this critical chromium content was about $14 \mathrm{wt} \%$. The width of the $\mathrm{Cr}$-depleted zone can be represented by the quantity $w$, where:

$$
w=2\left[2 D_{C_{r}} t\right]^{1 / 2}
$$

$D_{C_{r}}$ is the diffusion rate of $\mathrm{Cr}$ in austenite for a given temperature, and $\mathrm{t}$ is time.

When carbides are present as discrete particles and separated by large distances along a GB, a $\mathrm{Cr}$ concentration profile may exist between them. In many cases, the $\mathrm{Cr}$ concentration in a $\mathrm{GB}$ is by no means uniform, and in fact, large gradients can exist along GBs between particles. In cases such as this, the minimum chromium concentration along a particular section of a GB can increase and the GBs will not be uniformly sensitized. Carbide spacings greater than about 1 to 2 microns can result in non-uniform $\mathrm{Cr}$-depletion along a GB. This can have a significant effect on the corrosion behavior of the material. In most cases, however, because of rapid GB diffusion, GB $\mathrm{Cr}$-depletion is reasonably uniform despite finite carbide particle spacings. Chromium depletion normal to the GB (often referred to as the width of the Cr-depletion zone) is much less than along a $\mathrm{GB}$, but it can be as large as 0.2 to 0.4 microns. (19)

Cr-depletion profiles within the GBs, between carbide particles, and normal to the boundaries, vary with heat treatment temperature and time. At higher heat treatment temperatures, carbide spacings are larger, and the chromium concentration in equilibrium with the carbides is higher. ${ }^{\text {(19) }}$ 
Also, as precipitation and growth of carbides continues, the carbon content of the matrix decreases. This leads to increasing $\mathrm{Cr}$-minimums at the GBs and is responsible for the phenomena of desensitization. ${ }^{(6-8,19)}$

\subsection{Desensitization (Self-Healing)}

It has been known for more than fifty years that the corrosion resistance of sensitized austenitic SSs can be restored if aging is continued for a long time within the sensitization temperature regime. According to the depletion-zone theory, desensitization is due to the diffusion of chromium into the depleted zone from the matrix and/or from an increase in $\mathrm{GB} \mathrm{Cr}$ minimums. As the carbon content in the interior of the grains decreases, the carbon activity decreases, and the $\mathrm{Cr}$ content at the carbide interface increases. Desensitization actually occurs simultaneously with the precipitation of carbides. The annealing time required for healing is predicted to vary quadratically with the grain size of the material. ${ }^{(5,6,8)}$

\subsection{Effects of Alloying Elements on Sensitization}

The times required for nucleation and growth of carbides, and sensitization development, are dependent upon the bulk composition of the steel. The tendency of an austenitic SS to sensitize can be inferred directly from its carbon content, primarily because of the wide range of carbon compositions $(0.01$ to $0.08 \mathrm{wt} \%)$ that are possible in 304 and 316 SSs. The chromium content in 316 alloys varies only from about 16 to $18 \mathrm{wt} \%$ (18 to $20 \%$ in 304 alloys) and therefore provides little variation in its effect on carbide thermodynamics. An important consideration is the presence of other alloying elements which affect the diffusion characteristics and activities of $\mathrm{Cr}$ and $\mathrm{C}$, or elements that segregate to GBs and alter carbide nucleation and growth phenomena. ${ }^{(23)}$

Increasing carbon concentrations have been shown to greatly increase the temperature range over which carbides are stable. An increase in carbon content results in an increase in $M_{23} C_{6}$ carbide stability towards higher temperatures and promotes more extensive carbide precipitation due to a greater amount of insoluble carbon in the austenite matrix. This effact is illustrated in the time-temperature-sensitization (TTS) plot of Figure 3.

Increasing chromium concentrations lower the carbon activity coefficient and retard sensitization development. Chromium is a strong ferrite former and is balanced in austenitic SSs by the presence of nickel, which is a strong austenite stabilizer. Nickel acts to decrease the solubility and increase the activity coefficient of carbon and therefore enhances $\mathrm{Cr}$-carbide precipitation. This effect is not unexpected in view of the low solubility of carbon in nickel and the absence of stable carbides of nickel. ${ }^{(7,8,24)}$

Molybdenum is incorporated into the carbide structure and affects sensitization in SSs in a manner similar to that of $\mathrm{Cr}$. The diffusivity of $\mathrm{Cr}$ is slowed and the solubility of carbon in austenite is lowered due to the presence of Mo. Molybdenum pushes the nose of the TTS curve to higher temperatures and longer times, and therefore, the stability of carbides to higher temperatures. ${ }^{(13,18,25)}$

It has been reported that nitrogen acts to retard the nucleation and/or growth of carbides at GBs and hence increases the time necessary for sensitization. There has also been speculation that nitrogen slows down the diffusion of carbon to the GBs by residing in interstitial sites and preventing carbon from moving in as readily. $(27,28)$ 


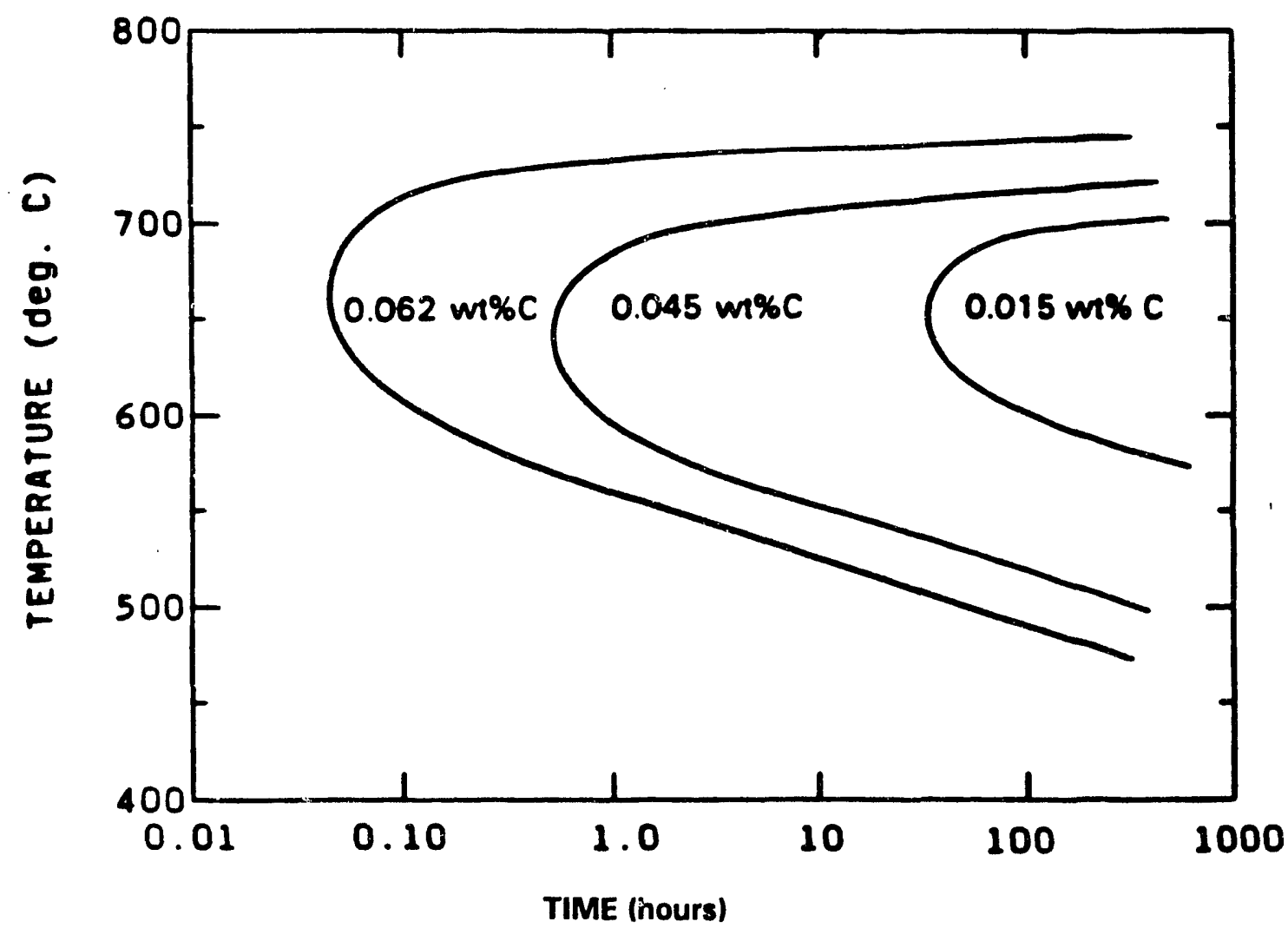

Figure 3. Time-Temperature-Sensitization (TTS) Curves Determined by Electrochemical Potentiokinetic Reactivation (EPR) Tests on Type 304 SS Alloys of Variable Carbon Contents (26)

\subsection{Methods of Preventing Sensitization}

Common methods of controlling sensitization include:

(1) avoiding exposure of the materials to temperatures within the sensitization regime;

(2) heat treating above the carbide solubility temperature, approximately $1000^{\circ} \mathrm{C}$, to put carbides in solution, followed by accelerated cooling through the sensitization region;

(3) reducing the carbon content of the steel;

(4) adding carbide forming elements to tie up the carbon preferentially; and

(5) modifying the composition of the material to produce a duplex structure of ferrite in an austenite matrix. ${ }^{(3)}$ 


\subsection{Measurement of the Degree of Sensitization (DOS)}

The DOS depends directly on the width of the Cr-depietion zone and the minimum chromium concentration in equilibrium with the carbides at the GBs, not merely on the presence of $\mathrm{Cr}$-rich carbides. The DOS of SSs has been correlated with their susceptibility to IGC and IGSCC. ${ }^{(8,29-31)}$ Therefore, experimental techniques used to measure the DOS of these materials must characterize the Cr-depletion zone. Ideally, for predictive modeling of sensitization and IGSCC, the DOS of sensitized materials should be quantifiable.

IGSCC susceptibility of a sensitized austenitic SS in a particular environment can be directly measured by a constant extension rate test (CERT) utilizing a slow strain rate. Direct measurement of the IGSCC susceptibility can be very useful under many circumstances, but the results are affected not only by the DOS of the material being tested, but by environmental conditions, the strain rate employed, and the magnitude and state of imposed stresses. Methods of direct measurement of IGSCC susceptibility are time consuming and expensive, and they do not provide a non-destructive evaluation of the DOS of a material in service. Most importantly, they are not ideally suited for fundamental studies of the development of a sensitized microstructure and Cr-depletion zone. ${ }^{(8,32,33)}$

The most commonly used methods for qualitatively and quantitatively measuring the DOS of austenitic SS materials are summarized below. These methods are the accepted ASTM Recommended Practices for Detecting Susceptibility to Intergranular Attack in Stainless Steels (ASTM A 262, Practices A \& E), ${ }^{(34)}$ the more recently developed electrochemical potentiokinetic reactivation (EPR) test, ${ }^{(29,35)}$ and direct measurement of the $\mathrm{Cr}$-depletion at GBs using analytical electron microscopy (AEM) techniques. The EPR test method, chosen for use in the present study to quantitatively study sensitization development during CCS, will be detailed.

\subsubsection{Oralic Acid Test (ASTM A 262, Practice A)}

In the oxalic acid test, metallographically prepared specimens are etched electrolytically with an aqueous solution of oxalic acid and evaluated for percent GB ditching. In the modified version of the test, the relative percentages of ditched GB length versus the total GB length are determined. The ASTM A 262, Practice A test really measures the relative amount of carbide precipitation in the GBs since oxalic acid attacks the carbides themselves and not the $\mathrm{Cr}$-depletion zone. Therefore, this test is not capable of detecting the actual DOS as defined by the Cr-depleted region, but merely confirms the presence of carbides. ${ }^{(28,29,34)}$

\subsubsection{Modified Strauss Test (ASTM A 262, Practice E)}

The modified Strauss test is performed by wrapping electropolished samples with copper wire, placing them in a beaker with copper shot, and covering the mixture with an aqueous solution of $\mathrm{Cu}_{2} \mathrm{SO}_{4} / \mathrm{H}_{2} \mathrm{SO}_{4}$. The samples are exposed to the boiling solution for three days. The electrochemical potential achieved during this test is approximately $-330 \mathrm{mV}$ vs. SHE (Standard Hydrogen Electrode). ${ }^{(23,29,34)}$ 
The conventional ASTM A 262, Practice E test is a qualitative "go/no go" test, either the specimen exhibits fissuring when bent due to intergranular corrosion, or it does not, indicating a lack of attack.

One method of obtaining semi-quantitative results with the modified Stiauss test is to measure the maximum penetration depths on tension specimens strained 3 to $5 \%$ after exposure to the test solution. The most widely used modified Strauss test method consists of measuring the penetration which occurs durirg the test period by means of the change in effective cross-sectional area of the specimen. This is accomplished by comparing the ultimate tensile strength (UTS) of an exposed specimen with that of a specimen of the same material not exposed to the test solution. ${ }^{(23,29,34)}$

In the modified Strauss test, an austenitic SS with a chromium content below about 13 wt\% Cr will suffer corrosive attack. However, in steels containing about 2 wt\% Mo las in 316 SS), the minimum $\mathrm{Cr}$ content required for attack is somewhere between 9 and $11 \mathrm{wt} \%$. It has been determined that corrosion is not observed in the Strauss test unless a Cr-depleted region is present at the GBs. ${ }^{(19,23,36)}$

Although the modified Strauss test has been found to correlate well with $\mathrm{Cr}$-depletion and the EPR test, it is only semi-quantitative, time consuming, destructive, and is not a suitable method for detecting very low degrees of sensitization. ${ }^{(7,19,29)}$

\subsubsection{Electrochemical Potentiokinetic Reactivation (EPR)Test}

The single loop EPR test method consists of developing potentiokinetic curves of a polarized specimen by the use of a controlled potential sweep from the passive region to the active region (reactivation). A passive film is first formed on the specimen surface and then break-down of this film is characterized as GB attack occurs in the $\mathrm{Cr}$-depleted regions during reactivation. (37)

Passivation is due to the formation of a protective oxide film and results in a reduction of the anodic dissolution rate of the electrode involved in corrosion. Reactivation is the disruption of a passive film by electrochemical methods. ${ }^{(35)}$

Cr-depleted zones behave like low-chromium steel, but because the width of the zones is narrow, a passive film can form in these areas. In an electrochemical test, when the potential moves from the passive to the active region, the passive film breaks down resulting in an increase in current density. In a sensitized material, the passive film at the GBs corresponding to $\mathrm{Cr}$-depleted zones are unstable and breakdown during the EPR test. If the steel is not sensitized, the passive film will remain intact for a short time in the active region and breakdown will not occur during the duration of the EPR test. ${ }^{(35)}$

Non-sensitized SSs exhibit a low current density during the reactivation step resulting from the stability of the passive film. However, sensitized SSs show a high current density due to breakdown of the passive film in $\mathrm{Cr}$-depleted regions near GBs. ${ }^{(38)}$

The nomenclature used in the single loop EPR test include the open circuit corrosion potential of the sample (Ec), the reactivation charge $O$ [total charge value in coulombs $(C)$, this is the integrated area below the reactivation peak], the peak current density in the active state (Ip), and the Flade potential $\left(E_{B}\right)$, which marks the start of passive film breakdown during reactivation. The integrated 
$Q$ value is normalized by specimen surface area and grain size and results in the normalized charge value $\mathrm{Pa}\left(\mathrm{C} / \mathrm{cm}^{2}\right)$. The $\mathrm{Pa}$ value is also known as the DOS value determined by the EPR test, or EPR-DOS. ${ }^{(29,38)}$ A schematic of the EPR test scan is shown in Figure 4.

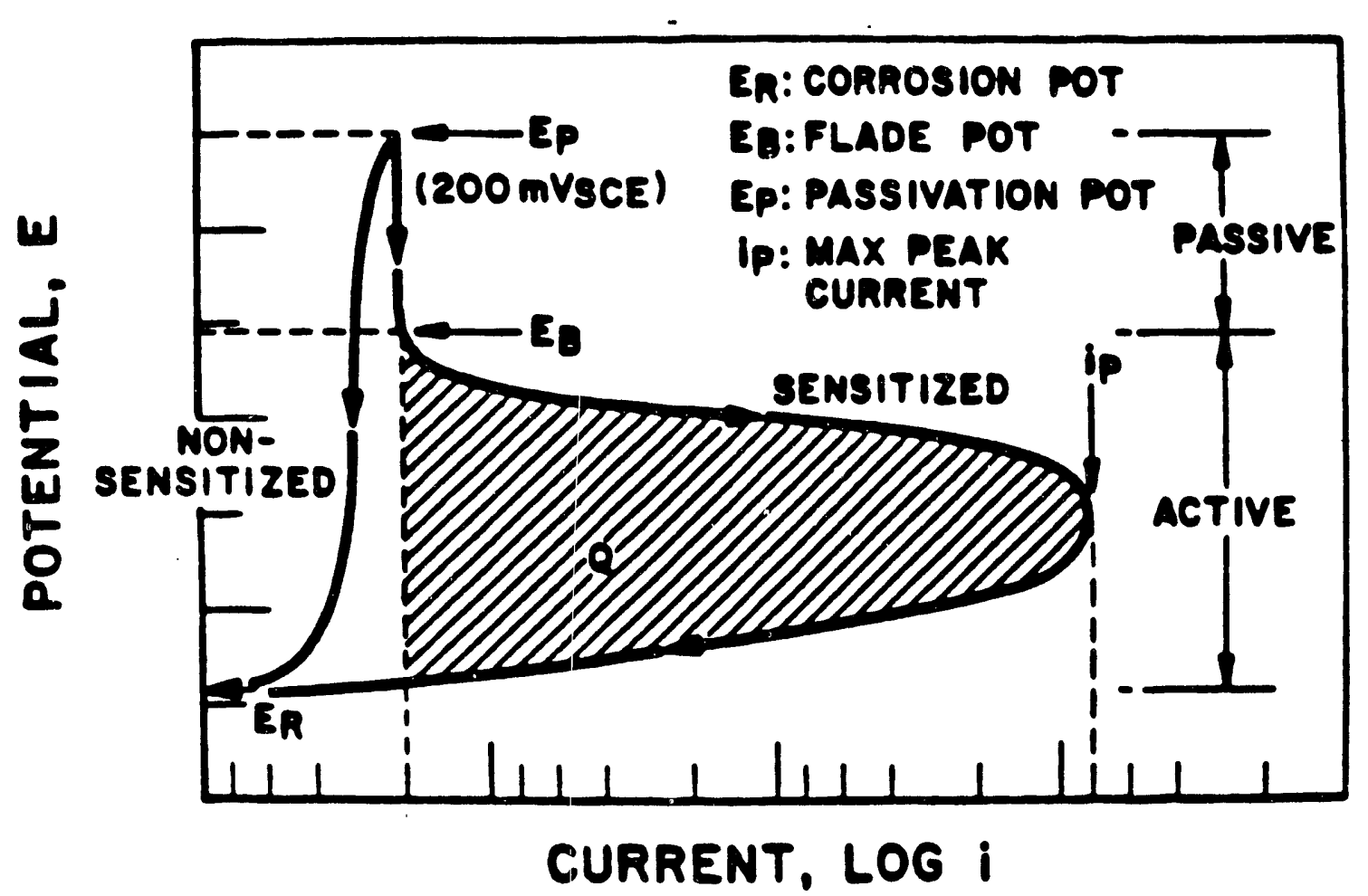

Figure 4. Schematic of the EPR Test Sca.1(38)

The electrolyte used in the EPR test is an aqueous solution of $0.5 \mathrm{M} \mathrm{H}_{2} \mathrm{SO}_{4}+0.01 \mathrm{M} \mathrm{KSCN}$. Potassium thiocyanate acts as a GB activator and enhances GB attack of a sensitized specimen during the reactivation scan.

The EPR technique is currently the most quantitative test for DOS measurement and can detect low sensitization levels which are of primary concern for industrial applicatione. ${ }^{(29,36)}$ The EPR test can also be performed quickly and non-destructively as compared to other methods of sensitization determination.

The EPR test provides an indirect measurement of the amount of $\mathrm{Cr}$-depletion at GBs.

Bruemmer ${ }^{(8)}$ correlated experimentally measured $\mathrm{GB}$ Cr-depletion (width and minimum) to EPR-DOS data and determined that although the GB Cr-minimum has an effect on EPR-DOS values, depletion width controls its magnitude in most cases. These direct measurements of depletion indicated that only regions below about 12.5 to $13.5 \mathrm{wt} \% \mathrm{Cr}$ were attacked in the EPR test. It was determined that the EPR test does quantitatively indicate $\mathrm{Cr}$-depletion, but significantly different widths and minimums can produce the same EPR-DOS value. 


\subsubsection{Direct Measurement of Chromium Depletion}

The best technique for directly measuring the width of the Cr-depletion region and minimum chromium concentrations at GBs is AEM using a scanning transmission electron microscope (STEM) equipped with an eneroy dispersive $X$-ray spectrometer. This approach has been utilized by a number of investigators and a typical GB Cr-depletion zone profile is shown in Figure $5 .(8,19-20,39)$

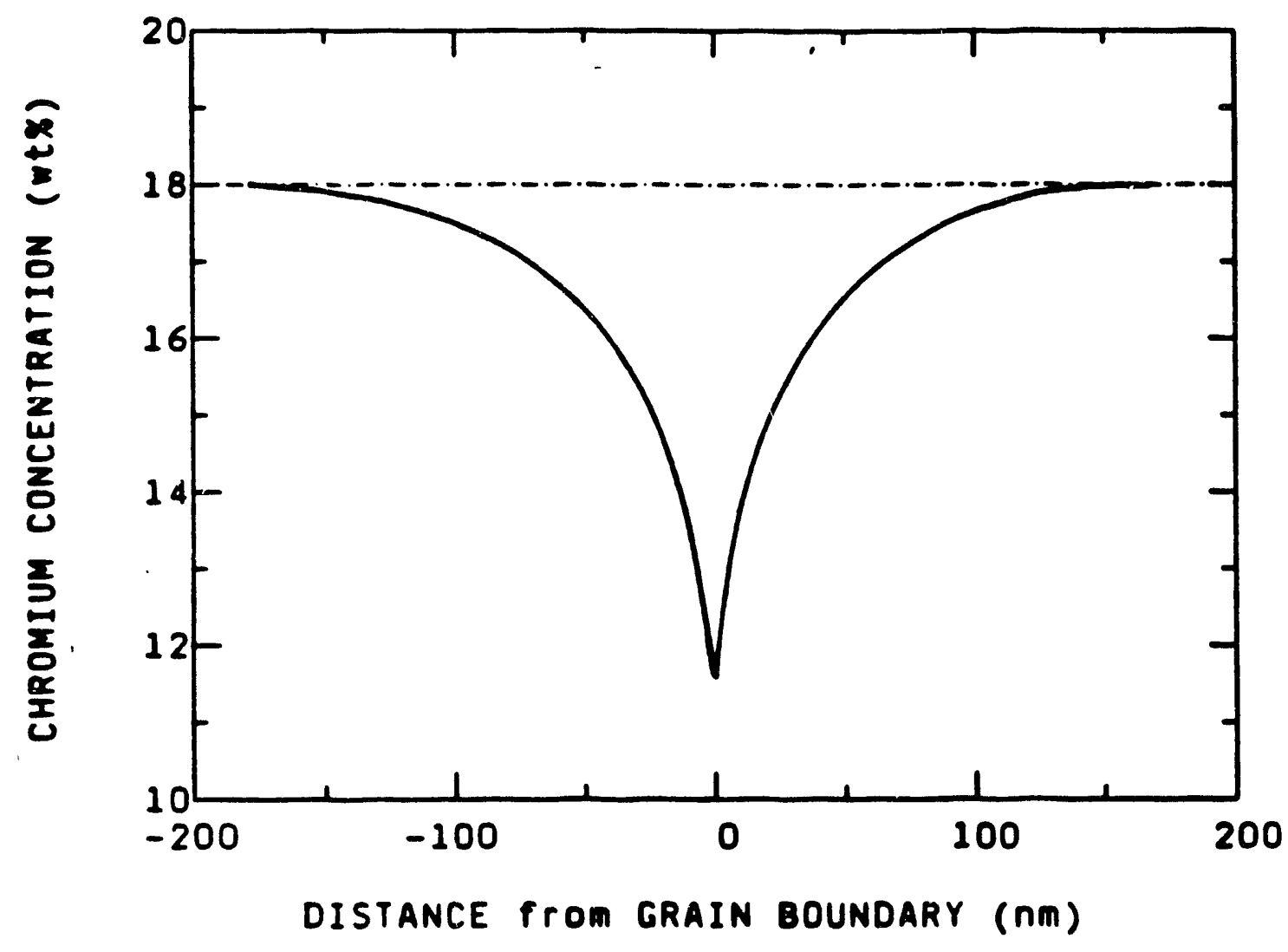

Figure 5. Illustration of Chromium Depletion Profile Normal to Grain Boundary in a Sensitized SS ${ }^{(25)}$ 
Significant variations in Cr-depletion profiles and chromium minimums between GBs exist within most materials. This is primarily due to the fact that carbide precipitation is not a homogeneous phenomena. Carbide growth rates, spacings, and morphologies, as well as $\mathrm{Cr}$-depletion zone development, can vary significantly from boundary-to-boundary. ${ }^{(8,19)}$

The direct migasurement of Cr-depletion profiles using AEM techniques requires a large amount of time and expens:e. Also, it is difficult to examine a statistically meaningful number of GBs to obtain bulk sensitization information from each sample since boundary-to-boundary variations exist.

Bruemmer ${ }^{(8,10)}$ dayeloped a data correlation between a volume depletion parameter, which takes into account the widih of the chromium depletion zone and the minimum chromium concentration at the GB, determined experimentally by STEM/EDS analyses, and EPR-DOS values from the same materials. The AEM results and correlations to EPR data were utilized in the development of a computer model used to predict material DOS as a function of material composition, initial condition, and thermomechanical history. ${ }^{(8,10)}$

\subsection{Continuous Cooling Sensitization (CCS)}

One of the most important occurrences of CCS in austenitic SSs, and probably the most complicated, is in weldment HAZs. The HAZ of a weld is not sensitized by a simple isothermal exposure but from veiy complicated non-linear continuous heating and cooling cycles. ${ }^{(40)}$

In weldments, the base material is exposed to temperatures ranging from the melting temperature of the material at the fusion line to the nominal temperature of the unheated and unaffected base-metal. Therefore, large thermal gradients exist in weldments which extend from the fusion zone to the unheated base material. The unheated portion of the weldment constrains the thermal expansion of the weld and HAZ during heating and also constrains the thermal contraction of these zones during cooling. Plastic deformation occurs in the HAZ of a weldment due to these constraints. ${ }^{(21,40)}$

Every point in the HAZ of a weldment is subjected to non-linear heating and cooling cycles with an associated peak temperature for each weld pass. A typical non-linear heating and cooling cycle of one point in the HAZ of a weldment is shown in Figure 6.

In multipass welding, there are distinct heating and cooling cycles, as well as complex strain cycles, associated with each pass (these occur as a function of time and distance from the fusion zone). The thermomechanical histories of single pass welds are certainly much less complex than multipass welds where the accumulation and interaction of several thermomechanical cycles takes place. ${ }^{(41)}$

Mechanical strains and thermal cycles during welding depend upon several factors: material physical properties (thermal conductivity, coefficient of thermal expansion), elevated temperature mechanical properties, welding parameters, and geometry of the weld joint (this affects system restraint). ${ }^{(21,42)}$

In order to achieve a greater understanding of the very complicated situation of weld-induced sensitization of austenitic SSs, it is necessary to first have a greater understanding of the effects of strain on sensitization for somewhat simpler thermal treatments. A basic understanding of linear CCS and the effects of strain on CCS in SSs can provide a greater understanding, and eventually lead to accurate predictive modeling, of the more complicated weld-induced sensitization. 


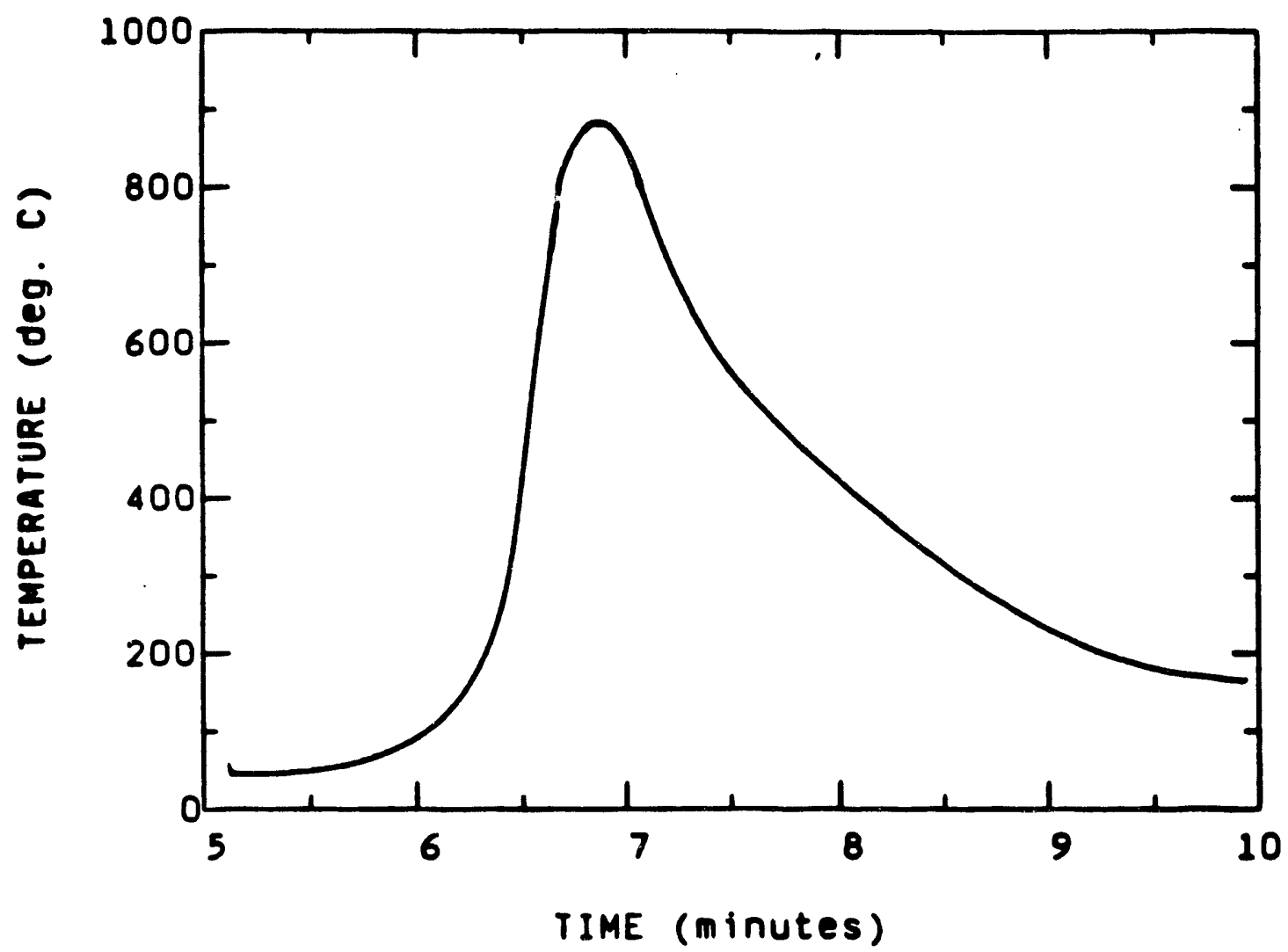

Figure 6. Non-Linear Heating and Cooling Cycle Typical of One Point in the HAZ of a Weldment

\subsection{Effects of Strain on Carbide Precipitation and Sensitization}

As with many solid state reactions, heterogeneous nucleation of carbides occurs preferentially at sites in which there is local perturbation in the crystal lattice (e.g., GBs and slip bands). As stated previously, the precipitation of carbides in an austenitic SS containing little or no plastic strain occurs sequentially on grain boundaries (GB triple points being the preferred sites for nucleation), incoherent and coherent twin boundaries, and within the matrix itself (transgranular precipitation). Less energy is involved in forming GB precipitates than in the formation of intragranular (matrix) precipitates since intergranular carbide precipitation results in a reduction of the high energy GB area and the strain energy barrier to nucleation is lower within the GBs. This process is further enhanced by accelerated diffusion rates in the boundaries and the probability of segregation of $C$ atoms. Segregation of atoms to GBs tends to reduce the lattice strains within the matrix associated with solid solutions and can occur during prior solution heat treatment. ${ }^{(43-47)}$

Reactions in the solid state are often accelerated by cold-working. High atomic diffusion rates have been associated with GBs and dislocations. Atomic diffusion is increased by cold working 
since plastic strain produces an increase in dislocation density. An increase in chromium diffusivity with plastic deformation in austenitic SSs is postulated to occur through a dislocation pipe diffusion mochanism. ${ }^{(43,48-52)}$

An acceleration in sensitization kinetics can be expected to occur with strain due to increasing dislocation densities and enhanced chromium diffusion. Higher chromium diffusivities ars expected to lead to more rapid carbide precipitation (an increase in sensitization kinetics), more rapid development of the $\mathrm{Cr}$-depletion zone, and higher EPR-DOS values at shorter times. The kinetics of desensitization are also expected to increase. Prior cold work has been shown experimentally to accelerate the rate of $\mathrm{M}_{23} \mathrm{C}_{6}$ carbide precipitation and isothermal sensitization devalopment in austenitic SSs. ${ }^{7,53-58)}$

Deformation has been reported to enhance the CCS development in austenitic SSs, but the results were not quantified. In some cases, the reported results have been contradictory to one another. $(41,42,59,60)$

The effects of strain on CCS are expected to be much more complicated than in cases of isothermal sensitization. This is primarily due to the fact that high temperatures encountered during $\mathrm{CC}$ are expected to initiate strain recovery and/or recrystallization within the material. The resulting dislocation densities present in the material during cooling, and ultimately, the diffusion rates of chromium will be affected, changing with time and temperature, and difficult to predict. Recrystallization of heavily deformed materials during high temperature exposure may have a dramatic effect on sensitization development during cooling. The kinetics of carbide nucleation, as compared to growth, are expected to become more important for sensitization occurring in continuous cooling applications at elevated temperatures. Carbide nucleation becomes less thermodynamically favorable at temperatures above the nose of the TTP curve since larger nuclei are required for stability near the carbide solubility temperature.

\subsection{Model Predictions of Sensitization}

A theoretically-based, empirically modified, predictive model (SSDOS) for quantitatively determining the DOS (Cr-depletion and EPR-DOS values) of 304 and 316 SSs was developed by S.M. Bruemmer. (8,10) The SSDOS model was developed at Battelle Pacific Northwest Laboratories and at the Oregon Graduate Institute of Science and Technology (OGI) [formerly the Oregon Graduate Center (OGC)] as part of a project sponsored by the Materials Engineering Technology Division of the Nuclear Regulatory Commission.

The SSDOS program predicts sensitization development of 304 and 316 SSs as a fiunction of material composition, initial condition (grain size, initial EPR-DOS value, etc.), and thermomechanical history for isothermal and continuous cooling thermal treatments. Model predictions result from a combination of theoretical equations and empirical data correlations from 304 and 316 SSs with a wide variety of compositions. Modifications to the model were based primarily on isothermal sensitization experiments.

The major components of the model include determination of the equilibrium chromium concentration at carbide/matrix interfaces based on the thermodynamics of carbide precipitation, $\mathrm{Cr}$-depletion zone development based on effective $\mathrm{Cr}$ diffusivities, and an empirical correlation between $\mathrm{Cr}$-depletion and DOS as measured by the EPR test. 
SSDOS model predictions can be made based on one of two analysis methods, one is denoted as "statistically most accurate" (SMA), and the other "conservative". The SMA predictions of a particular material are based on bulk composition where sensitization development of the heat is expected to follow the general trends of materials used for data base and model development. The conservative predictions represent an attempt to predict the DOS of materials in which sensitization development is much more rapid than is expected from their bulk composition. For conservative predictions, SSDOS makes adjustments to the input bulk composition of these "special" heats (to increase DOS development) in which DOS development is known to be unusually severe in relationship to the data base used for model development.

In the present work, comparisons are made between experimentally determined EPR-DOS measurements and SSDOS model predictions of CCS and the effects of pre-strain on CCS. Much of the present work was specifically designed so that the development of sensitization during CC could be experimentaliy determined and compared to the SSDOS model as a function of peak and minimum cycle temperatures, cooling rate, and deformation. The results should help provide the necessary data base for SSDOS model validation and/or modification and the development of its practical application to CES prediction. 


\section{EXPERIMENTAL PROCEDURES}

\subsection{Materials}

Two high carbon heats of AISI Type 316 austenitic SS were utilized in the present work and their compositions are given in Table 1. The materials were received in the form of $10 \mathrm{~cm}$ diameter pipes (Schedule 40) with wall thicknesses of $0.635 \mathrm{~cm} 0.25$. The pipes were in the mill-annealed (MA) condition (reported final anneal of $1100^{\circ} \mathrm{C} / 5$ minutes).

\begin{tabular}{|c|c|c|c|c|c|c|c|c|}
\hline Heat & C & $\mathrm{Cr}$ & $\mathbf{N i}$ & Mo & Mn & Si & $\mathbf{P}$ & $\mathbf{N}$ \\
\hline SS-16 & 0.058 & 17.11 & 11.43 & 2.26 & 1.77 & 0.41 & 0.014 & 0.008 \\
\hline SS-17 & 0.067 & 16.81 & 11.21 & 2.20 & 1.46 & 0.28 & 0.016 & 0.071 \\
\hline
\end{tabular}

Although most of the CCS experimentation was carried out on materials in the MA condition, some work was performed with materials in solution-annezled (SA) heat treated conditions. Solution heat treatments were done in a standard air furnace at temperatures of 1000,1050 , or $1100^{\circ} \mathrm{C}$, for one hour. Three temperatures were used in order to study the effects of solution annealing temperature on the subsequent CCS development of the materials. Specific uses of MA and SA materials will be outlined for each experimental test matrix.

\subsection{Deformation and Thermal Cycling}

\subsubsection{Specimen Geometry}

The test specimens for prior straining and continuous cooling thermal cycling were sectioned from the as-received pipes in the longitudinal direction and were $13 \mathrm{~cm}$ in length, $1.25 \mathrm{~cm}$ wide, and $0.635 \mathrm{~cm}$ thick (equal to the pipe thickness). The test specimen configuration for continuous cooling thermal cycling (Gleeble testing) and EPR testing is shown in the schematic of Figure 7. This specimen configuration was necessary in order to insure that an adequate isothermal temperature zone in the center of the samples could be maintained during thermal cycling. In the current work, a constant temperature zone of approximately $1.25 \mathrm{~cm}$ was required so that a uniformly sensitized microstructure could be obtained for EPR testing. The evolution of this specimen geometry will be outlined in more detail in the section on thermal cycling to follow. 


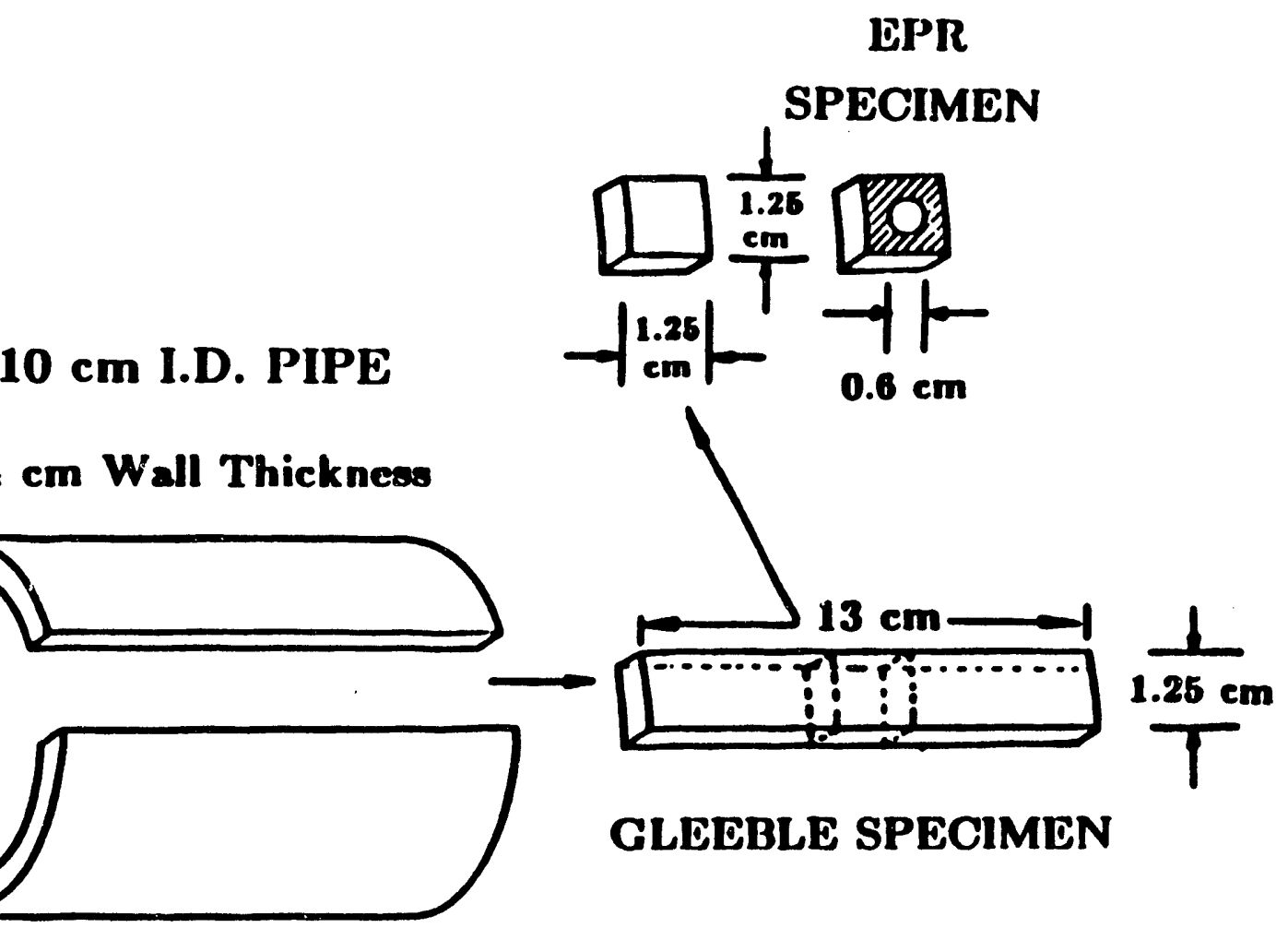

Figure 7. Schematic of Specimen Configurations for Gleeble and EPR Testing

\subsubsection{Deformation}

Prior to continuous cooling thermal cycling, selected specimens from heat SS-17 were strained in uniaxial tension at ambient temperature. Three levels of prior deformation (calculated as true-strain by reduction-of-area measurements) 5,10 , and $20 \%$ were used. The strain levels obtained in the specimens were within $+1-1 \%$ (absolute percentage of strain) of the nominal values.

\subsubsection{Continuous Cooling Thermal Cycling}

Continuous cooling thermal cycling of all specimens was performed in a computer-controlled Gleeble thermal simulator. in the Gleeble, the specimen to be cycled is generally held between two water-cooled copper grips and directly heated by its own electrical resistance by passing current through it. The feedback signal necessary for closed loop control of the current and accurate temperature control is obtained from a fine wire thermocouple welded to the specimen at mid-span. A K-type (chromel-alumel) thermocouple was used in the preseni work. ${ }^{(61,62)}$ 
The general geometry of the sample set-up used in the Gleeble is shown in Figure 8 . The maximum temperature within the specimen exists at mid-span between the grips. The longitudinal thermal gradient profile along the sample is primarily dependent upon the length of the sample (distance between the grips), its thermal conductivity, and thermal conduction through the jaws themselves. In order to control the rate of cooling of the specimen, the natural cooling rate obtainable (with little or no current flow) with the system must exceed the desired sample cooling rate. ${ }^{(82,63)}$

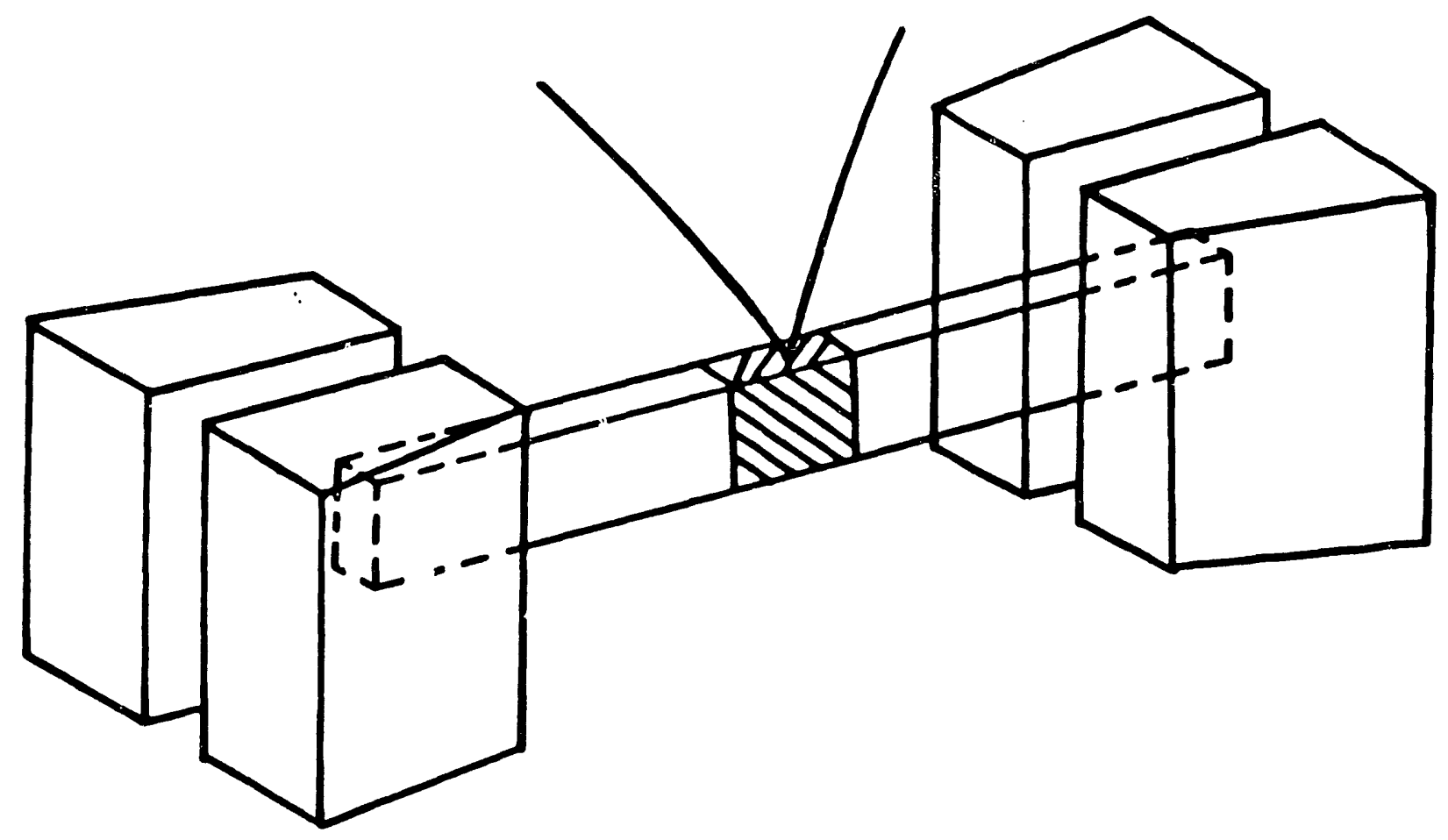

Figure 8. Illustration of Test Specimen in Jaws of the Gleeble Thermal Simulator Showing Thermocouple Placement at Mid-Span

To achieve the required constant temperature zone of approximately $1.25 \mathrm{~cm}$, stainless steel jaws were used in the Gleeble to reduce the conduction of heat through the grips. In addition, experiments were conducted to determine the sample length needed to obtain an adequate isothermal zone in the center of the Gleeble specimens. The longitudinal thermal gradient in Gleeble specimens was measured for two geometries; (1) a $13 \mathrm{~cm}$ long specimen $[8 \mathrm{~cm}$ gauge length or distance between jaw faces], and (2) a $10 \mathrm{~cm}$ long specimen [5 cm gauge length]. Four thermocouples were used, in addition to the controlling thermocouple at specimen mid-span, to 
measure the thermal gradient for each specimen geometry. The thermocouples were placed at $+1-$ $0.3 \mathrm{~cm}$ and at $+1-0.6 \mathrm{~cm}$ from the center thermocouple along the longitudinal axis of the specimens.

No thermal gradient was measured to exist (within experimental error) within the $13 \mathrm{~cm}$ specimen at a distance of $+1-0.6 \mathrm{~cm}$ from the center of the sample as shown in Figure 9 . However, a considerable gradient was found to exist within the same region for the $10 \mathrm{~cm}$ specimen geometry as illustrated in Figure 10 . The $13 \mathrm{~cm}$ specimen geometry was therefore adopted for Gleeble thermal cycling.

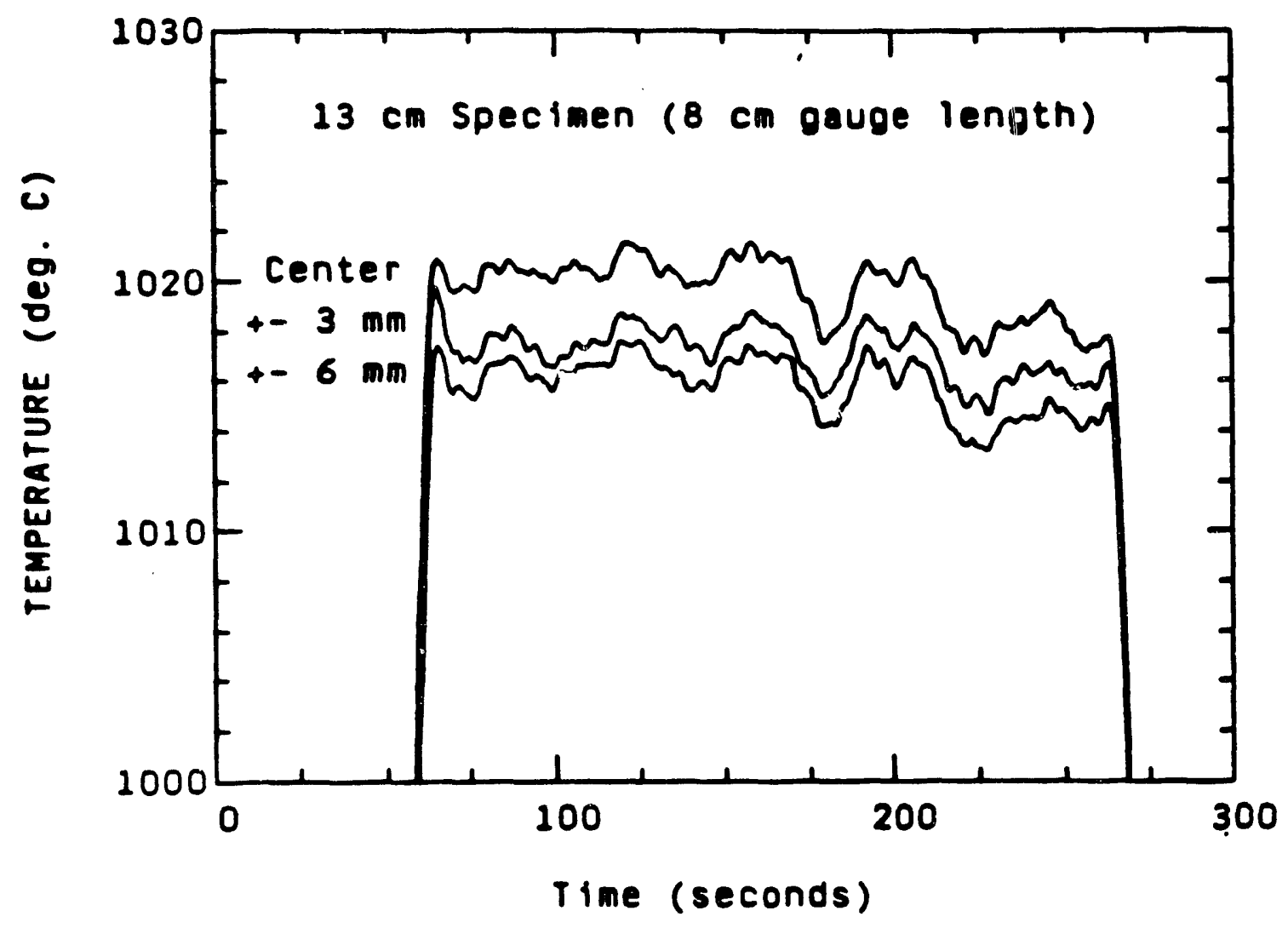

Figure 9. Thermal Gradient Profile from the Center of the $13 \mathrm{~cm}$ Gleeble Specimen 


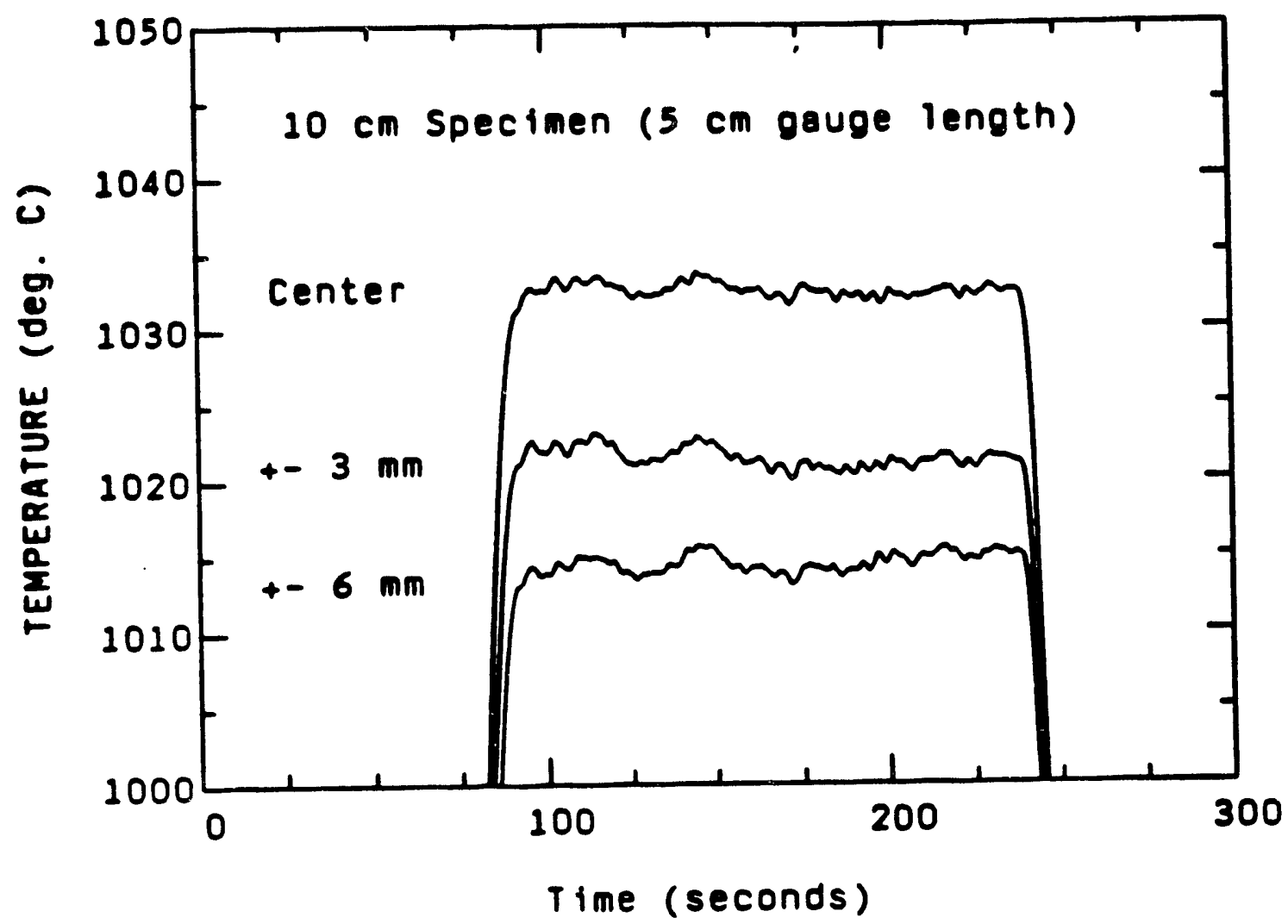

Figure 10. Thermal Gradient Profile from the Center of the $10 \mathrm{~cm}$ Gleeble Specimen

The Gleeble thermal cycle utilized in the current work consisted primarily of three segments, a linear heating portion, peak cycle temperature, and linear cooling region. A typical CC thermal cycle achieved during Gleeble testing is shown in Figure 11. Gleeble test specimens were heated linearly at a rate of $50^{\circ} \mathrm{C} / \mathrm{sec}$, subjected to peak temperatures ranging from 800 to $1050^{\circ} \mathrm{C}$, and continuously cooled using three linear cooling rates of $0.05,0.10$, and $1.0^{\circ} \mathrm{C} / \mathrm{sec}$. The cooling cycle was initiated immediately upon reaching the peak cycle temperature. 


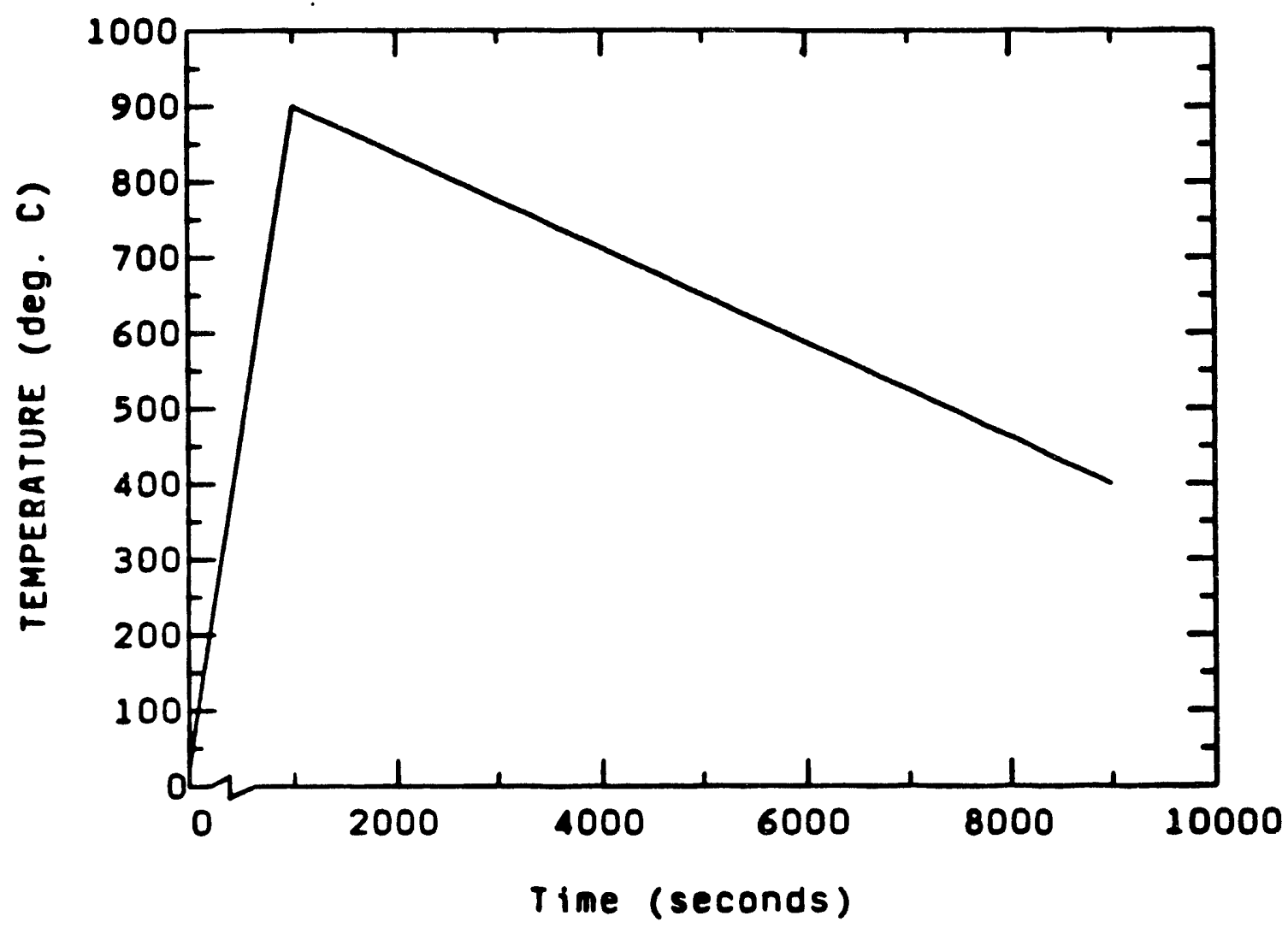

Figure 11. Typical Continuous Cooling Gleeble Thermal Cycle Utilized in the Current Work

\subsection{CCS of Mill-Annealed and Solution-Annealed Materials}

Continuous cooling sensitization development in MA and SA materials from pipe heats SS-16 and SS-17 was characterized as a function of peak cycle temperature, cooling rate, and initial material condition. For comparison purposes, SA and MA initial material conditions were subjected to identical Gleeble thermal treatments. The Gleeble specimens were continuously cooled at a specific rate down to a temperature of $400^{\circ} \mathrm{C}$ and then allowed to self-cool.

\subsubsection{Heat SS-16}

Mill-annealed and SA (annealed at $1100^{\circ} \mathrm{C}$ for 1 hour) materials from heat SS-16 were subjected to the CC thermal cycles shown in Table 2. 
Table 2 - Test Matrix for SS-16 MA \& SA Materials

\begin{tabular}{cccc}
\hline Material Condition & Heating Rate $\left({ }^{\circ} \mathrm{C} / \mathrm{sec}\right)$ & Maximum Tomp $\left({ }^{\circ} \mathrm{C}\right)$ & Cooling Rates $\left({ }^{\circ} \mathrm{C} / \mathrm{sec}\right)$ \\
\hline MA, SA & 50 & 900 & $0.05,0.10,1.0$ \\
MA, SA & 50 & 950 & $0.05,0.10,1.0$ \\
MA, SA & 50 & 1000 & $0.05,0.10,1.0$ \\
MA, SA & 50 & 1050 & $0.05,0.10,1.0$
\end{tabular}

\subsubsection{Heat SS-17}

Mill-annealed specimens from heat SS-17 were subjected to the CC thermal cycles shown in Table 3.

Table 3 - Test Matrix for SS-17 MA Materials

\begin{tabular}{cccc}
\hline Material Condition & Heating Rate $\left({ }^{\circ} \mathrm{C} / \mathrm{sec}\right)$ & Maximum Temp $\left({ }^{\circ} \mathrm{C}\right)$ & Cooling Rates $\left({ }^{\circ} \mathrm{C} / \mathrm{sec}\right)$ \\
\hline MA, SA & 50 & 800 & $0.05,0.10$ \\
MA, SA & 50 & 850 & $0.05,0.10$ \\
MA, SA & 50 & 900 & $0.05,0.10,1.0$ \\
MA, SA & 50 & 950 & $0.05,0.10,1.0$ \\
MA, SA & 50 & 1000 & $0.05,0.10,1.0$ \\
MA, SA & 50 & 1050 & $0.05,0.10,1.0$
\end{tabular}

In order to study the effects of solution annealing temperature on subsequent CCS development, specimens were solution heat treated at temperatures of 1000,1050, or $1100^{\circ} \mathrm{C}$ for one hour prior to $C C$ thermal cycling. These solution annealing treatments $\left(1000,1050\right.$, and $\left.1100^{\circ} \mathrm{C}\right)$ will be referred to as SA1, SA2, and SA3, respectively. The SA samples were subjected to the CC cycles shown in Table 4, which were identical with some used for the SS-17 as-received MA materials (Table 3). This was done so that comparisons could be made between the CCS behavior of MA and SA materials as well as the effects of solution annealing temperature on subsequent sensitization susceptibility. 
Table 4 - Tost Matrix for SS-17 SA Materials

\begin{tabular}{cccc}
\hline Solution Treatment & Heating Rate $\left({ }^{\circ} \mathrm{C} / \mathrm{sec}\right)$ & Maximum Tomp $\left({ }^{\circ} \mathrm{C}\right)$ & Cooling Rate $\left({ }^{\circ} \mathrm{C} / \mathrm{sec}\right)$ \\
\hline SA 1, 2, 3 & 50 & 950 & 0.05 \\
SA 3 & 50 & 800 & 0.10 \\
SA 3 & 50 & 850 & 0.10 \\
SA 1, 2,3 & 50 & 900 & 0.10 \\
SA 1, 2,3 & 50 & 950 & 0.10 \\
SA 1, 2, 3 & 50 & 1000 & 0.10 \\
SA 3 & 50 & 1050 & 0.10
\end{tabular}

\subsection{CCS of Pre-Strained Materials}

The effects of prior strain (PS) on the CCS development of heat SS-17 were characterized by subjecting as-received MA (Table 3) and pre-strained MA specimens (Table 5) to identical continuous cooling thermal cycles. As reported earlier, the three levels of prior deformation used were 5, 10, and 20\%. The as-received MA pipe material was considered to have a level of prior deformation equaling $0 \%$. The specimens in this test matrix were continuously cooled at the designated rate down to a temperature of $400^{\circ} \mathrm{C}$ and then allowed to self-cool.

Table 5 - Test Matrix for SS-17 Pre-Strained Materials

\begin{tabular}{cccc}
\hline Prior Strains $(\%)$ & Heating Rate $\left({ }^{\circ} \mathrm{C} / \mathrm{sec}\right)$ & Maximum Tomp $\left({ }^{\circ} \mathrm{C}\right)$ & Cooling Rates $\left({ }^{\circ} \mathrm{C} / \mathrm{sec}\right)$ \\
\hline $5,10,20$ & 50 & 800 & $0.05,0.10,1.0$ \\
$5,10,20$ & 50 & 850 & $0.05,0.10,1.0$ \\
$5,10,20$ & 50 & 900 & $0.05,0.10,1.0$ \\
$5,10,20$ & 50 & 950 & $0.05,0.10,1.0$ \\
$5,10,20$ & 50 & 1000 & $0.05,0.10,1.0$ \\
$5,10,20$ & 50 & 1050 & $0.05,0.10,1.0$ \\
$5,10,20$ & 50 & 1050 & $0.05,0.10,1.0$
\end{tabular}




\subsection{Heat and Quench Testing}

Gleeble treatments of MA materials, designated within this document as "heat and quench" (HO) tests, were performed in an effort to provide preliminary characterization of sensitization development during the cooling cycle itself. The work was designed to obtain characterization of DOS development and the effects of strain on the initiation and development of sensitization (EPRDOS) at elevated temperatures and aid future SSDOS model development.

\subsubsection{Heat SS-16}

Mill-annealed samples were heated at a rate of $50^{\circ} \mathrm{C} / \mathrm{sec}$ to a peak cycle temperature of $950^{\circ} \mathrm{C}$ and slow cooled at a rate of $0.05^{\circ} \mathrm{C} / \mathrm{sec}$ to various minimum temperatures. The samples were then water quenched from the minimum temperature achieved during CC. These CC thermal treatments were identical to those for standard testing of the MA and SA materials of Table 2 except that the samples were quenched from specific minimum temperatures as shown in Table 6 .

\begin{tabular}{cccc}
\hline \multicolumn{4}{c}{ Table 6 - Heat and Quench Matrix for SS-16 Materials } \\
\hline Heating Rate $\left({ }^{\circ} \mathrm{C} / \mathrm{sec}\right)$ & Maximum Temp $\left({ }^{\circ} \mathrm{C}\right)$ & Cooling Rate $\left({ }^{\circ} \mathrm{C} / \mathrm{sec}\right)$ & Minimum Temp $\left({ }^{\circ} \mathrm{C}\right)$ \\
\hline 50 & 950 & 0.05 & 950 \\
50 & 950 & 0.05 & 900 \\
50 & 950 & 0.05 & 850 \\
50 & 950 & 0.05 & 800 \\
50 & 950 & 0.05 & 750
\end{tabular}

\subsubsection{Heat SS-17}

The HO Gleeble test matrix from heat SS-16 was expanded and applied to heat SS-17 to include pre-strained MA materials. Expansion of the test matrix of heat SS-16 to the testing of heat SS-17 allowed sensitization development in the MA material during continuous cooling to be studied as a function of peak cycle temperature.

The CC thermal cycles applied were basically identical to those for standard testing of the MA and pre-strained MA specimens of Tables 3 and 5 except that the samples were quenched from specific minimum temperatures using high-pressure air (Table 7). 


\begin{tabular}{|c|c|c|c|c|}
\hline $\begin{array}{c}\text { Prior Strain } \\
(\%)\end{array}$ & $\begin{array}{l}\text { Heating Rate } \\
\left({ }^{\circ} \mathrm{C} / \mathrm{sec}\right)\end{array}$ & $\begin{array}{l}\text { Maximum } \\
\text { Tomp }\left({ }^{\circ} \mathrm{C}\right)\end{array}$ & $\begin{array}{l}\text { Cooling Rate } \\
\left({ }^{\circ} \mathrm{C} / \mathrm{sec}\right)\end{array}$ & $\begin{array}{l}\text { Minimum } \\
\text { Tomp }\left({ }^{\circ} \mathrm{C}\right)\end{array}$ \\
\hline 0 & 50 & 1050 & 0.05 & 950 \\
\hline 0 & 50 & 1050 & 0.05 & 900 \\
\hline 0 & 50 & 1050 & 0.05 & 850 \\
\hline 0 & 50 & 850,1050 & 0.05 & 800 \\
\hline 0 & 50 & 850,1050 & 0.05 & 750 \\
\hline 0 & 50 & 850,1050 & 0.05 & 700 \\
\hline 0 & 50 & 850,1050 & 0.05 & 650 \\
\hline 0 & 50 & 850,1050 & 0.05 & 600 \\
\hline 0,10 & 50 & 950 & 0.05 & 900 \\
\hline 0,10 & 50 & 950 & 0.05 & 850 \\
\hline 0,10 & 50 & 950 & 0.05 & 800 \\
\hline 0,10 & 50 & 950 & 0.05 & 750 \\
\hline 0,10 & 50 & 950 & 0.05 & 700 \\
\hline 0,10 & 50 & 950 & 0.05 & 650 \\
\hline 0,10 & 50 & 950 & 0.05 & 600 \\
\hline
\end{tabular}

\subsection{Interrupted Quench Thermal Cycling}

\subsubsection{Heat SS-16}

One MA sample from heat SS-16 was subjected to a complex continuous cooling thermal treatment as shown in Figure 12. The sample was heated at $50^{\circ} \mathrm{C} / \mathrm{sec}$ to a peak temperature of $1050^{\circ} \mathrm{C}$, slow cooled at a rate of $0.05^{\circ} \mathrm{C} / \mathrm{sec}$ to $950^{\circ} \mathrm{C}$, and water quenched. The sample was then reheated at $50^{\circ} \mathrm{C} / \mathrm{sec}$ to a peak temperature of $950^{\circ} \mathrm{C}$, slow cooled at $0.05^{\circ} \mathrm{C} / \mathrm{sec}$ to $400^{\circ} \mathrm{C}$, and allowed to self-cool. The purpose of this test was to determine the effects of quenching and reheating on sensitization development and its relationship with peak temperature effects. 


\subsubsection{Heat SS-17}

Four MA samples from heat SS-17 were subjected to complex continuous cooling thermal treatments similar to the MA sample from heat SS-16 (Figure 12). The first sample from heat SS-17 was subjected to the exact thermal treatment of the heat SS-16 sample as shown in Figure 12.

The second sample was subjected to the same thermal treatment as the first, but was cooled at an accelerated rate from $950^{\circ} \mathrm{C}$ to room temperature (RT) using high pressure air rather than water.

The third sample was also subjected to a thermal cycle similar to the one depicted in Figure 12, except that upon reaching $950^{\circ} \mathrm{C}$ during slow cooling, the sample was quenched to only $400^{\circ} \mathrm{C}$ (instead of RT) using high pressure air, then immediately reheated to a peak temperature of $950^{\circ} \mathrm{C}$, slow cooled at $0.05^{\circ} \mathrm{C} / \mathrm{sec}$ to $400^{\circ} \mathrm{C}$, and allowed to self-cool to RT. The fourth sample was subjected to the same thermal cycle as the third, except that a 20 second hold time was implemented at $400^{\circ} \mathrm{C}$ to insure that the sample did in fact reach $400^{\circ} \mathrm{C}$ prior to reheating.

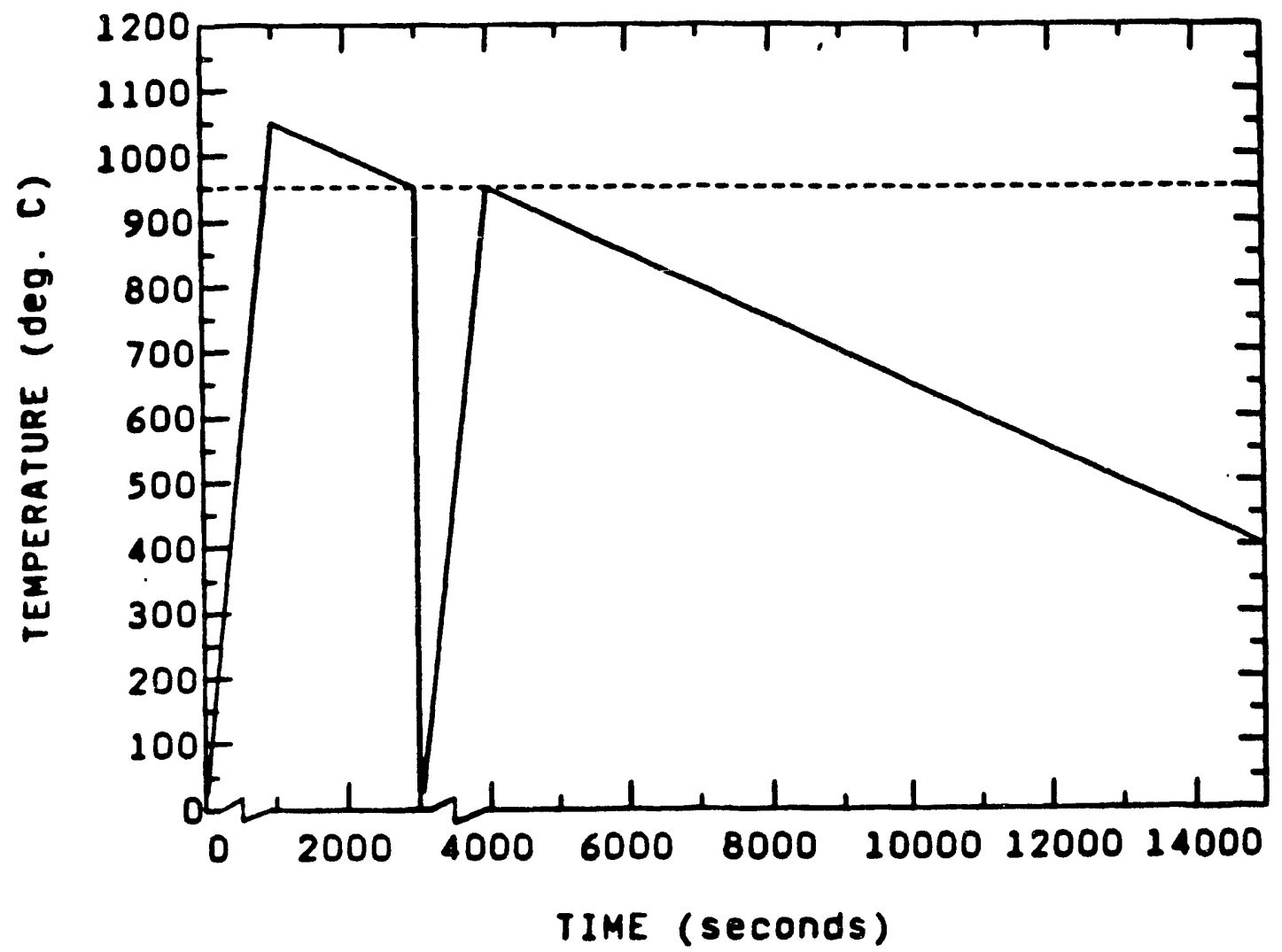

Figure 12. Complex Continuous Cooling Thermal Cycle Used for Interrupted-Quench Testing 
The purpose of these four tests was to provide a better understanding of the effects of quenching, quench rate, and reheating on sensitization development and their relationship with peak temperature effects than was determined with the heat SS-16 sample alone.

\subsection{Sensitization Modeling}

Degree of sensitization (EPR-DOS) values for the MA, SA, and HQ matrices of heat SS-16 (Tables 2 and 6) were predicted using the SMA and conservative prediction methods of the SSDOS sensitization model described previously.

The EPR-DOS values for the MA, MA + PS, and HO CCS specimens of heat SS-17 (Tables 3, 5, and 7), were also predicted using the SMA and conservative prediction methods of the SSDOS sensitization model.

The SSDOS model predictions were subsequently compared to experimental results. Although it was known that conservative predictions would be higher than SMA, they were still calculated for comparison to the heats used in the current work. However, it was not known prior to SSDOS prediction calculations how the current work would compare to either conservative or SMA model predictions.

\subsection{Measurement of DOS by EPR Testing}

The DOS of each test specimen was measured using the EPR test and reported as the normalized integrated charge value $\mathrm{Pa}$, or equivalent EPR-DOS value $\left(\mathrm{C} / \mathrm{cm}^{2}\right)$. The single loop EPR tests were performed using the testing methods proposed by Clarke et al., and others. ${ }^{(29,35)}$ The nomenclature and definition of terms for EPR testing has been outlined in a previous section.

\subsubsection{Equipment}

The electronic equipment needed for EPR testing consists of a scanning potentiostat, potential measuring device, and current measuring and integration instruments. An Instruspec Model WC-5 Metal Sensitization Detector was used in the current work and provided the necessary electronic equipment combined into a single instrument.

The electrochemical test cell (corrosion cell) used for EPR testing consisted of a specimen holder, reference electrode (SCE, saturated calomel electrode), counter electrode (graphite), and working electrode (sensitized specimen).

EPR specimens were cut from the Gleeble test specimens as shown in Figure 7 and a SS screw was attached to the backside of each specimen as an electrical connection. The specimens were subsequently mounted in an epoxy resin (room temperature cured), metallographically prepared using standard practices and silicon-carbide abrasive papers of 120 through 600 grit sizes, and final polished with 6 and 1 micron diamond pastes on nylon cloths. A circular area 
(6 mm dia. circle) of each sample was masked off for EPR testing using a specially prepared tape. A schematic of the EPR test set-up is shown in Figure 13. The specific parameters of the EPR test are listed in Table 8.

\section{Table 8 Parameters of EPR Testing}

\begin{tabular}{ll}
\hline Sample Surface Finish: & $1 \mu \mathrm{m}$ Diamond \\
Electrolyte: & $0.5 \mathrm{M} \mathrm{H}_{250^{4}+0.10 \mathrm{M} \mathrm{KSCN}}$ \\
Electrolyte Temp.: & $30^{\circ} \mathrm{C}+1-1^{\circ} \mathrm{C}$ \\
Corrosion Potential (Ec): & -0.330 to -0.360 volts \\
Passivation Potential (Ep): & +0.200 volts \\
Reactivation Scan Rate: & 3 volts/hour \\
Instrument & $\begin{array}{l}\text { Instruspec Model WC-5 } \\
\text { Metal Sensitization Detector }\end{array}$
\end{tabular}

\subsubsection{Procedures}

After the test cell was set-up with the sample in-place and the electrolyte at the proper temperature, the EPR test was performed in the following manner: (1) the open-circuit corrosion potential (EC) of the working electrode vs. SCE was measured; (2) the sample was passivated at an Ep of $+200 \mathrm{mv}$ for 2 minutes; (3) the reactivation scan was performed by sweeping the potential of the sample from the Ep to Ec at a rate of 3 volts/hour; (4) the area of the reactivation peak was integrated during the reactivation scan to obtain the total charge value, $Q$. 


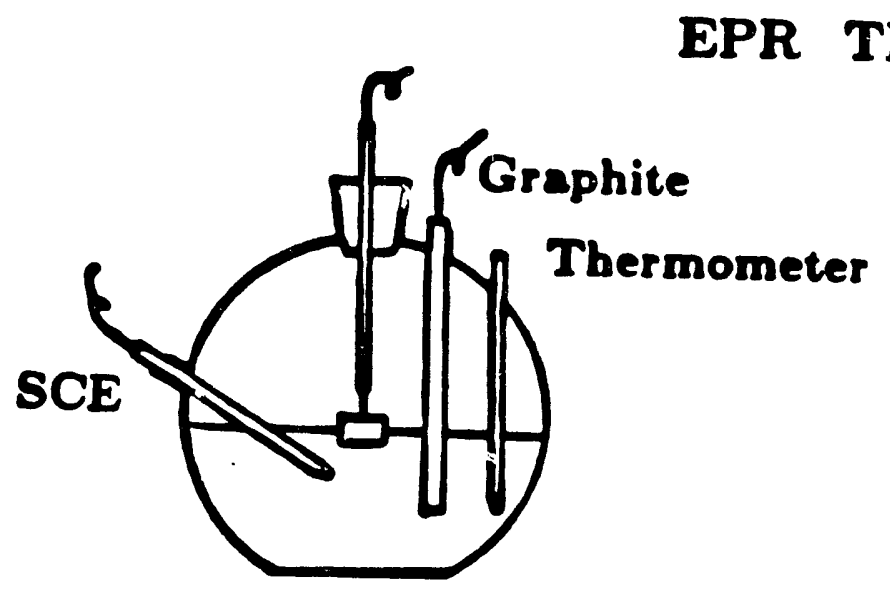

EPR Cell
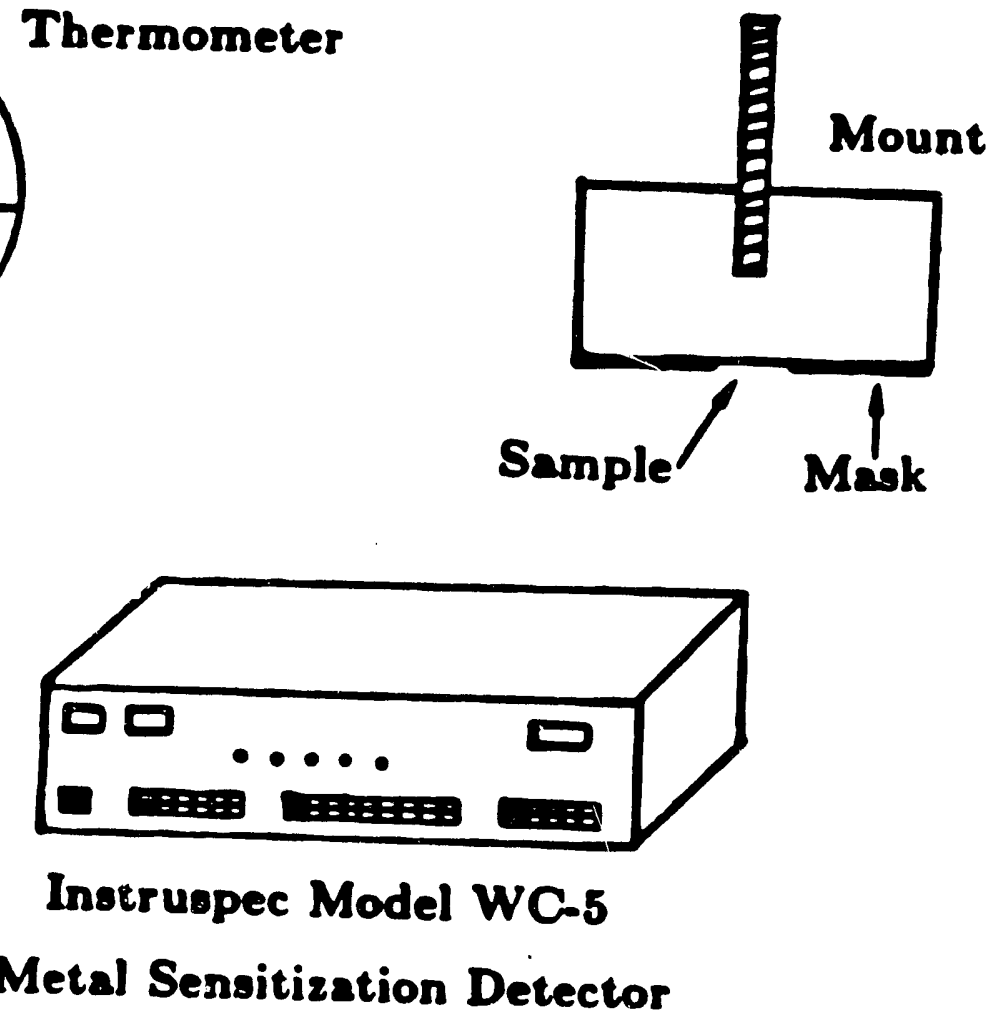

Figure 13. Schematic of the EPR Test Set-Up

The integral charge valuo, $Q$, was subsequently normalized to the grain boundary area (GBA) of

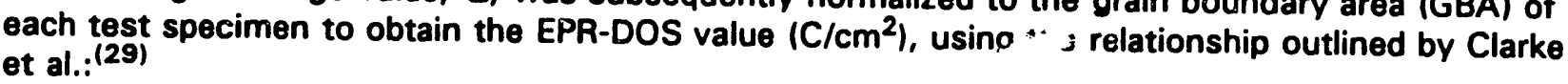

$$
\begin{aligned}
& \mathrm{Pa}\left(\text { Coul. } / \mathrm{cm}^{2}\right)=\mathrm{Q} /(\mathrm{GBA}) \\
& \text { where } \mathrm{O}=\text { integrated charge value } \\
& \text { and } \mathrm{GBA}=\mathrm{As}\left[5.1 \times 10^{-3} \exp (0.35 \mathrm{X})\right] \\
& \text { whereas }=\text { Masked specimen area }\left(\mathrm{cm}^{2}\right) \\
& \mathrm{X}=\mathrm{ASTM} \text { Grain Size at } 100 \times \text { magnification }
\end{aligned}
$$




\subsection{Microstructural Examinations}

All specimens were examined and photographed, after EPR testing, at magnifications ranging from $50 X$ to $400 X$, using a metallograph. Optical examinations were considered to be important to make sure that attack of the material did not occur outside of the masked area and that large variations in the degree of attack did not exist between specimen test runs (multiple testing of single specimens), which would indicate variations in testing procedures or equipment.

Also, intragranular EPR attack can occur in cases where transgranular (TG) carbide precipitation has taken place.

Specimens which had been electrolytically etched with an aqueous solution containing $60 \%$ nitric acid were also metallographically examined for grain size determination and photographed for documentation purposes.

\subsubsection{Grain Size Measurements}

The ASTM grain size for the specimens of each sample set were measured from etched specimens using the three-circle (or Abrams) method outlined in ASTM E 112. ${ }^{(64)}$ Use of the circular intercept procedure, rather than procedures which utilize straight test lines, was done because circular test arrays automatically compensate for departires from equiaxed grain shapes. The test pattern consists of three concentric circles having a totar circumference of $500 \mathrm{~mm}$. The pattern was successively applied to five blindly selected areas from each sample and the number of grain boundary intersections counted for each area. The ASTM grain size number was then subsequently determined using the charts, graphs, and procedures outlined in ASTM E $112 .{ }^{(64)}$ 


\section{RESULTS AND DISCUSSION}

\subsection{CCS of Mill-Annealed and Solution-Annealed Materials}

\subsubsection{Heat SS-16}

The average grain size of the MA material from heat SS-16 corresponded to an ASTM orain size number of 5.7 (a grain diameter of approximately 45 microns). The grain size for the MA material was determined by averaging the grain sizes of several samples which had been Gleeble tested at temperatures between 900 and $1050^{\circ} \mathrm{C}$. After the MA material was solution annealed at $1100^{\circ} \mathrm{C}$ for one hour, it had an average ASTM grain size of 3.4 (a grain diameter of approximately 95 microns). The grain structures of the MA and SA materials of heat SS-16 are shown in the optical micrographs of Figure 14.

Continuous cooling sensitization development (EPR-DOS) in the MA and SA materials of heat SS-16 is illustrated as a function of peak cycle temperature and cooling rate in the graphs of Figures 15 and 16. The experimentally determined EPR-DOS values, as well as those predicted using the SSDOS model, are presented in tabulated form in Appendix A.

For both material conditions, sensitization development was found to be a strong function of the peak temperature achieved during the thermal cycle. Continuous cooling from peak temperatures above $950^{\circ} \mathrm{C}$ (i.e. 1000 and $1050^{\circ} \mathrm{C}$ ) resulted in dramatic decreases in EPR-DOS values. It should be noted that samples heated to peak temperatures above $950^{\circ} \mathrm{C}$ spent at least as much time, in the sensitization regime as those heated to $950^{\circ} \mathrm{C}$. This indicates that heating above $950^{\circ} \mathrm{C}$ retarded sensitization development upon continuous cooling through the sensitization temperature range. Peak cycle temperatures below $950^{\circ} \mathrm{C}$ resulted in lower EPR-DOS values. Lower peak temperatures are expected to result in lower DOS values since the amount of time spent in the sensitization regime decreases.

For all peak temperatures, the DOS increased with decreasing cooling rates. This characteristic is also expected since the amount of time spent within the sensitization regime increases with decreasing cooling rates.

The critical peak temperature for CCS can be defined as the peak cycle temperature which produces the highest EPR-DOS values upon cooling such that peak temperatures either above or below this temperature result in lower DOS values. A critical peak temperature of $950^{\circ} \mathrm{C}$ was observed for the MA and SA materials of heat SS-16 for the thermal treatments employed in the present work.

Defining the critical peak cycle temperature as $950^{\circ} \mathrm{C}$ for the present work is not strictly correct since samples were not tested for peak cycle temperatures between 900 and $950^{\circ} \mathrm{C}$ or between 950 and $1000^{\circ} \mathrm{C}$. Despite this obvious limitation in defining the critical peak temperature in an exact manner, the term "critical peak temperature" will be used throughout this document as defined above for purposes of convenience.

The mechanism responsible for the presence of the critical peak temperature observed in CCS studies has not yet been determined. However, it is believed that the critical peak temperature occurs just above the carbide solubility temperature for a given material. It is expected that when the temperature reached during the thermal cycle exceeds the critical peak temperature, complete carbon solubility occurs in the material. Thus, any carbides or carbide nuclei present would be annihilated and nucleation and/or renucleation of carbides would be much more difficult upon subsequent cooling. ${ }^{(65)}$ The carbide solubility temperature for heat SS-16 was calculated from equation [1] to be approximately $980^{\circ} \mathrm{C}$. This value correlates well to the experimentally observed critical peak temperature of $950^{\circ} \mathrm{C}$. 


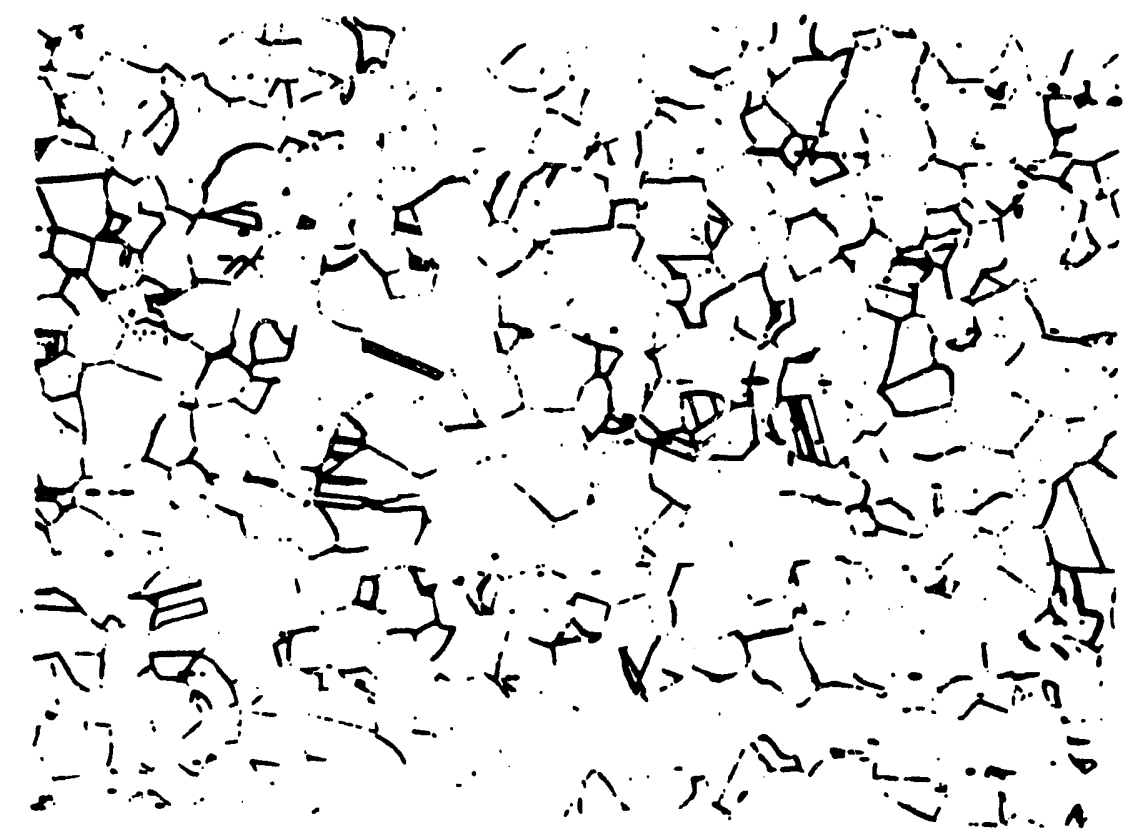

(a)

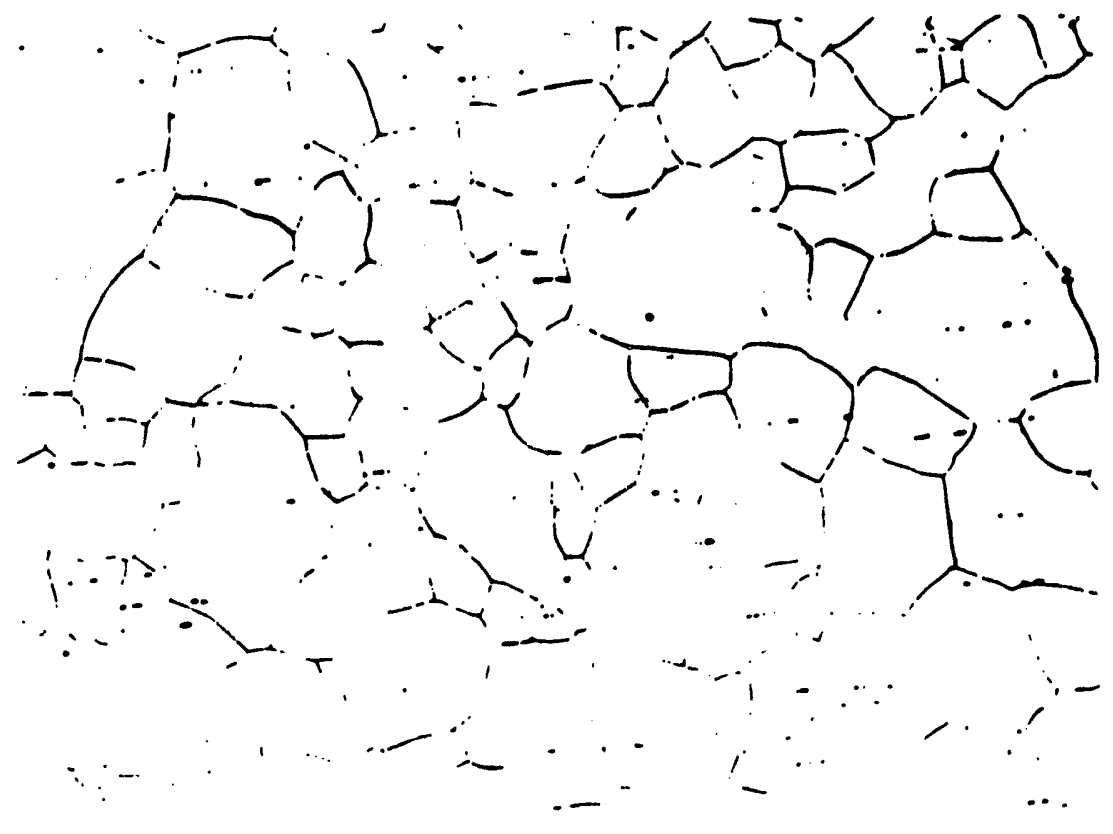

(b)

Figure 14. Optical Micrographs of Heat SS-16 (a) Mill-Annealed and (b) Solution-Annealed $\left(1100^{\circ} \mathrm{C} / 1\right.$ Hour) Materials 


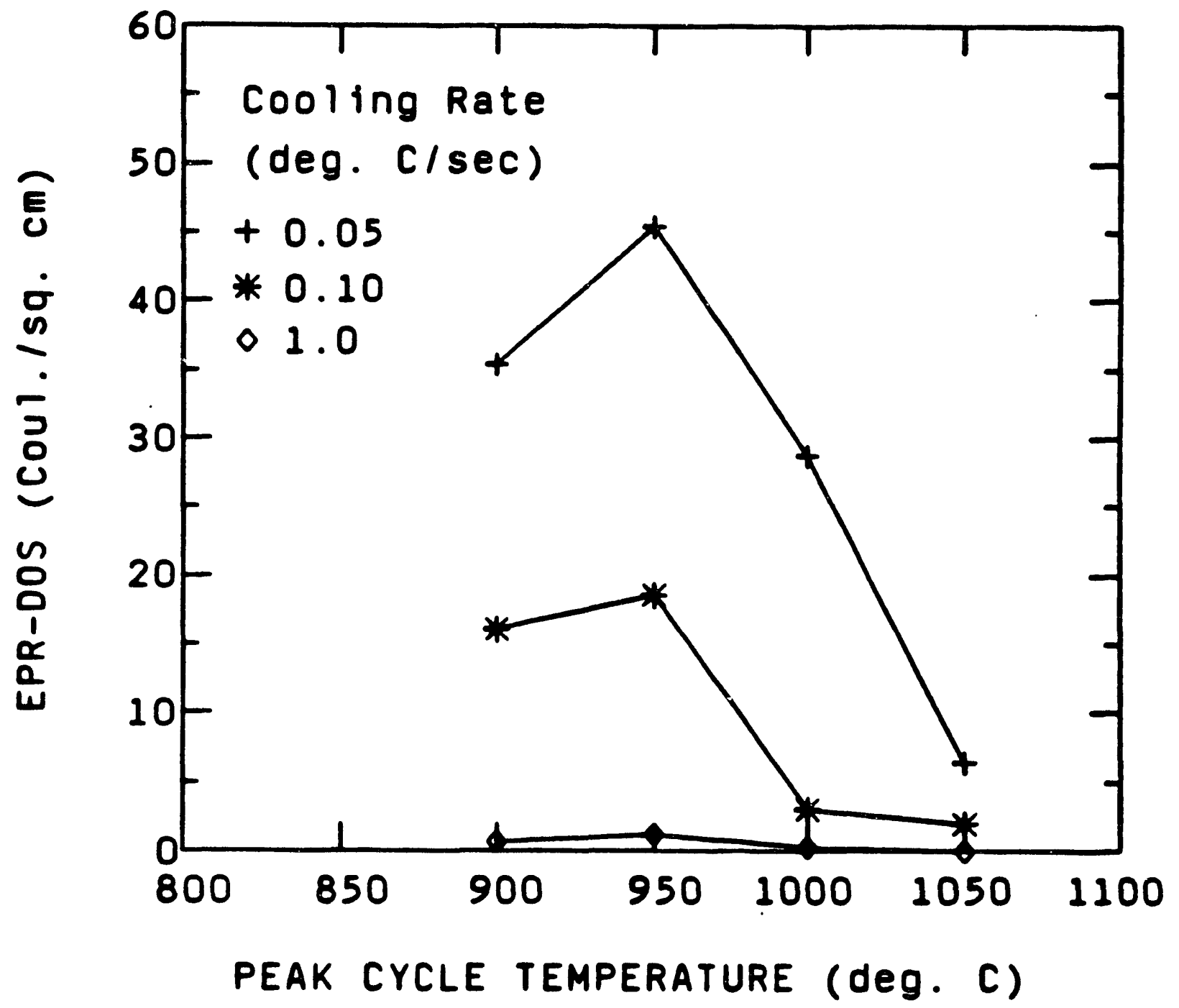

Figure 15. Continuous Cooling Sensitization Behavior of the MA Material from Heat SS-16 as a Function of Peak Cycle Temperature and Cooling Rate 


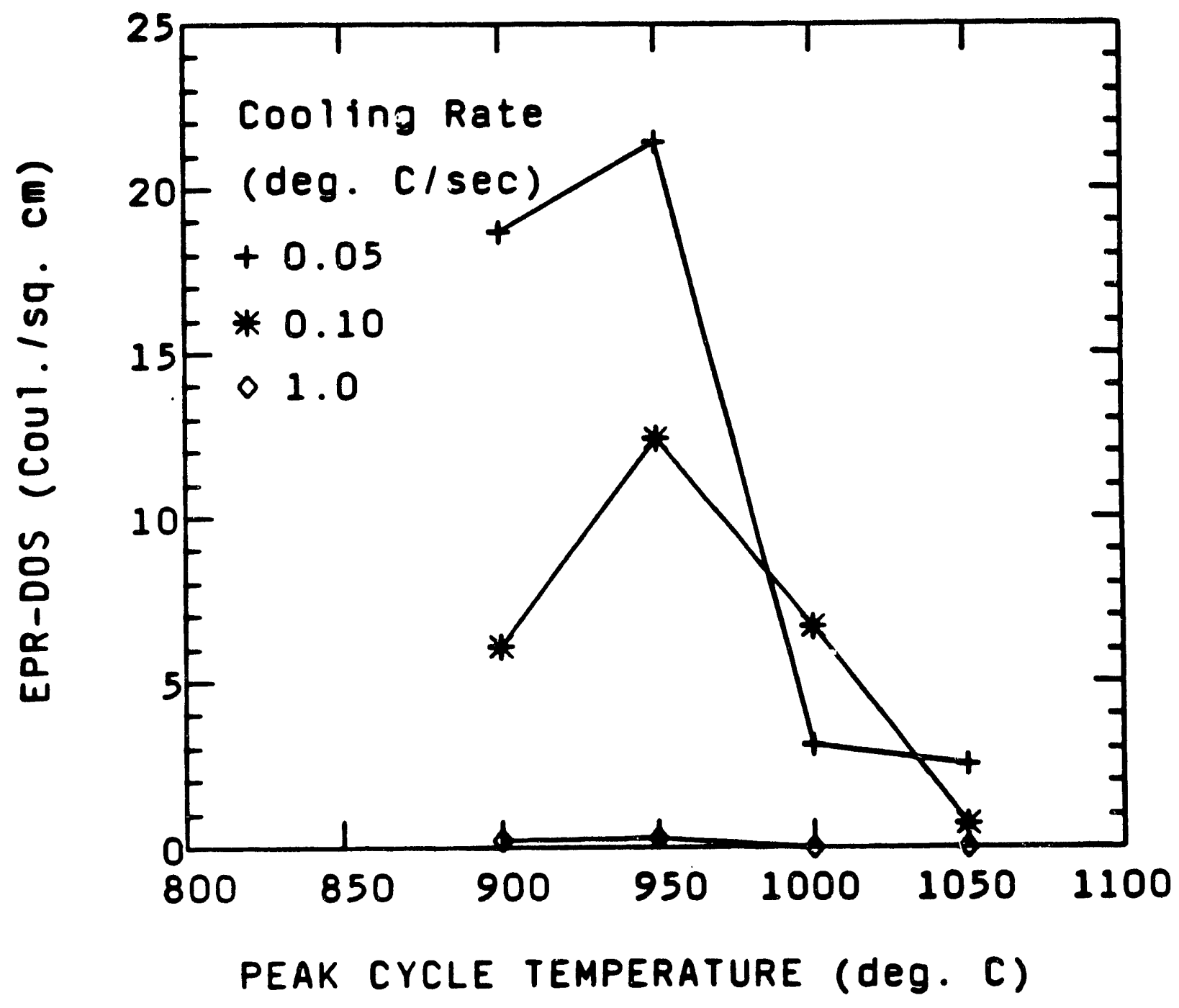

Figure 16. Continuous Cooling Sensitization Behavior of the SA Material from Heat SS-16 as a Function of Peak Cycle Temperature and Cooling Rate

Continuous cooling sensitization development was observed to be much more severe in asreceived MA materials than in samples that had been solution annealed (Figures 17, 18, and 19). Sensitization values (EPR-DOS) achieved in MA samples were significantly higher than SA materials, generally more than twice as high. The microstructure of the MA material was finer than the SA material, but the calculated EPR-DOS values were corrected for total grain boundary area to account for this difference.

The effect of grain size cannot totally be discounted as being contributory to the observed difference in sensitization development between the MA and SA materials. Grain size is known to have an effect on the rate of desensitization, so it is possible that it also has an effect on the rate of sensitization development itself. It is not known what differences in grain size are necessary to have a significant effect on carbide growth kinetics or $\mathrm{Cr}$-depletion zone development. A comprehensive study on the effects of grain size on the rate of sensitization development has not been reported. 


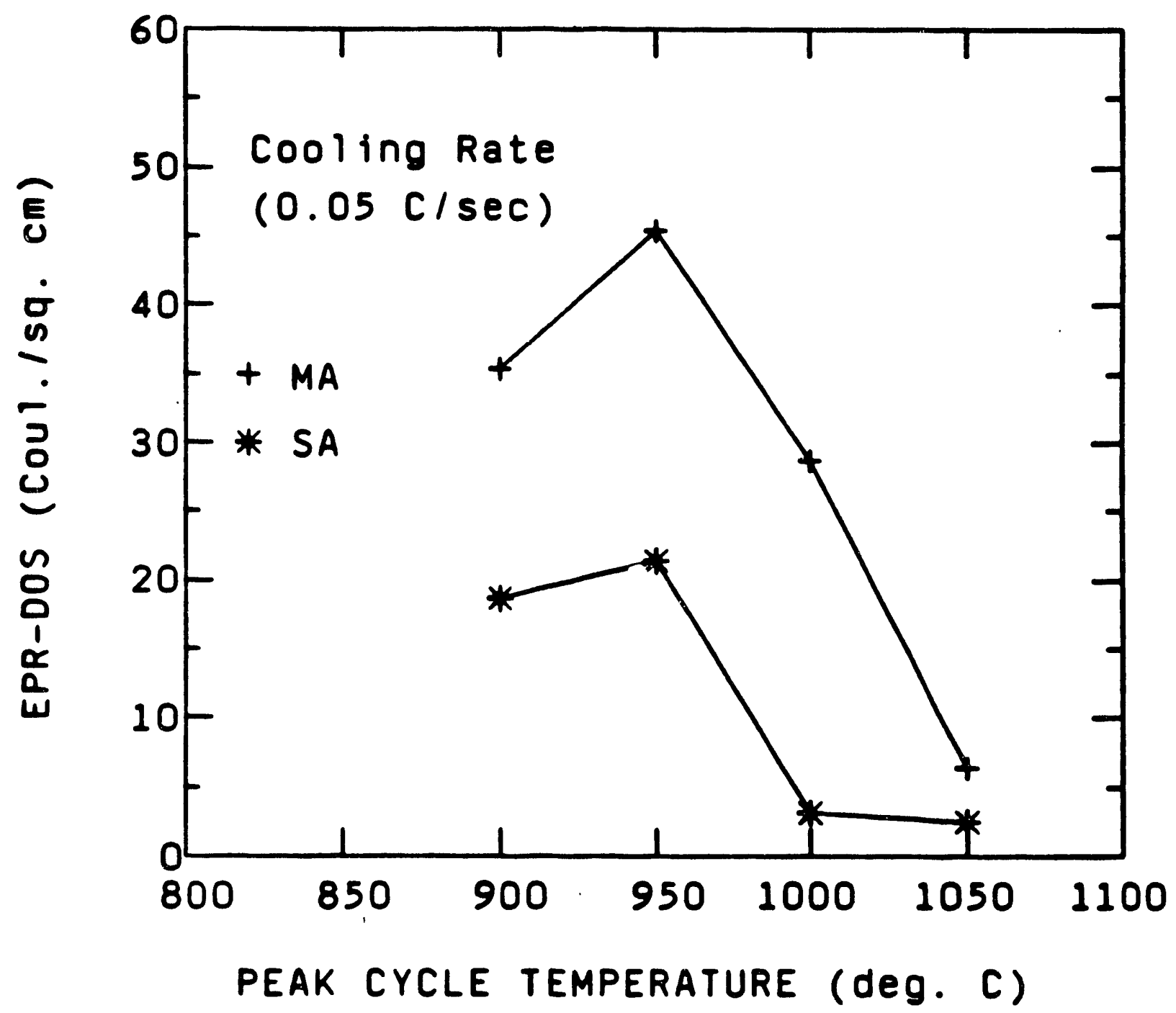

Figure 17. Comparison of the CCS Behavior of the MA and SA Materials from Heat SS-16 as a Function of Peak Cycle Temperature for a Cooling Rate of $0.05^{\circ} \mathrm{C} / \mathrm{sec}$ 


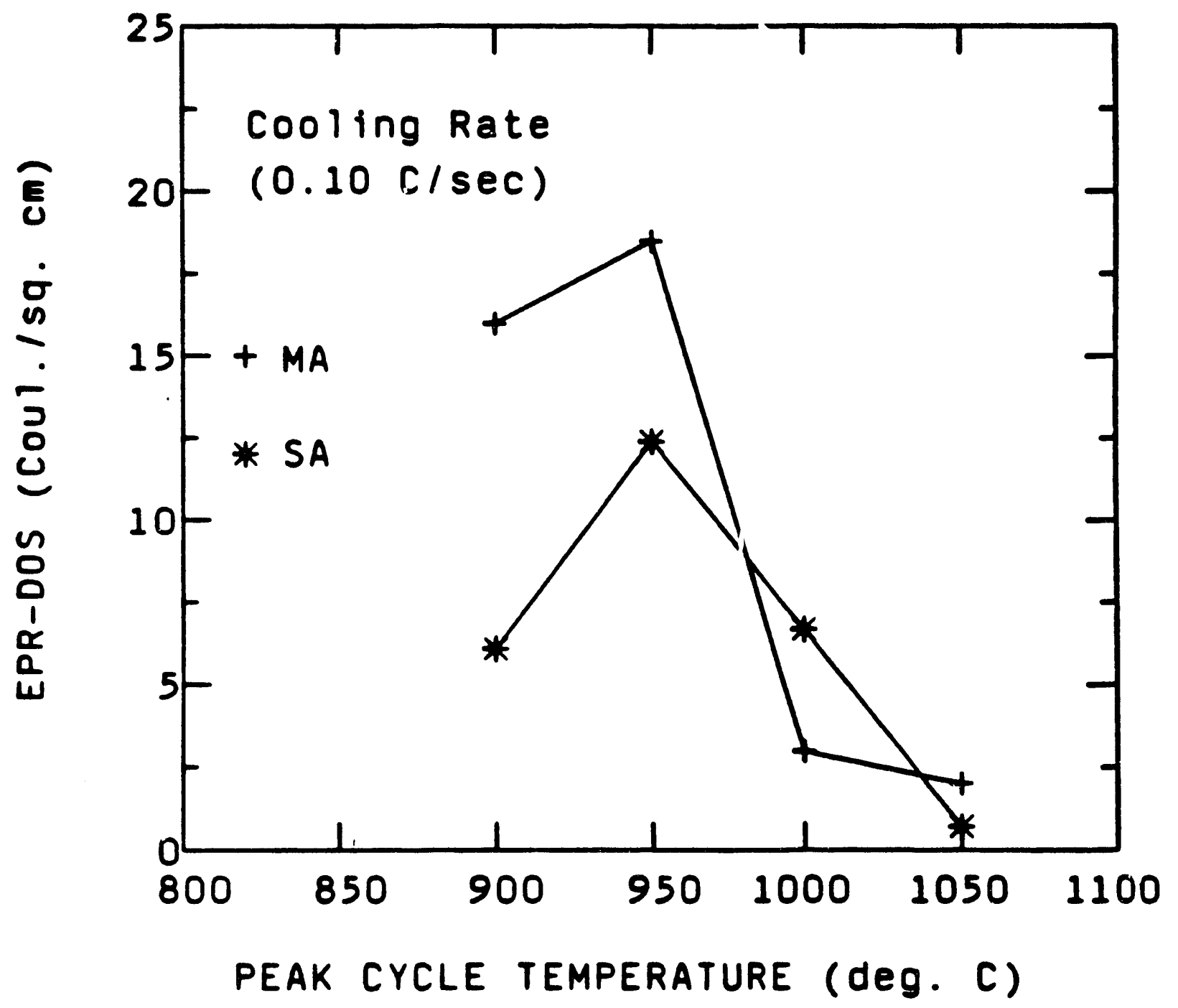

Figure 18. Comparison of the CCS Behavior of the MA and SA Materials from Heat SS-16 as a Function of Peak Cycle Temperature for a Cooling Rate of $0.10^{\circ} \mathrm{C} / \mathrm{sec}$ 


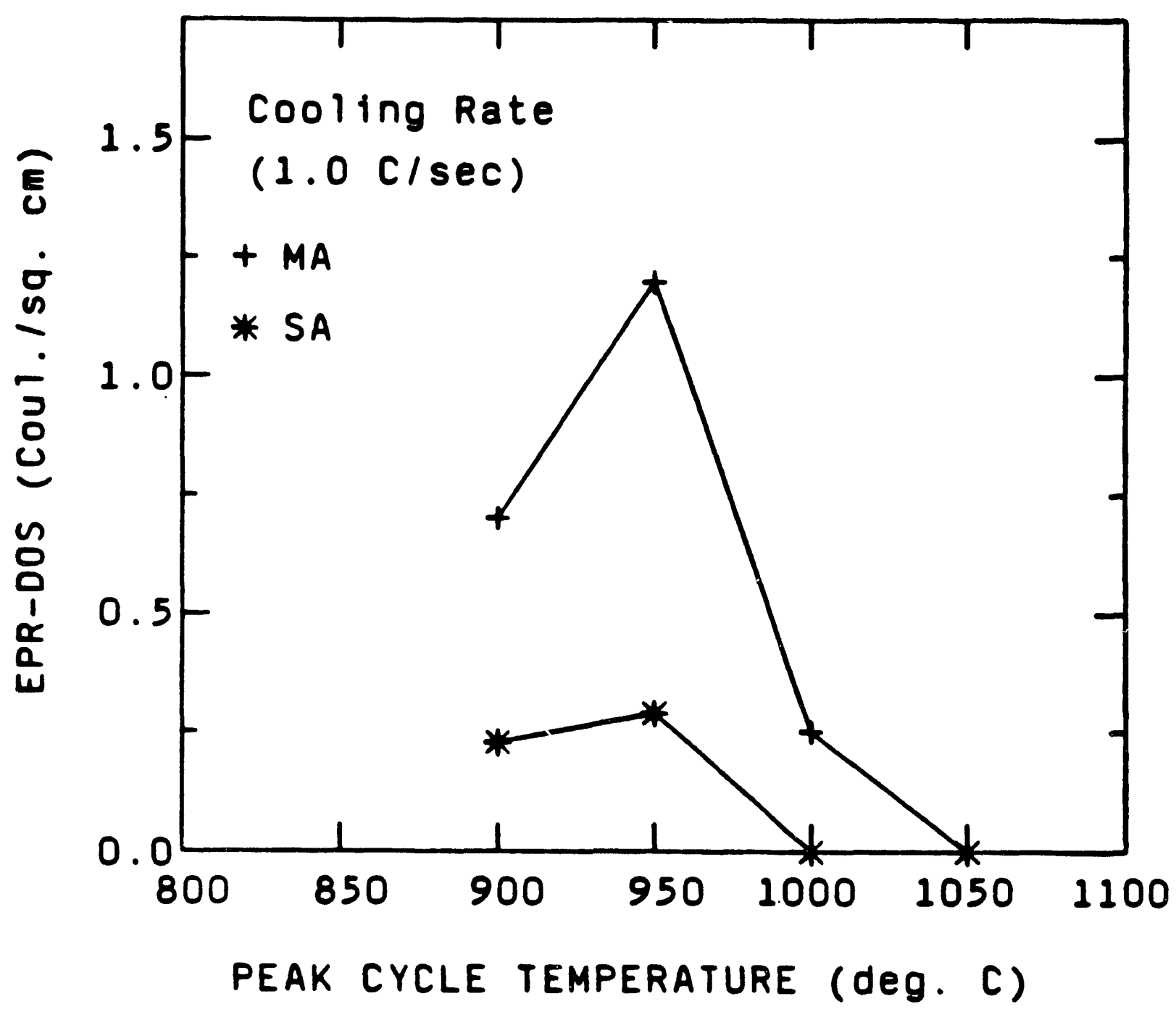

Figure 19. Comparison of the CCS Behavior of the MA and SA Materials from Heat SS-16 as a Function of Peak Cycle Temperature for a Cooling Rate of $1.0^{\circ} \mathrm{C} / \mathrm{sec}$

As mentioned previously, the presence of deformation has been shown to accelerate sensitization development in SSs. Deformation is often present in MA materials in final product form. Final annealing operations are often insufficient and fail to remove the effects of prior thernomechanical processing. Also, deformation can be induced into final product materials after mill-annealing (e.g., straightening procedures). However, results 'of transmission electron microscopy (TEM) studies conducted by $A d v a n{ }^{(86)}$ indicated that the initial MA pipe material from heat SS-16 did not contain any GB carbides and that the MA and SA $\left(1100^{\circ} \mathrm{C} / 1\right.$ hour $)$ materials contained approximately equal dislocation densities. Thus, it can be concluded that the MA material did not contain a large degree of strain as compared to the SA material and strain was not a factor in the observed difference in their rate of sensitization development. 
The reason for the large difference in the rates of sensitization development between the MA and SA materials has not been determined. There remains a possibility, however, that there were very small undetected carbides present in the MA material that were subsequently destroyed upon solution annealing and not renucleated during quenching. The actual cooling rate of the MA material is unknown, but it is likely that the cooling rate of the SA materials was faster since the samples were small and quenched directly into room temperature water with vigorous agitation.

Small carbides in the MA material, if they were large enough to be stable at the elevated temperatures (below the critical peak temperature) employed in the present study $\left(950^{\circ} \mathrm{C}\right.$ and below), could have eliminated the need for a carbide nucleation incubation time. This should result in enhancement of sensitization development in the MA material since nucleation becomes increasingly important at higher temperatures (larger nuclei are required for stability). If the necessity for nucleation was eliminated in the MA material, carbide growth could take place immediately at elevated temperatures (for peak temperatures below the critical peak temperature). In contrast, nucleation and growth of carbides in the SA material may have occurred at lower temperatures during continuous cooling.

\subsubsection{Heat SS-17}

The MA pipe material of heat SS-17 had an ASTM grain size of 4.95 (60 micron grain diameter). The grain structure of the as-received MA material is shown in the optical micrograph of Figure 20.

Samples solution annealed at temperatures of 1000,1050 , and $1100^{\circ} \mathrm{C}$ from heat SS-17 had ASTM grain sizes of 4.75, 4.65, and 4.35, respectively. The average grain diameters for samples solution annealed at 1000 and $1050^{\circ} \mathrm{C}$ were virtually identical (approximately 65 microns). The samples solution annealed at $1100^{\circ} \mathrm{C}$ had only a slightly coarser grain structure laverage grain diameter of approximately 75 microns). The grain structure of the MA material did not appear to have changed significantly as a result of solution annealing. The grain structures of the SA materials from heat SS-17 are shown in the optical micrographs of Figure 21. 


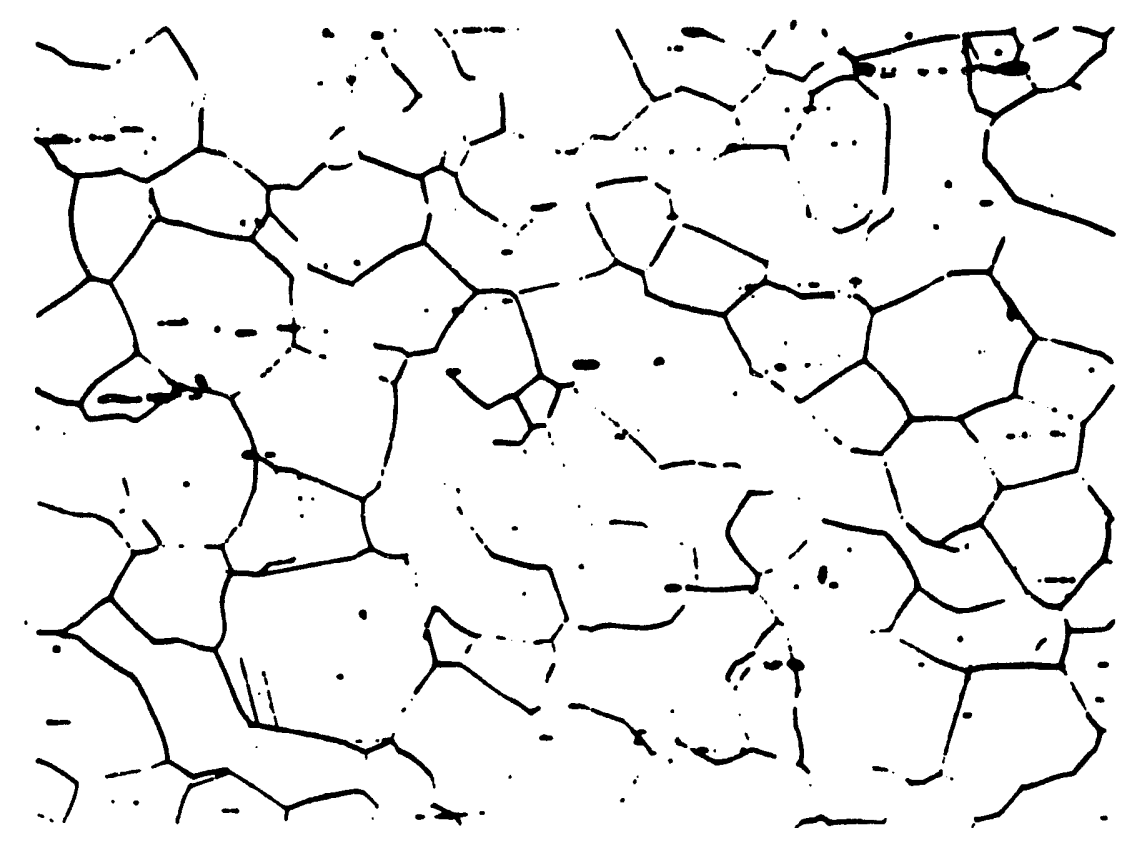

Figure 20. Optical Micrograph of Heat SS-17 Mill-Annealed Material

Continuous cooling sensitization development of the MA material from heat SS-17 is illustrated as a function of peak cycle temperature and cooling rate in the graph of Figure 22 . Experimentally determined EPR-DOS values for the MA material are presented in tabulated form in Appendix B, Table B1. Comparisons of the sensitization development (EPR-DOS) in MA and SA materials are illustrated as a function of peak cycle temperature, cooling rate, and solution annealing temperature in the graphs of Figures 23 and 24.

Development of sensitization in the SS-17 MA and SA materials was similar to the materials of heat SS-16 in that the results were found to be a strong function of peak cycle temperature la critical peak temperature was observed for (CS) and the DOS increased with decreasing cooling rates.

The MA material from heat SS-17 did not have the same experimentally determined critical peak temperature for all cooling rates (Figure 22). A critical peak temperature of $950^{\circ} \mathrm{C}$ was obtained for cooling rates of 0.05 and $1.0^{\circ} \mathrm{C} / \mathrm{sec}$, while the $0.10^{\circ} \mathrm{C} / \mathrm{sec}$ cooling rate indicated a critical peak temperature of $900^{\circ} \mathrm{C}$ for the material. However, the total EPR-DOS values obtained for a cooling rate of $1.0^{\circ} \mathrm{C} / \mathrm{sec}$ were very small and the values for peak temperatures of 900 and $950^{\circ} \mathrm{C}$ are not significantly different. In addition, a difference of only $3 \mathrm{C} / \mathrm{cm}^{2}$ existed between the EPR-DOS values for peak cycle temperatures of 900 and $950^{\circ} \mathrm{C}$ for the $0.10^{\circ} \mathrm{C} / \mathrm{sec}$ cooling rate. Small differences in EPR-DOS values of this magnitude are probably not significant due to the number of variables involved in their determination. Sensitization response may vary slightly from sample-tosample depending on possible material inhomogeneities and thermal cycle testing parameter variations. 


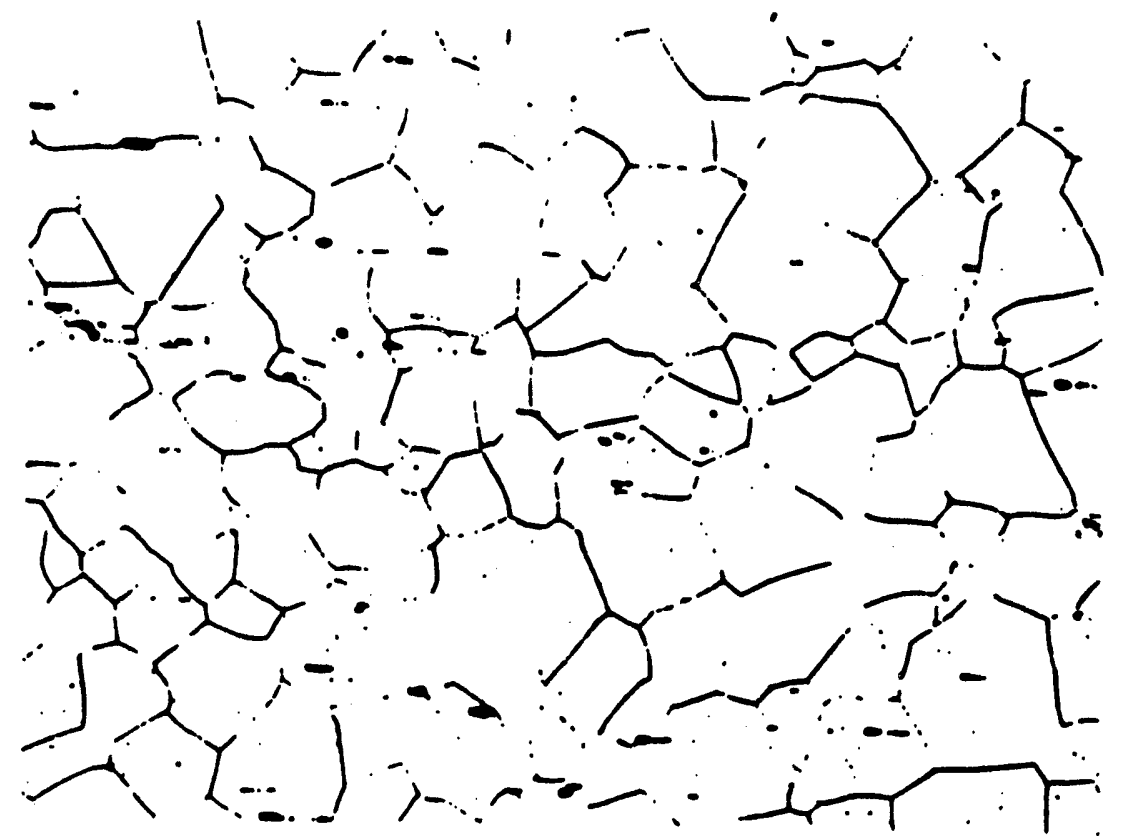

(a)

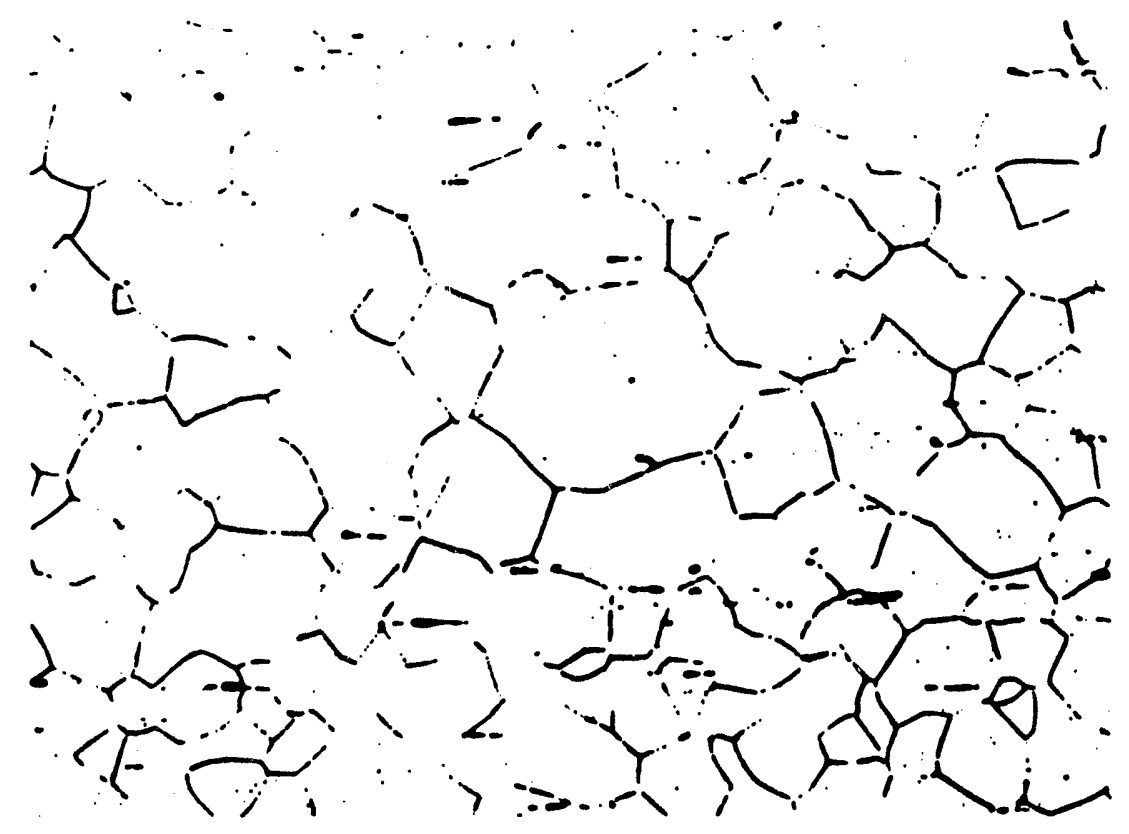

(b)

Figure 21. Optical Micrographs of Heat SS-17 Samples Solution Annealed at Temperatures of (a) 1100, (b) 1050 , and (c) $1000^{\circ} \mathrm{C}$ for One Hour 


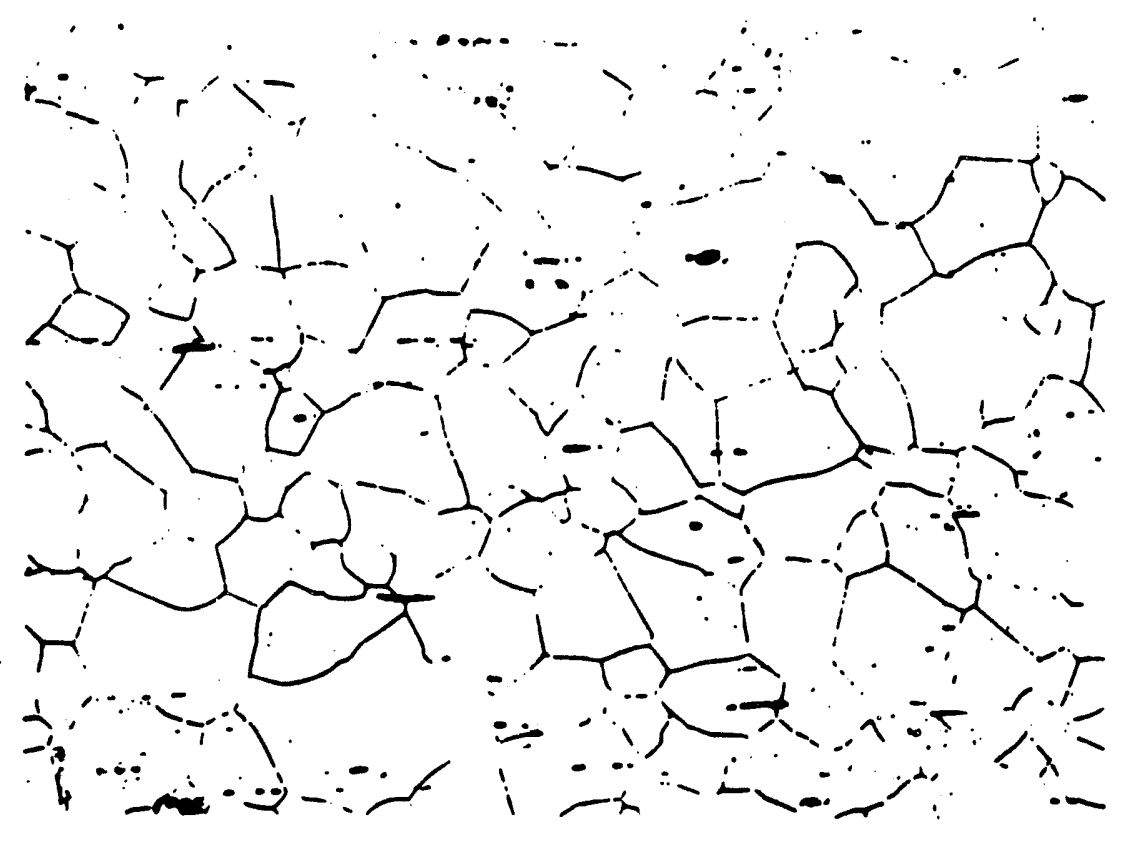

(c)

Figure 21. Continued 


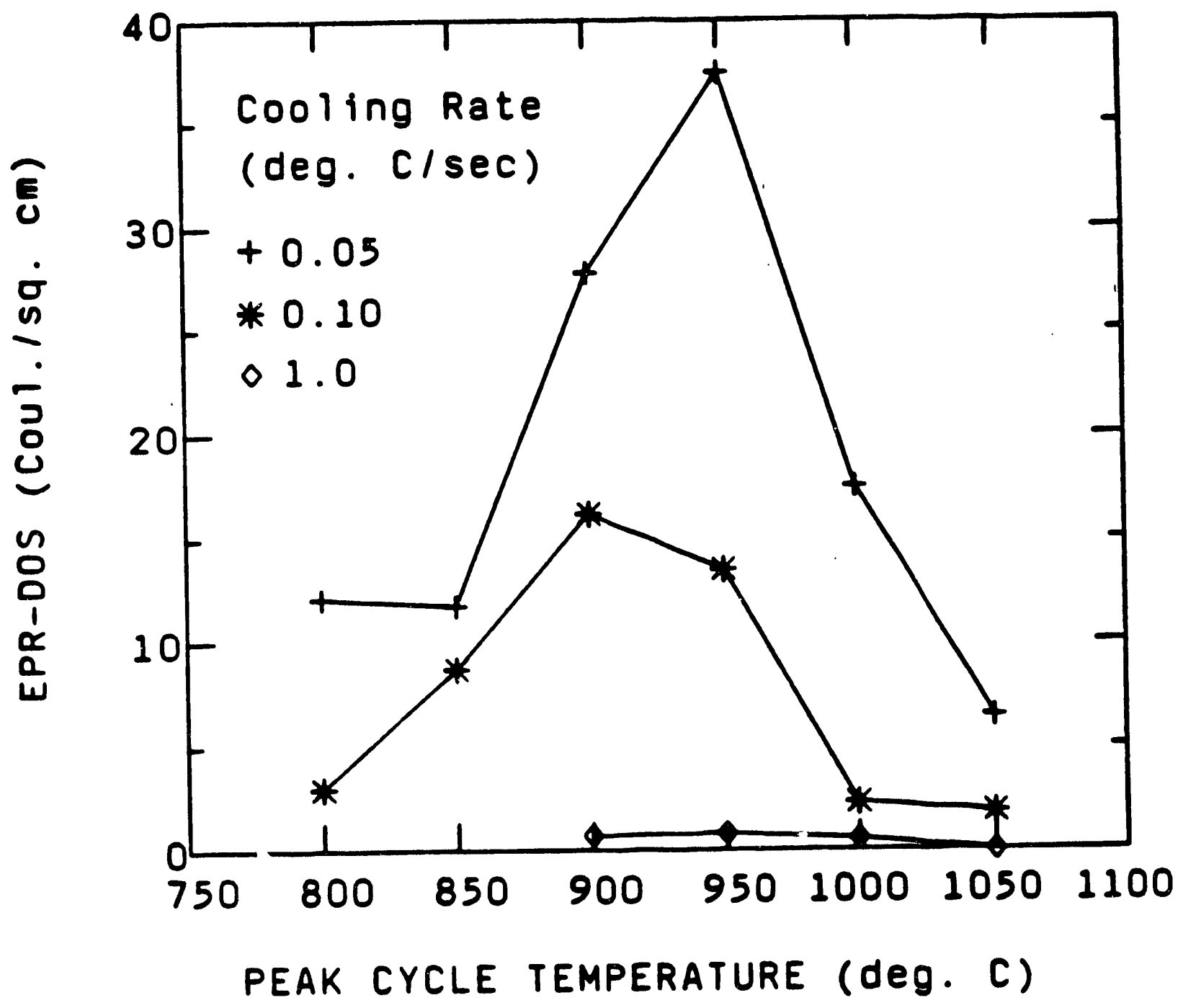

Figure 22. Continuous Cooling Sensitization Behavior of the MA Material from Heat SS-17 as a Function of Peak Cycle Temperature and Cooling Rate 


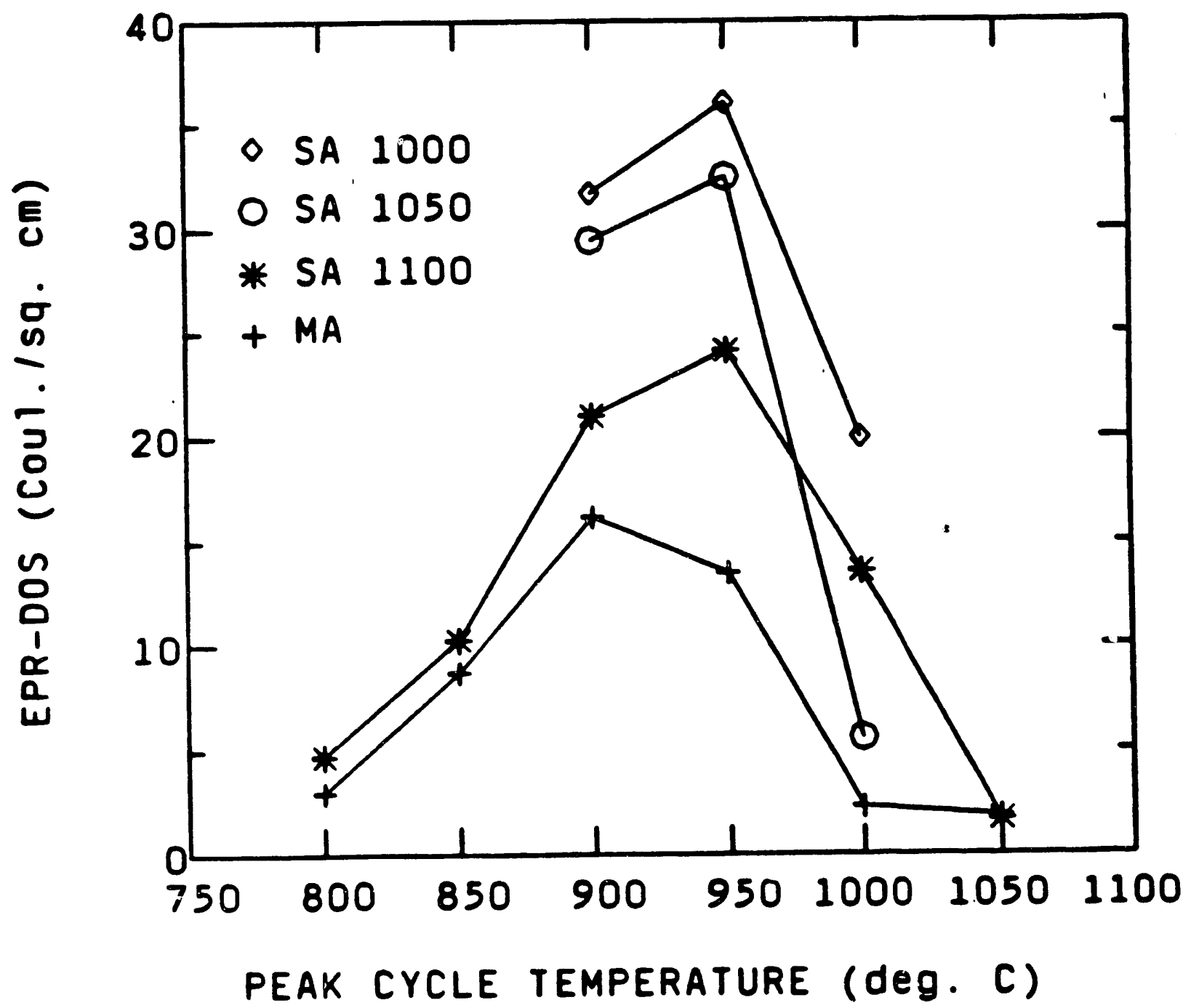

Figure 23. Effects of Solution Annealing Temperature on the CCS Behavior of Heat SS-17 as a Function of Peak Cycle Temperature for a Cooling Rate of $0.10^{\circ} \mathrm{C} / \mathrm{sec}$ 


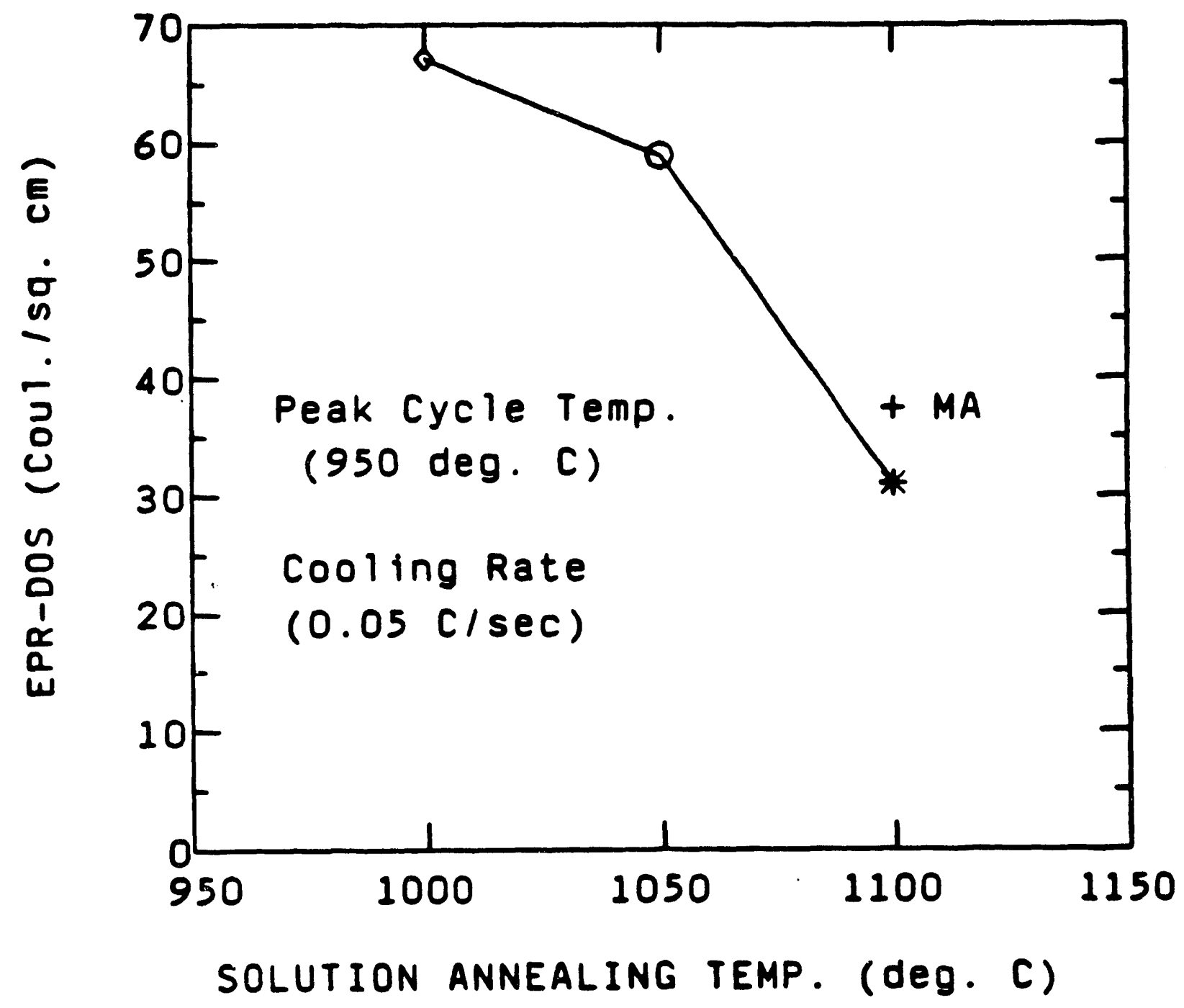

Figure 24. Effects of Solution Annealing Temperature on the CCS Behavior of Heat SS-17

Sensitization development in heat SS-17 materials was most severe for samples solution treated at 1000 and $1050^{\circ} \mathrm{C}$, followed by samples solution treated at $1100^{\circ} \mathrm{C}$. The EPR-DOS values obtained for the MA material from heat SS-17 were slightly less than the values for the $1100^{\circ} \mathrm{C}$ SA samples. The EPR-DOS values are slightly lower for the MA material compared to samples solution annealed at $1100^{\circ} \mathrm{C}$ and the reason for this is not known.

The rapid sensitization development of samples solution treated at 1000 and $1050^{\circ} \mathrm{C}$, compared to the $1100^{\circ} \mathrm{C} \mathrm{SA}$ and MA samples, is illustrated in Figures 23 and 24 for two different cooling rates. An explanation for this behavior is that carbides developed during solution treating at temperatures of 1000 and $1050^{\circ} \mathrm{C}$ and eliminated the need for nucleation during Gleeble treatments. In fact, TEM examinations performed by Advani(66) on similarly heat treated samples from heat SS-16 revealed the presence of carbides in samples solution treated at temperatures of 1000 and $1050^{\circ} \mathrm{C}$. Advani reported the presence of carbides in samples solution annealed at $1050^{\circ} \mathrm{C}$ for 15 minutes, but their disappearance after one-hour. Samples solution annealed at $1000^{\circ} \mathrm{C}$ had carbides on the GBs after on's-hour at temperature. These results indicate that 
carbides formed during heating in the furnace and that they either continued to grow or dissolved very slowly at $1000^{\circ} \mathrm{C}$, but were unstable at $1050^{\circ} \mathrm{C}$ and dissolved within one-hour.

These results are somewhat in contradiction to the CCS results reported earlier where a reduction in sensitization development was observed for samples exposed to temperatures of 1000 and $1050^{\circ} \mathrm{C}$ during Gleeble testing. One explanation for the observed phenomena is that the temperatures of the samples were not equal for furnace and Gleeble thermal treatments. Another explanation is that because heating rates obtained in the Gleeble $\left(50^{\circ} \mathrm{C} / \mathrm{sec}\right)$ were very fast in comparison to those likely obtained in the furnace, carbides developed during heating in the furnace and not in the Gleeble testing. In either case, it would require that the carbides be stable in the furnace at solution annealing temperatures for a short while and not dissolve. If carbides did form during heating in the furnace and there was a slight temperature difference between the Gleeble and furnace treatments (the Gleeble specimens being at higher temperatures), this would explain the lower EPR-DOS values for Gleeble specimens heated to peak cycle temperatures of 1000 and $1050^{\circ} \mathrm{C}$.

Actual temperatures within Gleeble thermal simulation samples have been reported to vary significantly from surface temperature measurements. These temperature discrepancies are most often attributed to thermocouple measurement errors due to bead geometries of welded fine-wire thermocouple hot junctions and surface cooling of the specimens due to convection and radiation. ${ }^{(81)}$ This generally means that temperatures within Gleeble samples would be higher than those indicated by thermocouple measurements.

It is also conceivable that temperatures within the furnace varied by $+1-10$ or $20^{\circ} \mathrm{C}$ since exact calibration of the furnace controller or the K-type shielded thermocouple used for temperature measurement was not performed.

The exact critical peak temperature for CCS in the Gleeble work was not well defined and could have actually been anywhere between 900 and $1000^{\circ} \mathrm{C}$. This is important because it is not known just how sensitive the dissolution of carbides is to small changes in temperature. A combination of the observations outlined above is most likely responsible for the discrepancies noted between the furnace and Gleeble results.

\subsubsection{Comparison of Heats SS-16 and SS-17}

Sensitization development in the as-received MA materials of the two high carbon 316 SS heats, designated SS-16 and SS-17, was quite similar (Figures 25 and 26). The SS-16 MA material had slightly higher EPR-DOS values for a cooling rate of $0.05^{\circ} \mathrm{C} / \mathrm{sec}$, but sensitization response of the two materials for cooling rates of 0.10 and $1.0^{\circ} \mathrm{C} / \mathrm{sec}$ were virtually identical. The carbon contents of the materials varied slightly, with SS-17 being higher 10.064 compared to $0.058 \mathrm{wt} \%$ ), and the MA material of SS-16 had a finer grain size. Of course, in comparing EPR testing results, total integrated peak values (charge values, $Q$, in coulombs) were much higher for SS-16 specimens, but after normalization of the results for total GB area, the EPR-DOS $\left(\mathrm{C} / \mathrm{cm}^{2}\right)$ values for the two materials were very similar. 


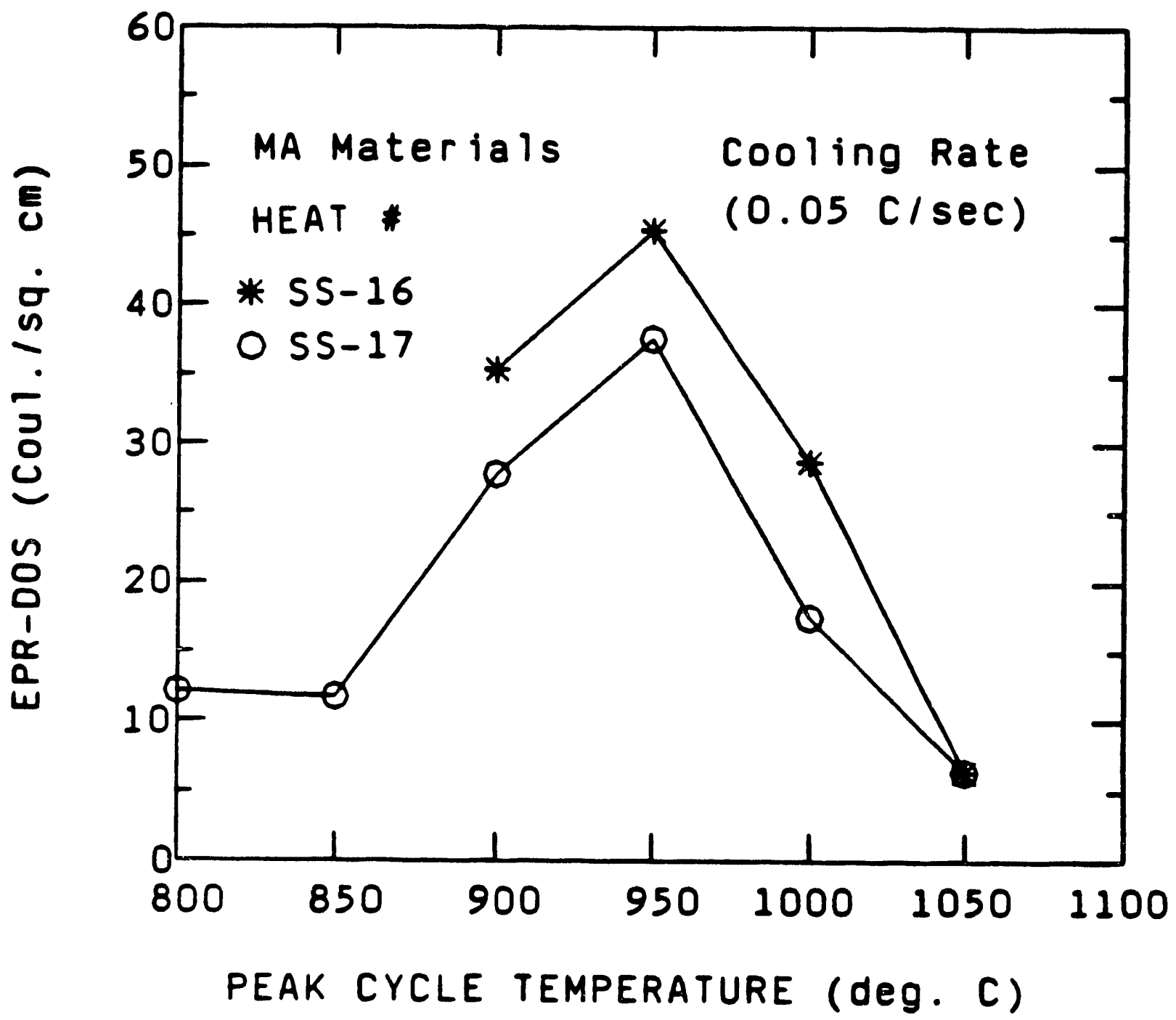

Figure 25. Comparison of the CCS Development of the MA Materials from Heats SS-16 and SS17 as a Function of Peak Cycle Temperature for a Cooling Rate of $0.05^{\circ} \mathrm{C} / \mathrm{sec}$ 


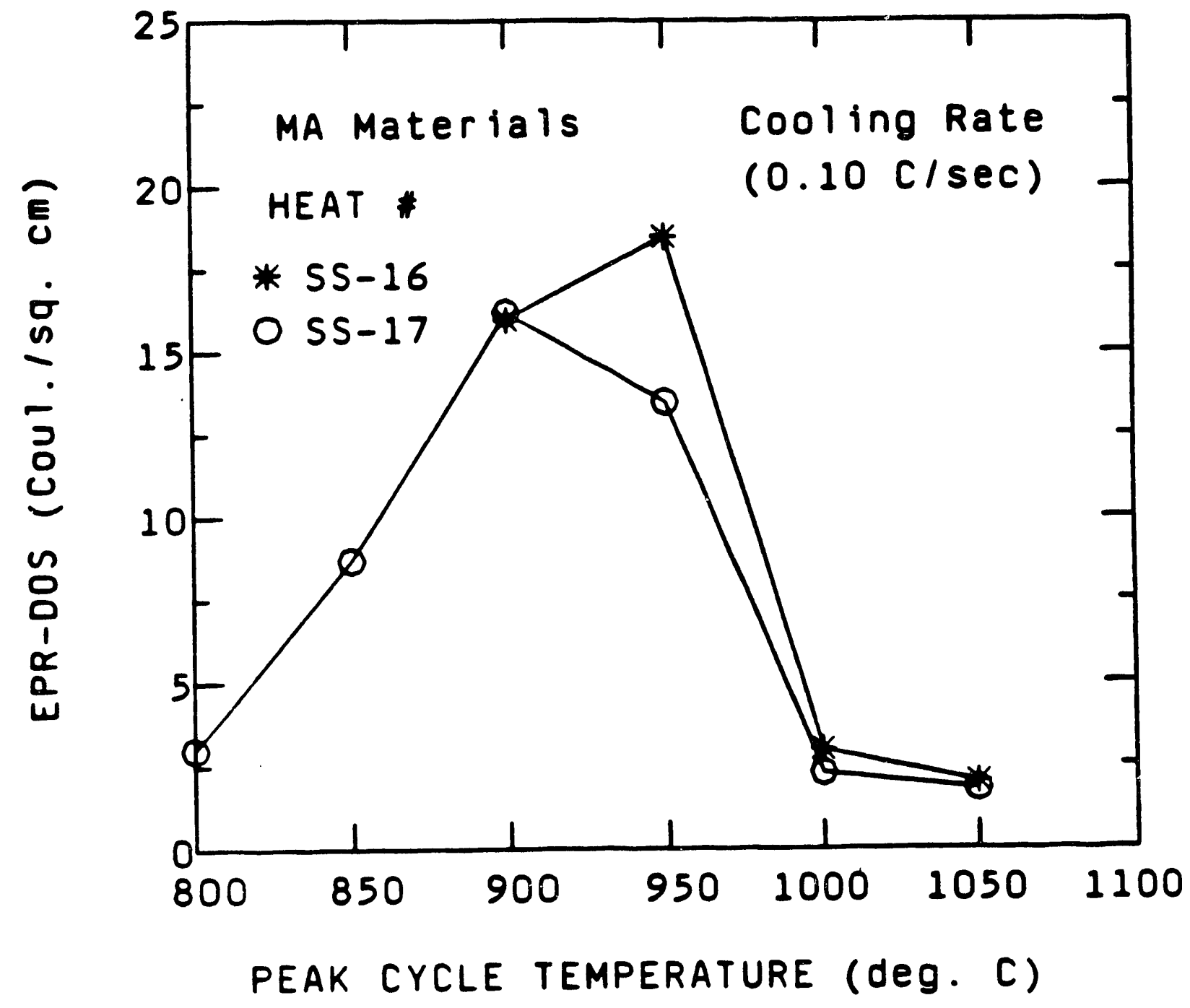

Figure 26. Comparison of the CCS Development of the MA Materials from Heats SS-16 and SS17 as a Function of Peak Cycle Temperature for a Cooling Rate of $0.10^{\circ} \mathrm{C} / \mathrm{sec}$

In contrast, for specimens which had been solution treated at $1100^{\circ} \mathrm{C}, \mathrm{CCS}$ development was more severe in heat SS-17 than heat SS-16 materials (Figure 27). The grain size differences for the SA materials of the two heats was just opposite that of the MA materials. The heat SS-17 SA material had an average grain diameter of 75 microns, compared to 95 microns, for heat SS-16. The magnitude of change in grain size from the MA to SA material conditions was much greater for heat SS-16 (45 to 95 microns) than for heat SS-17 (60 to 75 microns). 


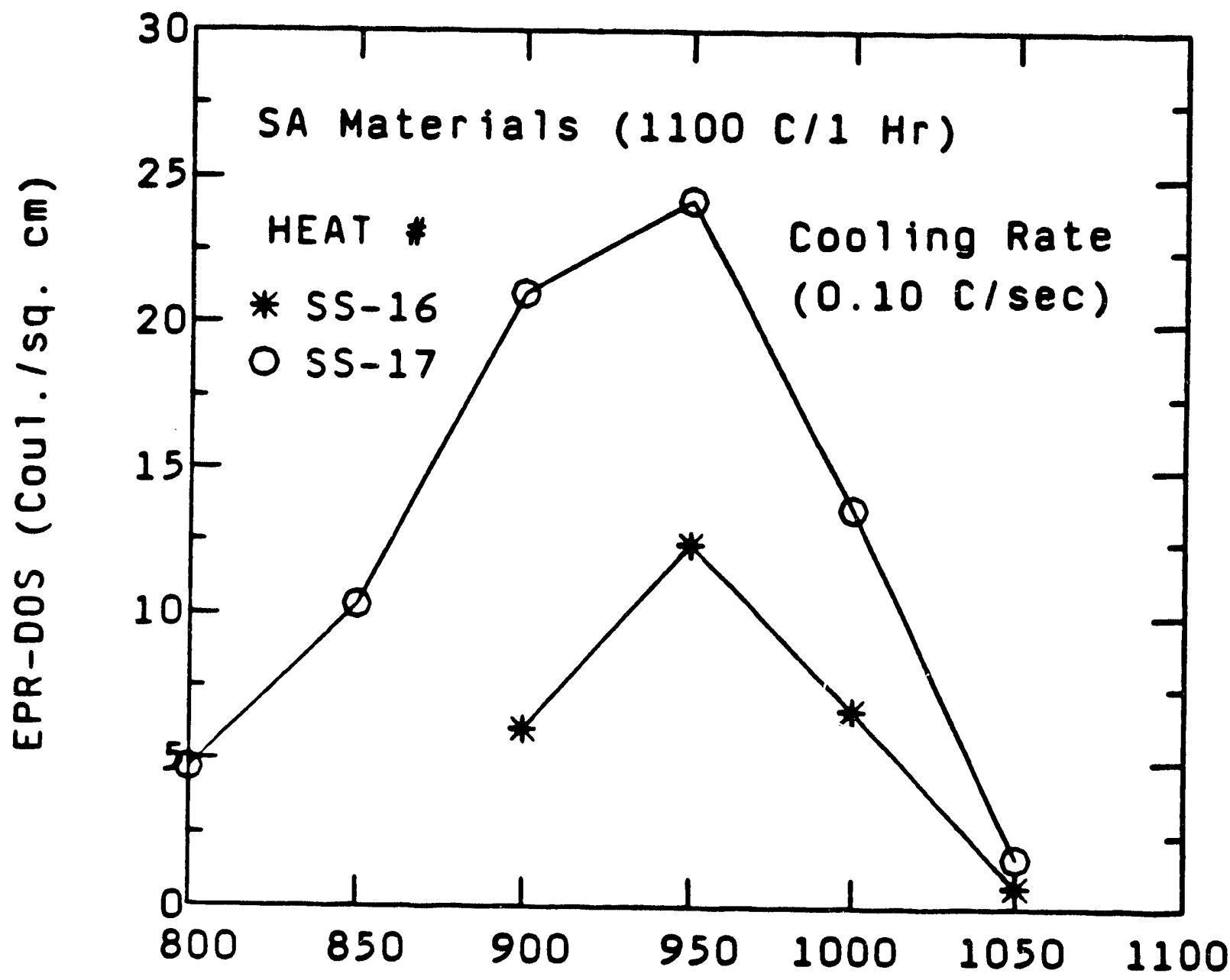

\section{PEAK CYCle temperature (deg. C)}

Figure 27. Comparison of the CCS Development of the SA Materials $\left(1100^{\circ} \mathrm{C} / 1\right.$ Hour $)$ from Heats SS-16 and SS-17 as a Function of Peak Cycle Temperature for a Cooling Rate of $0.10^{\circ} \mathrm{C} / \mathrm{sec}$

These results indicate that solution annealing did not significantly affect the microstructure of the SS-17 MA material but did have a large effect on the SS-16 material. Thus, the driving force for grain growth appears to have been much greater in the MA material of heat SS-16. This could have been due to differences in grain geometries or GB structure between the two heats, both of which would have been affected by prior thermomechanical processing.

The general trends of the MA and SA CCS development from both high carbon heats of material studied correlate well with those of other investigators, most notably those of Solomon and Bruemmer. $(8,9,59,60,65)$ Comparisons to the CCS results of other researchers and the SSDOS sensitization prediction model are made in the SSDOS MODEL PREDICTIONS section. 


\subsection{Effects of Prior Deformation on CCS Developments}

Prior deformation significantly enhanced the rate of CCS development in heat SS-17 as illustrated in the graphs of Figures 28-30. Most importantly, EPR-DOS was found to increase with increasing amounts of prior strain. The experimentally determined EPR-DOS values for the pre-strained MA CCS specimens are presented in Appendix B, Tables B2, B3, and B4.

The pre-strained specimens showed the same effects of peak temperature (they exhibited a critical peak temperature for CCS) as the MA material. The peak temperature observed was not constant for all cycles, but was either 900 or $950^{\circ} \mathrm{C}$. The critical peak temperature $\left(950^{\circ} \mathrm{C}\right)$ was generally the same for the MA and $5 \%$ PS specimens. For a cooling rate of $1.0^{\circ} \mathrm{C} / \mathrm{sec}$, all of the specimens had a critical peak temperature of $950^{\circ} \mathrm{C}$ (Figure 28). However, for a cooling rate of $0.10^{\circ} \mathrm{C} / \mathrm{sec}$, the $20 \%$ PS specimen showed slightly higher EPR-DOS values at a peak temperature of $900^{\circ} \mathrm{C}$ than for a peak temperature of $950^{\circ} \mathrm{C}$ (Figure 29). Finally, at a cooling rate of $0.05^{\circ} \mathrm{C} / \mathrm{sec}$, the 10 and $20 \%$ PS specimens showed a definite decrease in the critical peak temperature from 950 to $900^{\circ} \mathrm{C}$ (Figure 30).

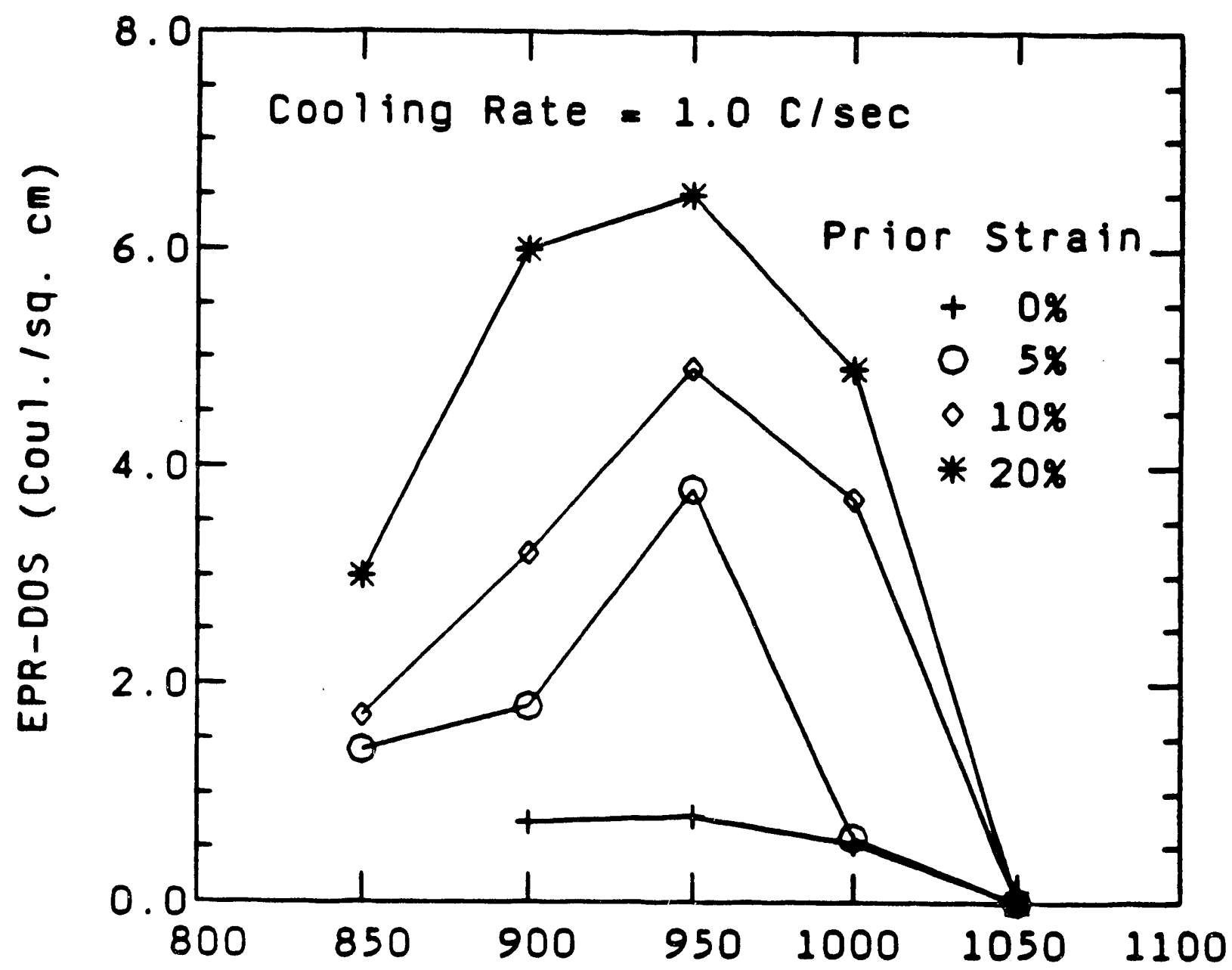

\section{PEAK CYCLE TEMPERATURE (deg. C)}

Figure 28. Prior Strain Effects on the CCS Development of the MA Material from Heat SS-17 as a Function of Peak Cycle Temperature for a Cooling Rate of $1.0^{\circ} \mathrm{C} / \mathrm{sec}$ 


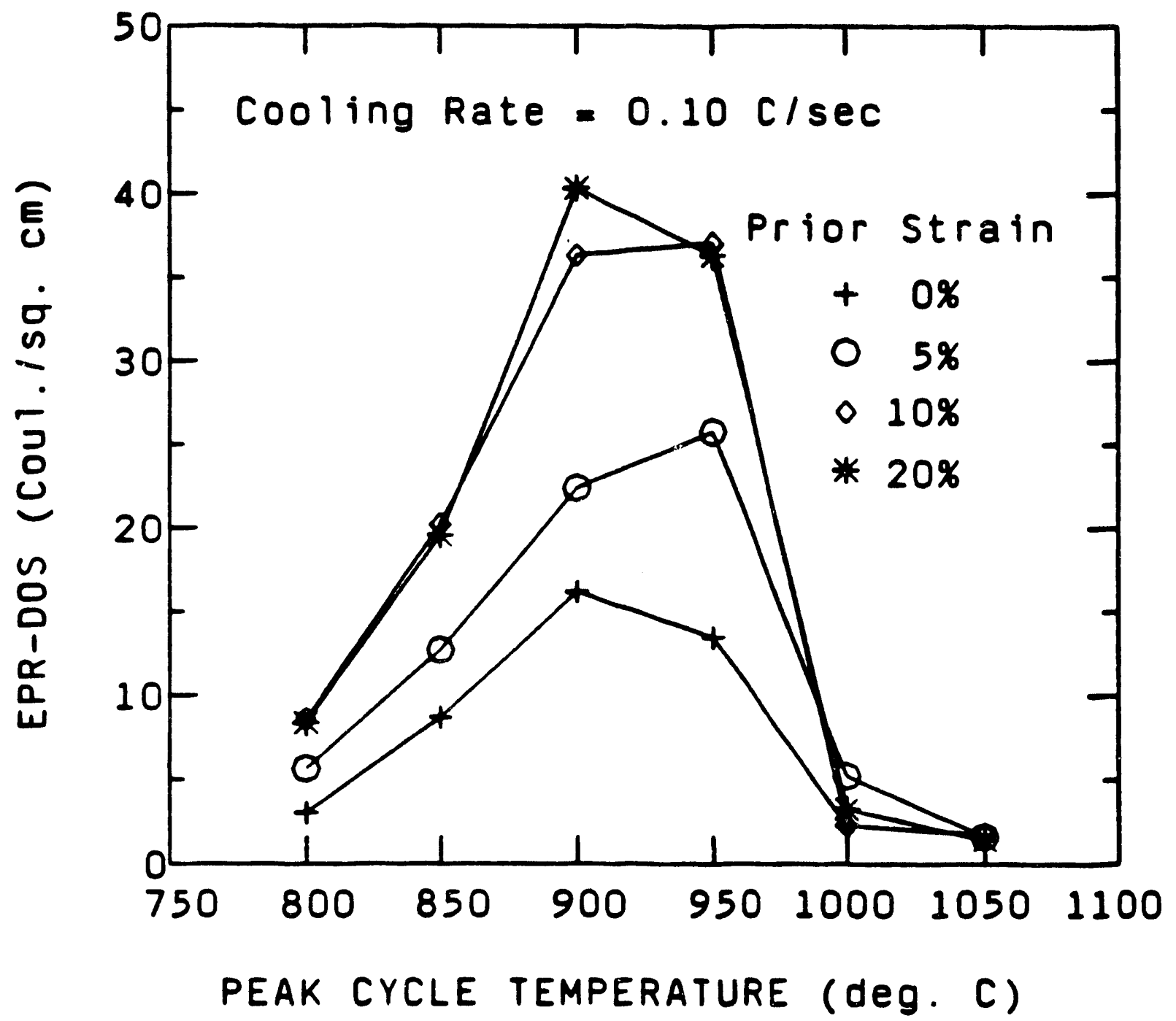

Figure 29. Prior Strain Effects on the CCS Development of the MA Material from Heat SS-17 as a Function of Peak Cycle Temperature for a Cooling Rate of $0.10^{\circ} \mathrm{C} / \mathrm{sec}$ 


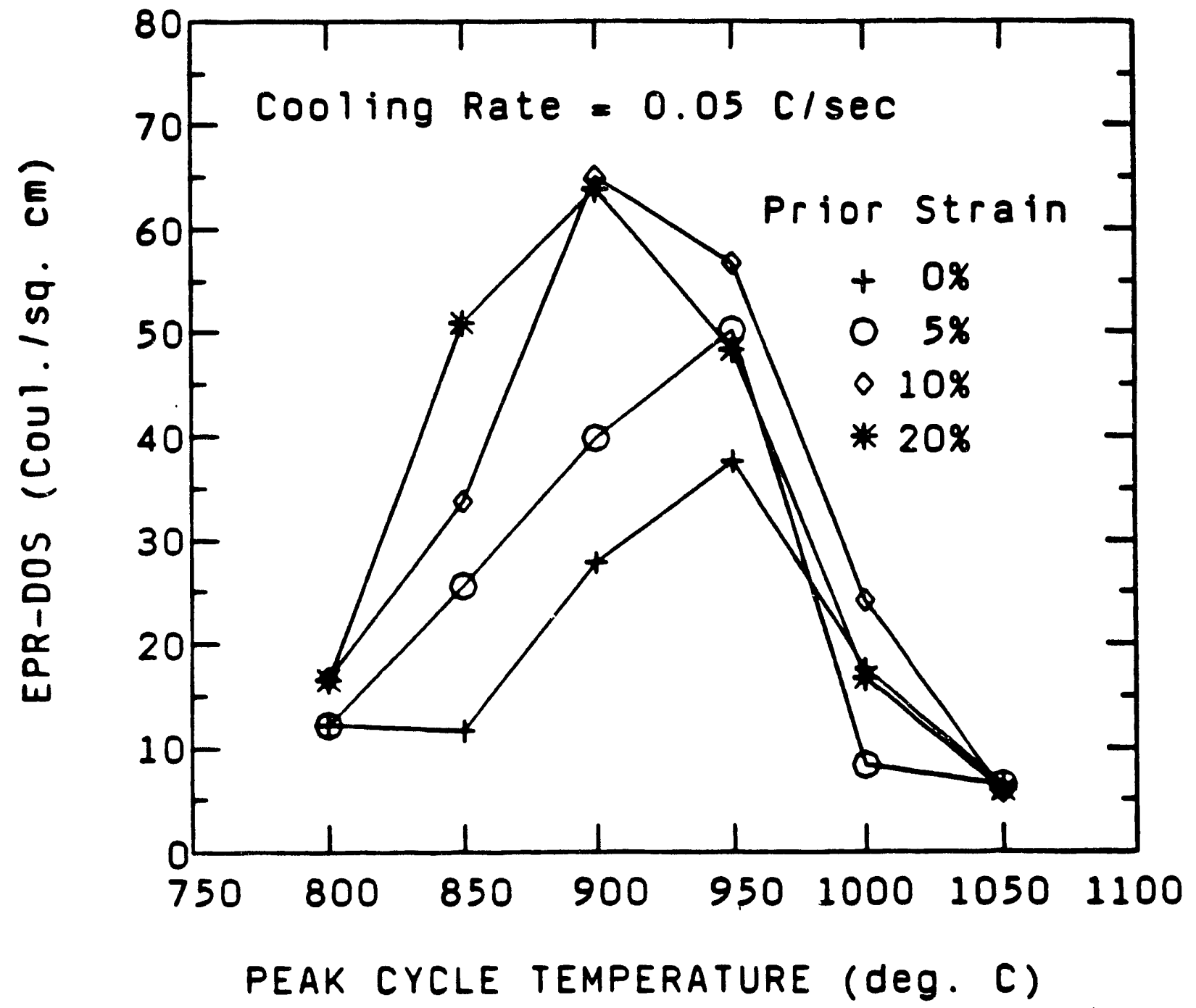

Figure 30. Prior Strain Effects on the CCS Development of the MA Material fronı Heat SS-17 as a Function of Peak Cycle Temperature for a Cooling Rate of $0.05^{\circ} \mathrm{C} / \mathrm{sec}$

It is believed that recovery of the strain at elevated temperatures, in 10 and $20 \%$ prior strain specimens, was primarily responsible for the observed shift in critical peak temperature with decreasing cooling rates.

As discussed earlier, strain results in increased dislocation densities in materials with increasing strains resulting in higher dislocation densities. Increasing dislocation densities are thought to increase chromium diffusivity through a dislocation pipe diffusion mechanism. These increases in $\mathrm{Cr}$-diffusivity are presumed to result in the acceleration of sensitization kinetics. Thus, it is expected that increasing strains lead to increasing dislocation densities, $\mathrm{Cr}$-diffusivity, and sensitization development. Recovery, as defined by the reduction in dislocation density of a material, if occurring in pre-strained materials, is expected to result in decreasing Cr-diffusivity las 
compared to non-recovered pre-strained materials). Thus, an overall reduction in the effectiveness of a particular strain value in increasing sensitization kinetics is expected as a result of recovery.

Recovery of strain (reduction in dislocation densities) has been demonstrated for a creepdeformed Type 316 alloy. ${ }^{(67)}$ Strain recovery was demonstrated to have occurred in the 316 SS material during isothermal exposure at temperatures between 625 and $800^{\circ} \mathrm{C}$. Dislocation densities decreased with time at temperature, and with increasing temperature. Temperatures higher than $800^{\circ} \mathrm{C}$ should result in greater rates of recovery within these materials. The rate of recovery was also determined to be dependent on the initial dislocation density, with higher dislocation densities having greater rates of recovery.

Limited transgranular (TG) carbide precipitation was observed in the $20 \%$ PS samples heated to peak temperatures of 800,850 , and $900^{\circ} \mathrm{C}$ (cooling rates of 0.05 and $0.10^{\circ} \mathrm{C} / \mathrm{sec}$ ). However, TG precipitation was not evident in the $20 \%$ PS specimens heated to a peak temperature of $950^{\circ} \mathrm{C}$. These results are illustrated in the micrographs of Figure 31 taken from 20\% PS samples (after EPR testing and with no additional etching), which had been heated to peak temperatures of 900 and $950^{\circ} \mathrm{C}$, and continuously cooled at a rate of $0.05^{\circ} \mathrm{C} / \mathrm{sec}$. These results indicate that significant strain recovery occurred in the $20 \%$ PS specimens heated to peak temperatures of $950^{\circ} \mathrm{C}$ and above.

The $20 \%$ strain samples, subjected to peak temperatures of 800,850 , and $900^{\circ} \mathrm{C}$ (for cooling rates of 0.10 and $0.05^{\circ} \mathrm{C} / \mathrm{sec}$ ), were the only specimens that showed TG attack after EPR testing. Therefore, the EPR-DOS results shown for these samples slightly overestimate the actual grain boundary $\mathrm{Cr}$-depletion. Transgranular attack in the $0.10^{\circ} \mathrm{C} / \mathrm{sec}$ samples was so slight that the EPRDOS results for this cooling rate should be accurate.

Recrystallization did not seem to have occurred in any of the samples heated to peak temperatures of $950^{\circ} \mathrm{C}$ as indicated by microstructural comparison of the thermally treated center and cold-end of the $950^{\circ} \mathrm{C}$ peak temperature sample of Figure $31 \mathrm{~b}$. These different areas of the specimen were available due to the specimen configuration used in the Gleeble thermal simulator.

The results indicate that even in pre-strained materials, nucleation of carbides at grain boundaries is preferred and TG carbide precipitation occurs, at the temperatures employed in the present work, after longer times. Also, the nucleation and precipitation of TG carbides required large amounts of strain (at least above 10\%) for the temperatures, and times at temperature, used in the present study. Transgranular precipitation in the material was strongly affected by high temperature exposures which tended to cause recovery of the strain in the matrix and limit its effect.

Although sensitization development generally increased with increasing amounts of prior strain, the results varied considerably, primarily as a function of peak temperature and cooling rate.

Recovery of the strain is assumed to have occurred in the materials during the elevated temperature exposures and complicated the effects of strain on sensitization development. In order to assess the effects of recovery, and of increasing strains on sensitization development, the EPRDOS results were replotted as a function of prior strain for each peak cycle temperature and cooling rate. The results are illustrated in the graphs of Figures 32-34.

For a cooling rate of $1.0^{\circ} \mathrm{C} / \mathrm{sec}$ and peak cycle temperatures of $850,900,950$, and $1000^{\circ} \mathrm{C}$, DOS values basically increased linearly with increasing prior strain. Although there was some scatter in the EPR-DOS values for this cooling rate, the general trends are still clear (Figure 32). Apparently, recovery of the strain was not a significant factor at this relatively fast cooling rate and peak temperatures of $1000^{\circ} \mathrm{C}$ and below. 


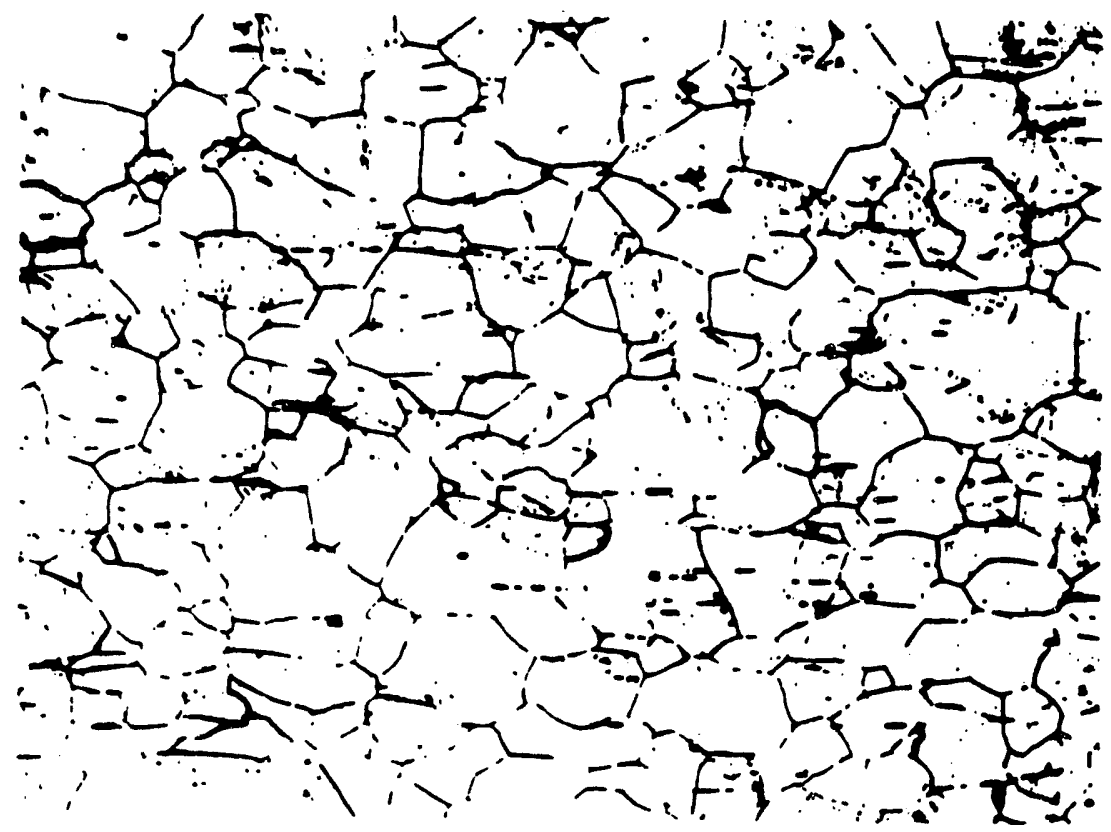

(a)

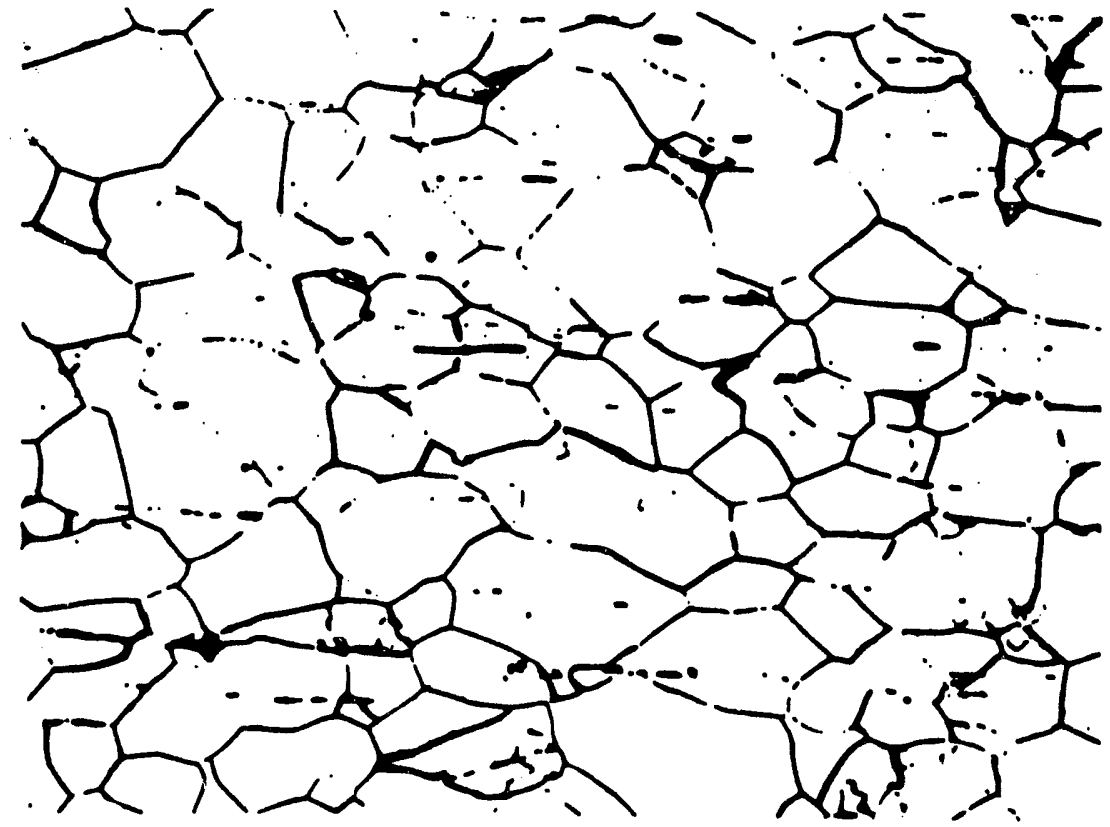

(b)

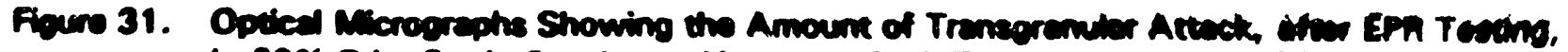

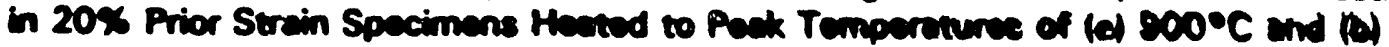
$950^{\circ} \mathrm{C}$ and Cooled a a Rave of $0.05^{\circ} \mathrm{Clacc}$ 
Peak cycle temperatures of 800 and $850^{\circ} \mathrm{C}$ produced increasing EPR-DOS values with increasing amounts of prior strain for cooling rates of 0.10 and $0.05^{\circ} \mathrm{C} / \mathrm{sec}$. Strain recovery does not appear to have been a factor in the current work for peak temperatures of $850^{\circ} \mathrm{C}$ and below (Figures 33 and 34.)

For peak cycle temperatures of 900 and $950^{\circ} \mathrm{C}$ (cooling rates of 0.10 and $0.05^{\circ} \mathrm{C} / \mathrm{sec}$ ), the EPR-DOS values increased with increasing strain values up to $10 \%$. Strain recovery apparently caused a significant reduction in the effectiveness of $20 \%$ PS in accelerating sensitization kinetics. Prior strain values of $20 \%$ were about as effective as $10 \%$ in increasing the rate of sensitization development of the MA material under these conditions (Figures 33 and 34). In fact, for a cooling rate of $0.05^{\circ} \mathrm{C} / \mathrm{seC}$, the measured EPR-DOS values were actually greater for samples with $10 \%$ PS. The EPR-DOS results also indicate that some strain recovery may have occurred in samples with prior strain values of $10 \%$, since the EPR-DOS values were greater for a peak temperature of $900^{\circ} \mathrm{C}$ (cooling rate of $0.05^{\circ} \mathrm{C} / \mathrm{sec}$ ) than for $950^{\circ} \mathrm{C}$.

For cooling rates of 0.10 and $0.05^{\circ} \mathrm{C} / \mathrm{sec}$ and a peak cycle temperature of $1000^{\circ} \mathrm{C}$, prior strain appears to have been generally ineffective in increasing the rate of sensitization development of the MA material (Figures 33 and 34). Most likely, a combination of the critical peak temperature effect and strain recovery acted to limit the effectiveness of prior strain on sensitization development.

Prior deformation did not increase the rate of sensitization development in the MA material, for any of the three cooling rates, when a peak cycle temperature of $1050^{\circ} \mathrm{C}$ was used. The addition of prior deformation to the MA material was apparently not enough to overcome the effects of the elevated temperature exposure $\left(1050^{\circ} \mathrm{C}\right)$ in retarding sensitization development (Figures 32-34).

Although the 10 and $20 \%$ PS samples showed evidence of recovery at $950^{\circ} \mathrm{C}$ (as indicated by the EPR-DOS results and lack of TG carbide precipitation), the DOS in these specimens was still significantly higher than the MA samples. Interestingly, both the 10 and $20 \%$ PS samples showed enhanced EPR-DOS values at a peak temperature of $1000^{\circ} \mathrm{C}$ and a cooling rate $1.0^{\circ} \mathrm{C} / \mathrm{sec}$. Apparently, the time at elevated temperature was not sufficient to cause complete recovery.

Strain recovery appears to have played a significantly greater role in $20 \%$ PS samples than in $10 \%$ PS samples. The kinetics of recovery for the $20 \%$ PS samples were greater than for the 10\% PS samples (as indicated by the EPR-DOS and TG precipitation evidence presented earlier). Apparently, there is a complicated correlation between the amount of prior deformation, peak cycle temperature, time spent at elevated temperatures, and the amount of recovery that takes place in pre-strained specimens. All of these factors significantly influence the effect of prior deformation on the enhancement of sensitization as well as the presence of transgranular carbides. 

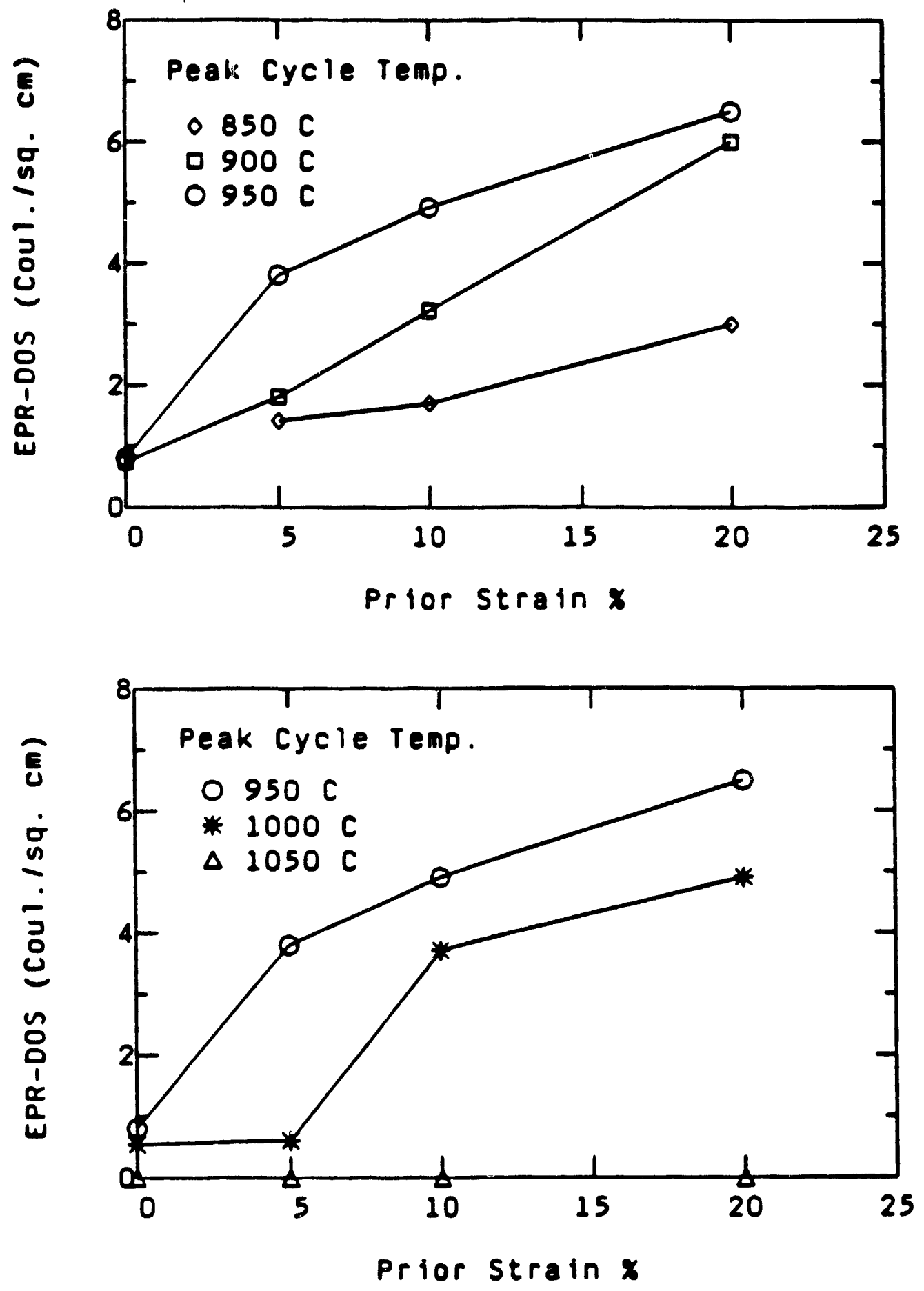

Figure 32. Deformation Effects on the CCS Development of the MA Material from Heat SS-17 as a Function of Prior Strain for a Cooling Rate of $1.0^{\circ} \mathrm{C} / \mathrm{sec}$ 

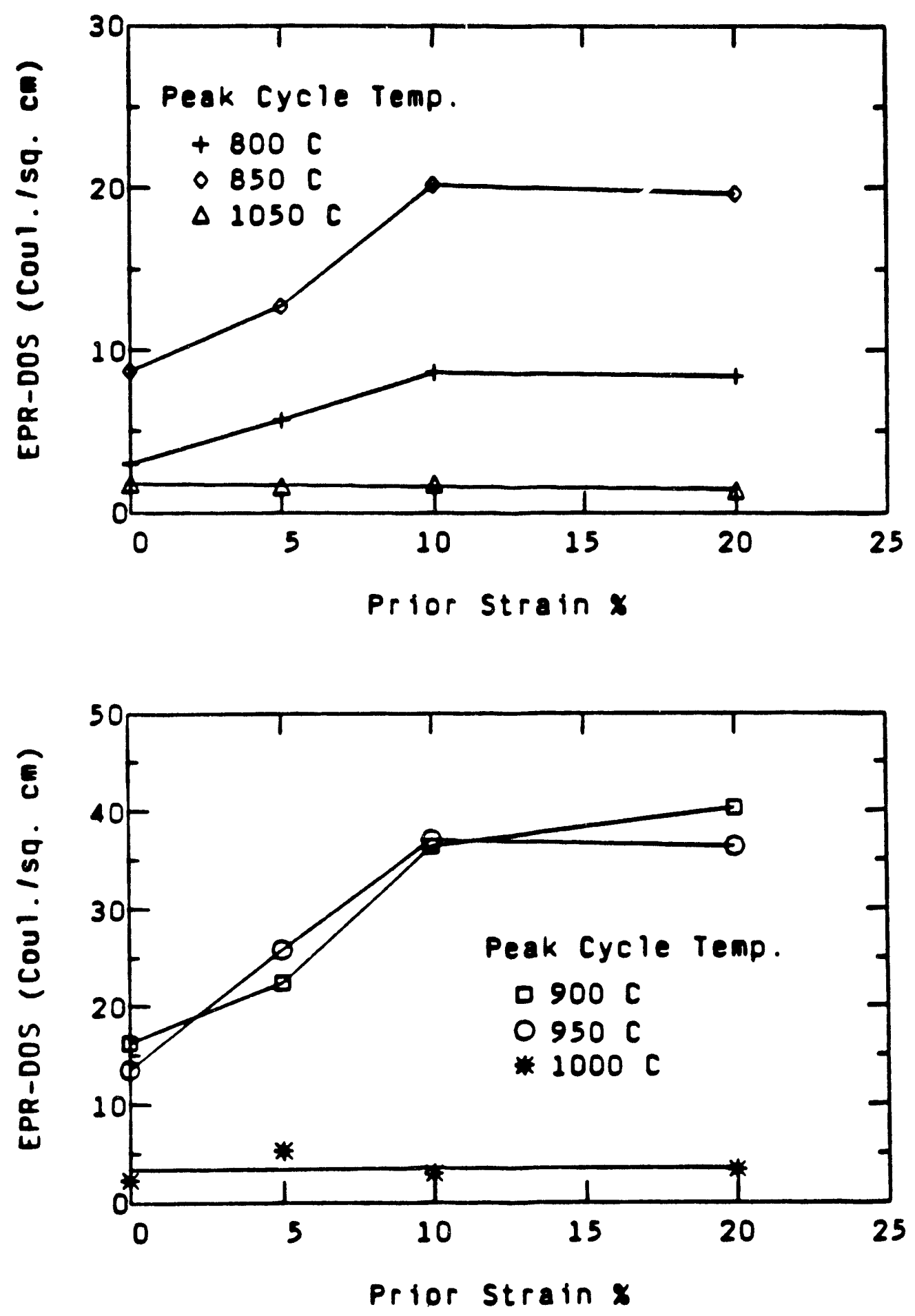

Figure 33. Deformation Effects on the CCS Development of the MA Material from Heat SS-17 as a Function of Prior Strain for a Cooling Rate of $0.10^{\circ} \mathrm{C} / \mathrm{sec}$ 

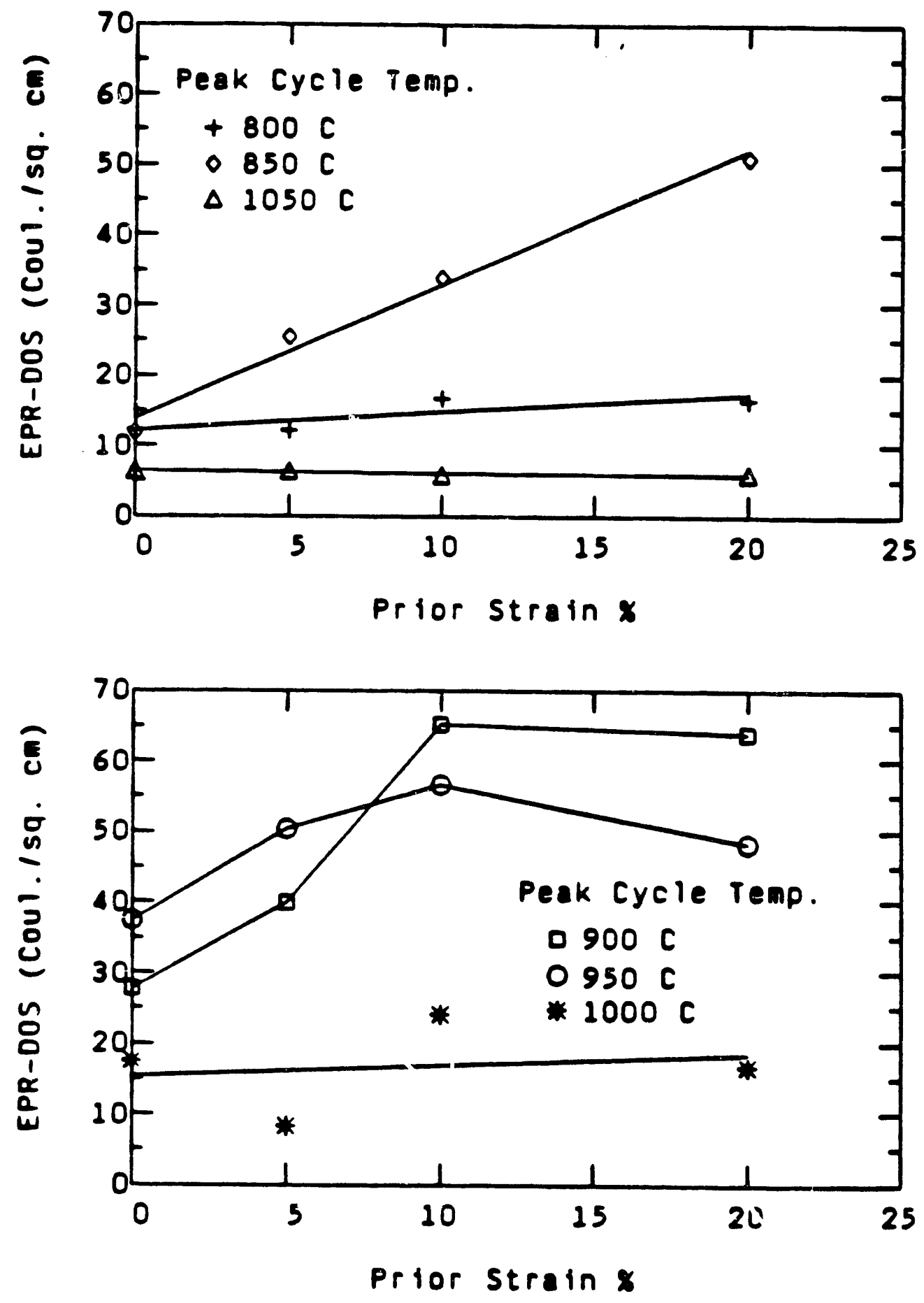

Figure 34. Deformation Effects on the CCS Development of the MA Material from Heat SS-17 as a Function of Prior Strain for a Cooling Rate of $0.05^{\circ} \mathrm{C} / \mathrm{sec}$ 


\subsection{Heat and Quench Testing}

\subsubsection{Heat SS-16}

The experimental results of the heat and quench CC thermal cycling of the MA material from heat SS-16 (test matrix of Table 6) are shown in Table 9. As stated previously, the thermal treatments given to these specimens were identical to those for a "standard" MA specimen heated to a peak cycle temperature of $950^{\circ} \mathrm{C}$ (S/N MA51, Table A1) except that the samples were water quenched from a specific minimum temperature instead of being slow cooled all the way down to $400^{\circ} \mathrm{C}$.

Table 9 Results for SS-16 Heat and Quench Samples

\begin{tabular}{ccccc}
\hline S/N & Maximum Tomp. $\left({ }^{\circ} \mathrm{C}\right)$ & Minimum Temp. $\left({ }^{\circ} \mathrm{C}\right)$ & Cooling Rato $\left({ }^{\circ} \mathrm{C} / \mathrm{sec}\right)$ & $\mathrm{Pa}\left(\mathrm{C} / \mathrm{cm}^{2}\right)$ \\
\hline $\mathrm{H} 081$ & 950 & 950 & 0.05 & 0 \\
$\mathrm{H} 082$ & 950 & 900 & 0.05 & 0.9 \\
$\mathrm{H} 083$ & 950 & 850 & 0.05 & 4.8 \\
$\mathrm{H} 084$ & 950 & 800 & 0.05 & 35.7 \\
H085 & 950 & 750 & 0.05 & 50.9 \\
MA51 & 950 & 400 & 0.05 & 45.4
\end{tabular}

The previous MA51 specimen that was slow cooled down to $400^{\circ} \mathrm{C}$ had an EPR-DOS value of $45.4 \mathrm{C} / \mathrm{cm}^{2}$ and sample HO85 had an EPR-DOS value of $50.9 \mathrm{C} / \mathrm{cm}^{2}$. These results would indicate that the majority of sensitization development in this material, for the applied thermal treatment, occurred prior to $750^{\circ} \mathrm{C}$ and that further slow cooling added little to the DOS of the material. Additional specimens quenched from temperatures below $750^{\circ} \mathrm{C}$ would have helped to clarify this point. Further work of this nature was done with heat SS-17 as detailed below.

\subsubsection{Heat SS-17}

The HO experimental results for CC thermal cycling of the MA and pre-strained MA materials from heat SS-17 (test matrix of Table 7) are illustrated in the graphs of Figures 35-37. The experimental results and SSDOS predictions are tabulated in Appendix B, Tables B5 and B6. The experimental EPR-DOS results for "standard" specimens cooled all the way down to $400^{\circ} \mathrm{C}$ are shown for comparison purposes (as horizontal dotted and solid lines) in the graphs of Figures 35 to 37. 


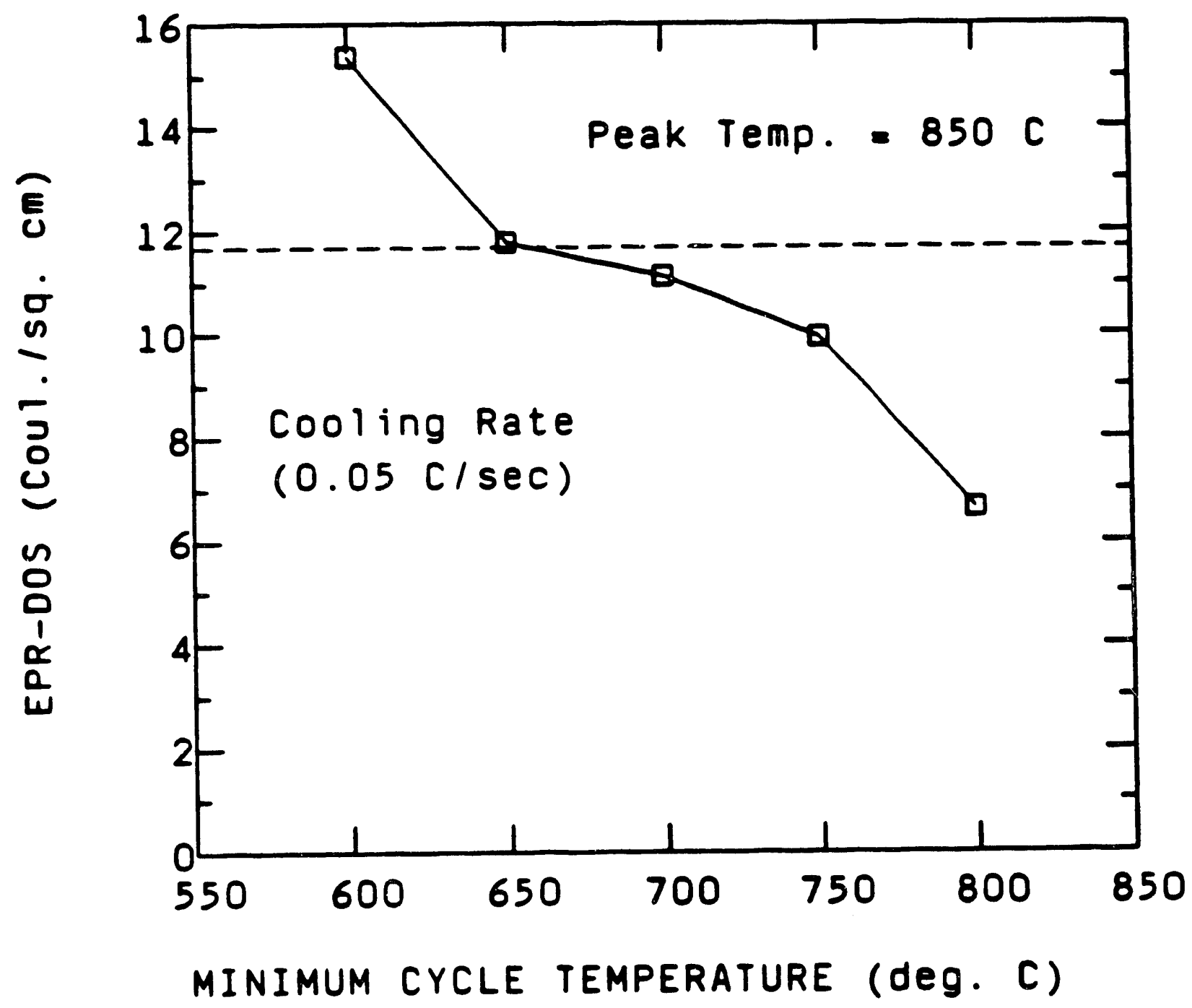

Figure 35. CCS Development of Heat SS-17 MA Material as a Function of the Minimum Temperature Reached During Slow Cooling, Prior to Quenching. The Dotted Line Represents the EPR-DOS Value for a Specimen Continuously Cooled Down to $400^{\circ} \mathrm{C}$ 


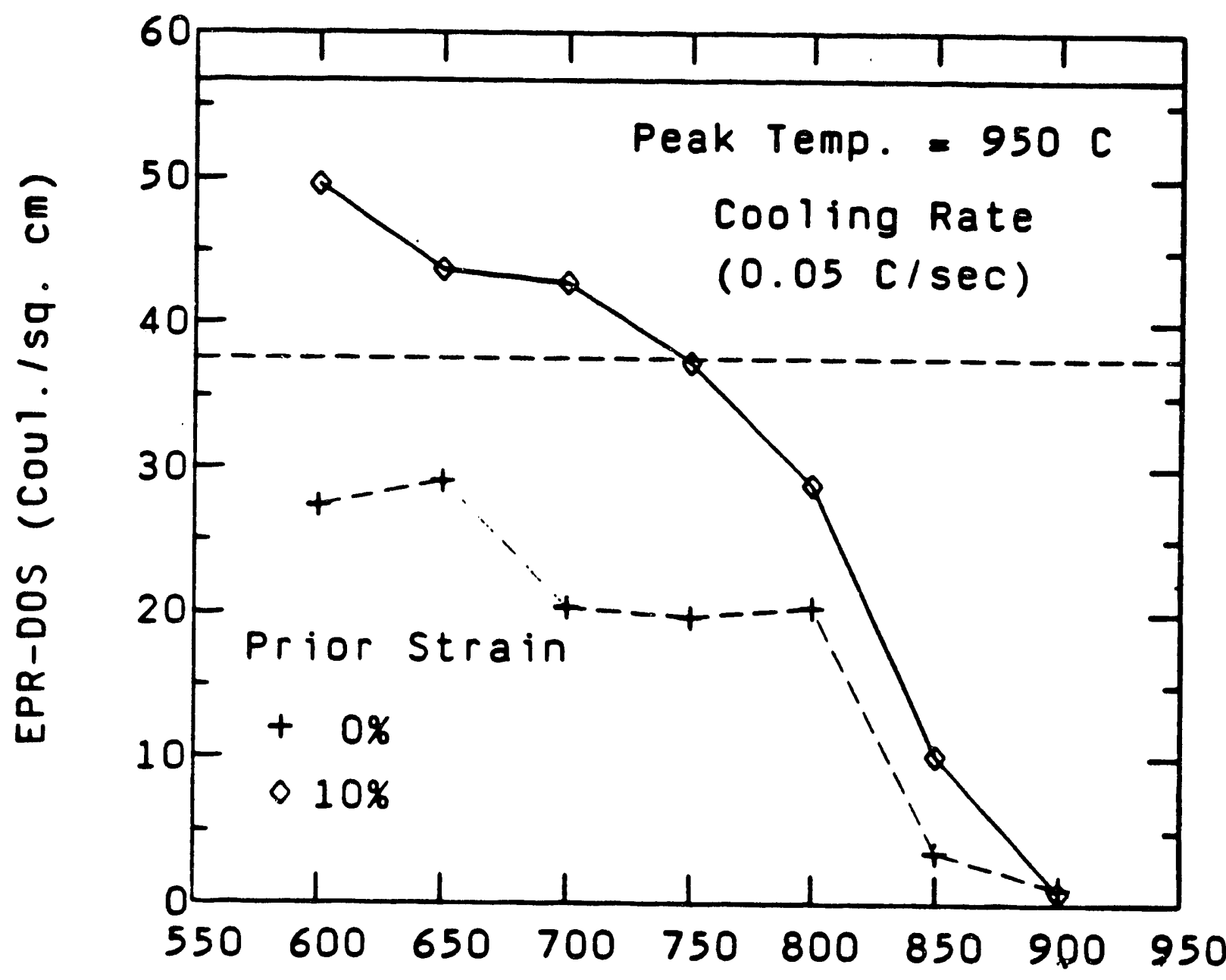

MINIMUM CYCLE TEMPERATURE (deg. C)

Figure 36. Deformation Effects on the CCS Development of Heat SS-17 MA Material as a Function of the Minimum Temperature Reached During Slow Cooling, Prior to Quenching. The Dotted and Solid Horizontal Lines Represent the EPR-DOS Values for Specimens Continuously Cooled Down to $400^{\circ} \mathrm{C}$ 


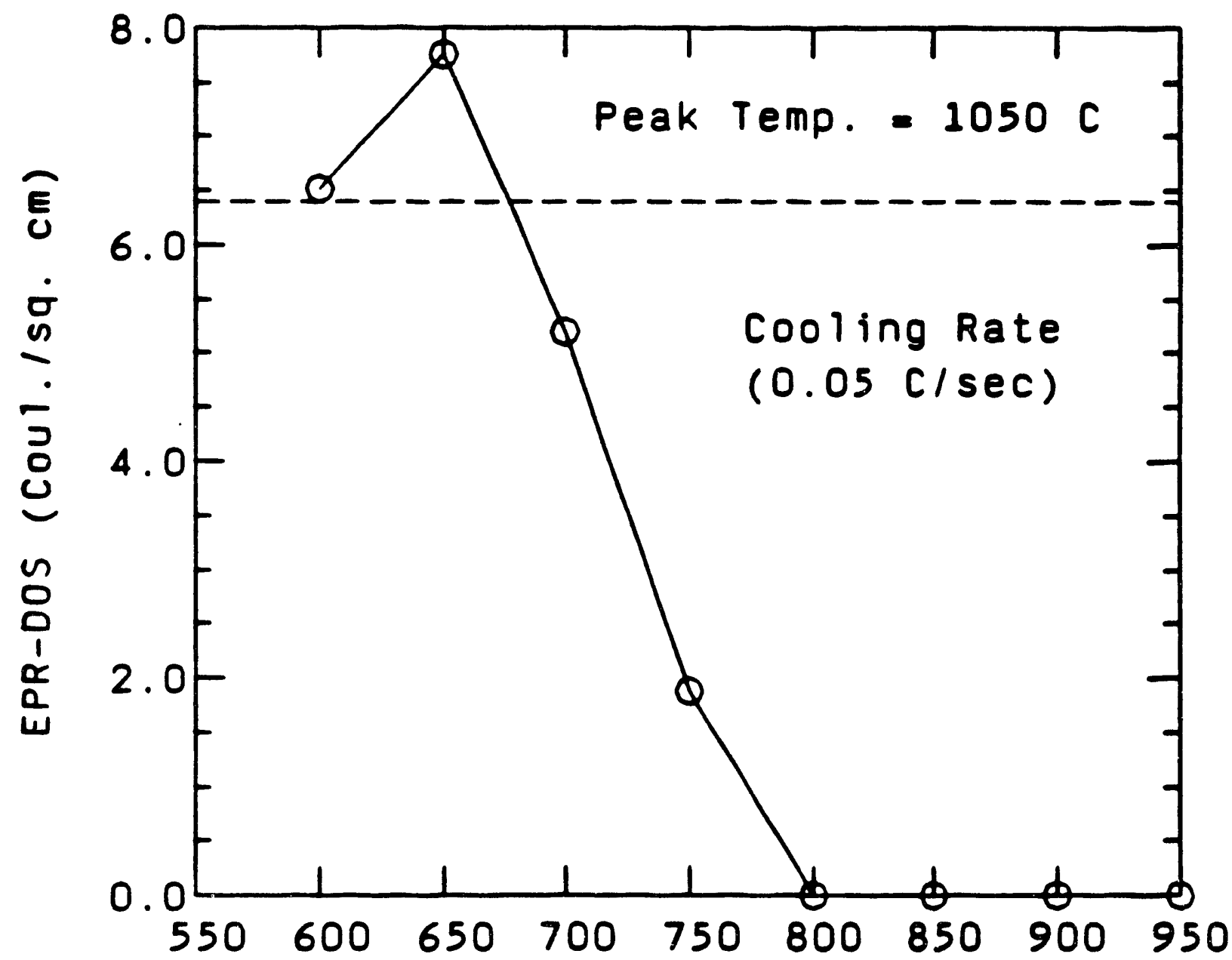

\section{MINIMUM CYCLE TEMPERATURE (deg. C)}

Figure 37. CCS Development of Heat SS-17 MA Material as a Function of the Minimum Temperature Reached During Slow Cooling, Prior to Quenching. The Dotted Line Represents the EPR-DOS Value for a Specimen Continuously Cooled Down to $400^{\circ} \mathrm{C}$

Almost all of the sensitization development in samples heated to a peak temperature of $850^{\circ} \mathrm{C}$ occurred by the time the sample was slow cooled $\left(0.05^{\circ} \mathrm{C} / \mathrm{sec}\right)$ to a temperature of about $700^{\circ} \mathrm{C}$. About half of the total sensitization value had already developed during slow cooling between the peak cycle temperature of $850^{\circ} \mathrm{C}$ and a temperature of $800^{\circ} \mathrm{C}$ (Figure 35). Apparently, short nucleation times and rapid carbide growth are characteristic of temperatures between 850 and $800^{\circ} \mathrm{C}$.

Sensitization development of MA and pre-strained MA (10\% PS) samples, heated to a peak temperature of $950^{\circ} \mathrm{C}$ and slow cooled at a rate of $0.05^{\circ} \mathrm{C} / \mathrm{sec}$, are compared in Figure 36 . Deformation was found to significantly enhance the sensitization development of the MA material throughout the CCS temperature regime (at least down to $600^{\circ} \mathrm{C}$ ). A small, but equal amount, of sensitization was found to have developed in MA and 10\% PS samples cooled to a minimum temperature of $900^{\circ} \mathrm{C}$. This result is not surprising since the EPR-DOS values obtained for a 
sample quenched from a high peak temperature such as $900^{\circ} \mathrm{C}$ are primarily controlled by the minimum GB $\mathrm{Cr}$ concentration which is expected to be very high and severely limit DOS values. Howover, the results do indicate that carbide nucleation and growth occur easily at relatively high temperatures, that is between 950 and $900^{\circ} \mathrm{C}$.

Pre-strained MA samples had EPR-DOS values higher than MA samples for all minimum temperatures of $850^{\circ} \mathrm{C}$ and below. As cooling progressed to lower temperatures, the difference in EPR-DOS values between the pre-strained and MA samples became larger.

Pre-strained and MA samples heated to a peak temperature of $950^{\circ} \mathrm{C}$ and slow cooled to temperatures as low as $600^{\circ} \mathrm{C}$ never developed EPR-DOS values as high as the samples slow cooled all the way down to $400^{\circ} \mathrm{C}$. These results are in contrast to samples heated to peak temperatures of 850 and $1050^{\circ} \mathrm{C}$. The reason for this discrepancy is not known. One possible explanation is that for specimens with extremely high sensitization values, such as those heated to peak temperatures of $950^{\circ} \mathrm{C}$, EPR-DOS values continue to rise at lower temperatures because they are more sensitive to the effects of decreasing $\mathrm{GB} \mathrm{Cr}$ minimums with temperature than specimens with low EPR-DOS values.

For a peak cycle temperature of $1050^{\circ} \mathrm{C}$ and a cooling rate of $0.05^{\circ} \mathrm{C} / \mathrm{sec}$, most of the sensitization development appears to have occurred by the time the sample was slow cooled to a temperature of about $700^{\circ} \mathrm{C}$ (Figure 37). However, for a peak temperature of $1050^{\circ} \mathrm{C}$, no sensitization values were measured for samples slow cooled to minimum temperatures down to $800^{\circ} \mathrm{C}$. This is in contrast to the 850 and $950^{\circ} \mathrm{C}$ peak temperature results where sensitization development appears to have occurred immediately upon cooling from the peak temperature. For the $950^{\circ} \mathrm{C}$ peak temperature, EPR-DOS values (greater than zero $\mathrm{C} / \mathrm{cm}^{2}$ ) were measured in samples quenched from $900^{\circ} \mathrm{C}$, indicating sensitization. In addition, only about $25 \%$ of the total sensitization value had developed during slow cooling between the peak cycle temperature of $1050^{\circ} \mathrm{C}$ and a temperature of $750^{\circ} \mathrm{C}$.

These results indicate that high temperature exposures, above the critical peak cycle temperature, significantly retarded carbide nucleation and sensitization development upon slow cooling through the primary sensitization temperature regime of approximately 900 to $750^{\circ} \mathrm{C}$. Ikawa et al. ${ }^{(88)}$ demonstrated that heating 304 SS samples initially to $1100^{\circ} \mathrm{C}$ for two-minutes prior to isothermal annealing at temperatures between about 650 and $900^{\circ} \mathrm{C}$ (without returning to room temperature), resulted in a shift of the $C$-curve for $M_{23} C_{6}$ precipitation to longer times as compared to samples heated directly from room temperature to the aging temperature.

\subsection{Interrupted Quench Thermal Cycling}

\subsubsection{Heat SS-16}

As stated previously, the 10 sample for heat SS-16 was heated at $50^{\circ} \mathrm{C} / \mathrm{sec}$ to a peak temperature of $1050^{\circ} \mathrm{C}$, slow cooled at a rate of $0.05^{\circ} \mathrm{C} / \mathrm{sec}$ to $950^{\circ} \mathrm{C}$, and water quenched. The sample was then reheated at $50^{\circ} \mathrm{C} / \mathrm{sec}$ to a peak temperature of $950^{\circ} \mathrm{C}$, slow cooled at $0.05^{\circ} \mathrm{C} / \mathrm{sec}$ to $400^{\circ} \mathrm{C}$, and then allowed to self-cool (Figure 12). The EPR-DOS of this specimen measured after the second thermal cycle was $45.1 \mathrm{C} / \mathrm{cm}^{2}$. 
The above result can be compared to two MA samples which were subjected to identical heating and cooling rates but which were slow cooled from peak cycle temperatures of $1050^{\circ} \mathrm{C}$ (S/N MA53) and $950^{\circ} \mathrm{C}$ (S/N MA51) to $400^{\circ} \mathrm{C}$, then allowed to self-cool. The DOS values for these specimens are shown below:

$$
\begin{aligned}
& \text { S/N MA53 }\left(1050^{\circ} \mathrm{C}\right): \text { EPR-DOS }=6.4 \mathrm{C} / \mathrm{cm}^{2} \\
& \text { S/N MA51 }\left(950^{\circ} \mathrm{C}\right): \text { EPR-DOS }=45.4 \mathrm{C} / \mathrm{cm}^{2}
\end{aligned}
$$

It is evident that the 10 specimen, although it had first been heated to a peak temperature of $1050^{\circ} \mathrm{C}$, had a sensitization response similar to the MA51 specimen heated to a peak temperature of $950^{\circ} \mathrm{C}$. The 10 sample was exposed to the exact thermal cycle of MA53 except that it was quenched from $950^{\circ} \mathrm{C}$ and reheated. The effects of the high temperature exposure on retarding sensitization development observed in sample MA53 were apparently nullified in the 10 sample by quenching and reheating.

It seems unlikely that reheating at a very fast rate of $50^{\circ} \mathrm{C} / \mathrm{sec}$ could affect carbide renucleation. The time spent within the sensitization range during heating at this fast rate is only a very small fraction of the time spent within the sensitization regime upon slow cooling. If a reheating cycle by itself is sufficient to cause renucleation after a high temperature exposure, then it seems likely that during slow cooling through the critical temperature range (approximately $900^{\circ} \mathrm{C}$ down to $750^{\circ} \mathrm{C}$ ), carbide nucleation would occur rapidly. The results indicate that this does not occur for samples heated above the critical peak temperature. ${ }^{(65)}$

The quenching operation seems more likely to be responsible for the observed phenomena. Water quenching is a very severe operation and could alter the grain boundary structure of the material and create sites favorable for nucleation. Also, rapid quenching results in the highest possible degree of supersaturation of carbon in the matrix. These factors would tend to increase the driving force for nucleation upon reheating to a temperature within the sensitization regime.

\subsubsection{Heat SS-17}

The results of 10 testing of MA specimens from heat SS-17 are listed in Table 10. These results can be compared to two "standard" MA samples, subjected to identical heating and cooling rates, but which were slow cooled from peak cycle temperatures of $1050^{\circ} \mathrm{C}$ (S/N MA73) and $950^{\circ} \mathrm{C}$ (S/N MA71) to $400^{\circ} \mathrm{C}$, then allowed to self-cool.

The samples quenched all the way to room temperature, using water or air, had sensitization values equal to the standard MA71 specimen. These results are similar to those obtained for the IO samples of heat SS-16 and indicate that quenching to room temperature and reheating nullified the effects of the high temperature exposure. 
Table 10 - Results for SS-17 Interrupted Quench Samples

\begin{tabular}{|c|c|c|c|c|c|}
\hline \multicolumn{6}{|c|}{ First Gleeble Thermal Cycle } \\
\hline $\mathbf{S} / \mathbf{N}$ & Maximum Temp. $\left({ }^{\circ} \mathrm{C}\right)$ & $\begin{array}{c}\text { Cooling Rate } \\
\left({ }^{\circ} \mathrm{C} / \mathrm{sec}\right)\end{array}$ & Minimum Temp. $\left({ }^{\circ} \mathrm{C}\right)$ & $\begin{array}{c}\text { Quench } \\
\text { Temp. }\left({ }^{\circ} \mathrm{C}\right)\end{array}$ & $\begin{array}{l}\text { Quench } \\
\text { Media }\end{array}$ \\
\hline 10204 & 1050 & 0.05 & 950 & 20 & Air \\
\hline 10206 & 1050 & 0.05 & 950 & 20 & Water \\
\hline 10208 & 1050 & 0.05 & 950 & $400 *$ & Air \\
\hline 10209 & 1050 & 0.05 & 950 & $400 *$ & Air \\
\hline \multicolumn{6}{|c|}{ Second Gleeble Thermal Cycle } \\
\hline S/N & Maximum Tomp. $\left({ }^{\circ} \mathrm{C}\right)$ & $\begin{array}{c}\text { Cooling Rate } \\
\left({ }^{\circ} \mathrm{C} / \mathrm{sec}\right)\end{array}$ & Minimum Temp. $\left({ }^{\circ} \mathrm{C}\right)$ & $\mathrm{Pa}\left(\mathrm{C} / \mathrm{cm}^{2}\right)$ & \\
\hline 10204 & 950 & 0.05 & 400 & 39.9 & \\
\hline 10206 & 950 & 0.05 & 400 & 40.3 & \\
\hline 10208 & 950 & 0.05 & 400 & 27.6 & \\
\hline 10209 & 950 & 0.05 & 400 & 21.7 & \\
\hline MA73 & 1050 & 0.05 & 400 & 6.4 & \\
\hline MA71 & 950 & 0.05 & 400 & 37.5 & \\
\hline
\end{tabular}

- Reheated immediately upon reaching $400^{\circ} \mathrm{C}$.

- Held at $400^{\circ} \mathrm{C}$ for 20 seconds prior to reheating.

Interestingly, although the samples acceleration-cooled to $400^{\circ} \mathrm{C}$ using high pressure air had sensitization values less than S/N MA71, they were still much greater than S/N MA73 which was slow cooled directly from $1050^{\circ} \mathrm{C}$. This establishes not only the importance of quench rate on subsequent sensitization development, but also the final temperature reached during the quenching operation. The final temperature reached may have an effect on the grain boundary structures realized during the quench and also on the amount of carbon available for segregation to GBs.

The rate of quenching for the water-cooled specimen was certainly much faster (probably at least $300 \%$ faster) than for the air quenched samples, yet this did not seem to affect sensitization development. However, the minimum temperature achieved during quenching does seem to affect subsequent sensitization development. More experimentation would be necessary to determine the exact roles played in the observed phenomena by the minimum temperature reached during quenching, and the quenching and reheating rates. 


\subsection{SSDOS Model Predictions}

\subsubsection{Heat SS-16}

The experimentally determined EPR-DOS values for the MA and SA materials from heat SS-16 are compared in Figures 38-40 to the statistically most accurate predictions calculated using the SSDOS model (tabulated results are listed in Appendix A, Tables A1 and A2).

The SSDOS model consistently overpredicted the CCS development of heat SS-16 with conservative predictions obtained from the model always being much higher than SMA predictions (the tabulated SSDOS prediction values located in Apperidices A and B reflect this). In addition, the model gave identical predictions for the MA and SA material conditions which is in contrast to the experimental results.

For cooling rates of 0.05 and $0.10^{\circ} \mathrm{C} / \mathrm{sec}$ (Figures 38 and 39), the SMA predictions overestimated the experimental results for both material conditions, and were over 300 percent higher than experimental results for SA materials.

For a cooling rate of $1.0^{\circ} \mathrm{C} / \mathrm{sec}$, the SMA EPR-DOS predictions were close to the experimental results for the MA material and slightly overestimated SA sensitization values (Figure 40). The experimentally determined and predicted EPR-DOS values, for the MA and SA material conditions, are compared on a one-to-one correlation basis in the graph of Figure 41. It is clear that SMA predicted DOS values correlate poorly with experimental EPR-DOS values.

The primary factors used by the model in prediction calculations are material composition, prior strain, initial EPR-DOS value, and thermal treatment. All of these factors were identical for the MA and SA material conditions of heat SS-16. Small differences in grain sizes between materials do not affect model predictions.

The SSDOS model is not expected to inherently predict a difference in sensitization development between SA and MA materials if neither are perceived to contain deformatior. or an initial EPR-DOS value. This is true since the data base the model was validated with was based primarily on millannealed materials and significant differences in sensitization behavior between MA and SA materials were not observed. 


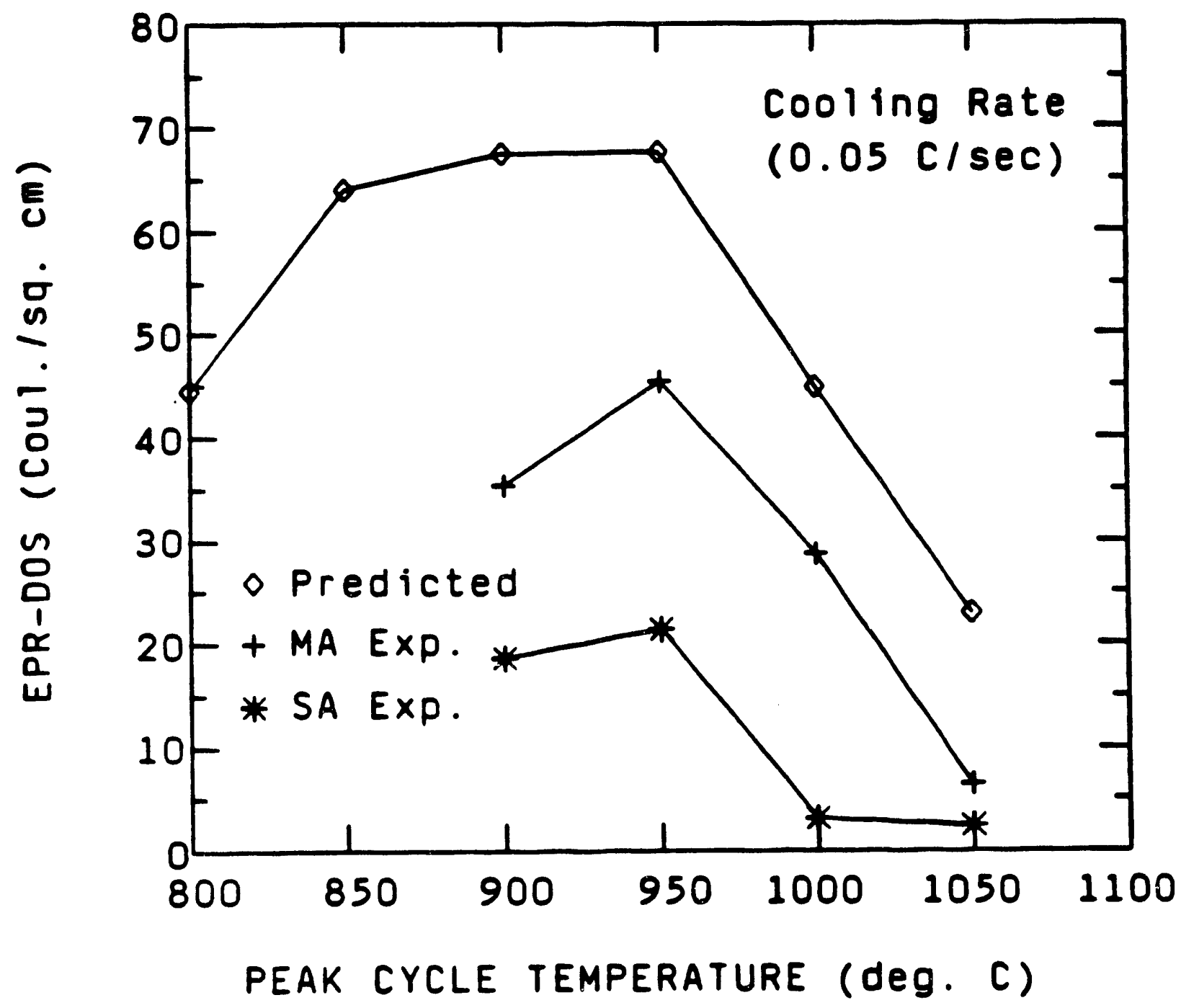

Figure 38. Comparisons of SMA SSDOS Predictions with Experimental CCS Results for MA and SA Materials from Heat SS-16 for a Cooling Rate of $0.05^{\circ} \mathrm{C} / \mathrm{sec}$ 


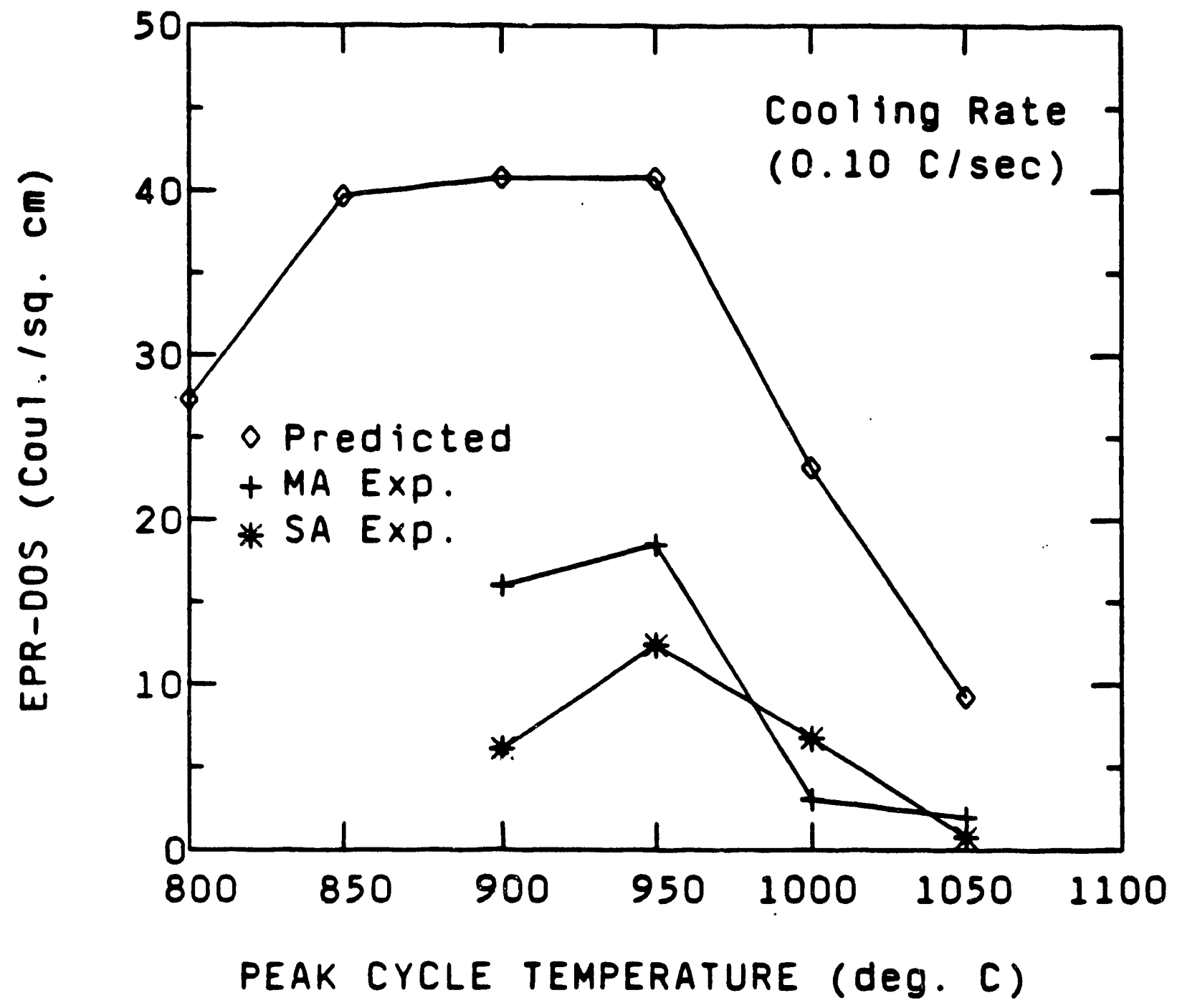

Figure 39. Comparisons of SMA SSDOS Predictions with Experimental CCS Results for MA and SA Materials from Heat SS-16 for a Cooling Rate of $0.10^{\circ} \mathrm{C} / \mathrm{sec}$ 


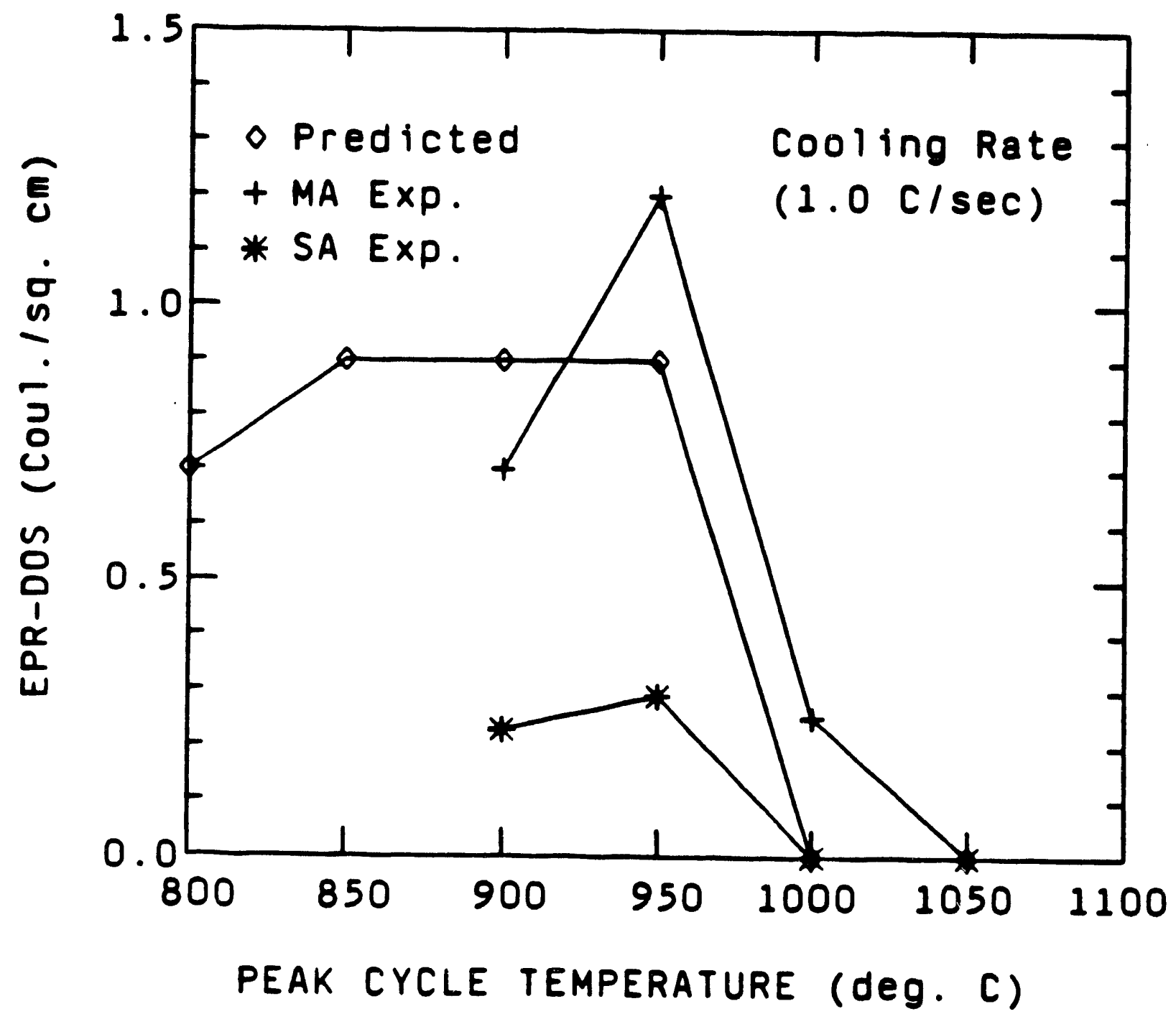

Figure 40. Comparisons of SMA SSDOS Predictions with Experimental CCS Results for MA and SA Materials from Heat SS-16 for a Cooling Rate of $1.0^{\circ} \mathrm{C} / \mathrm{sec}$ 


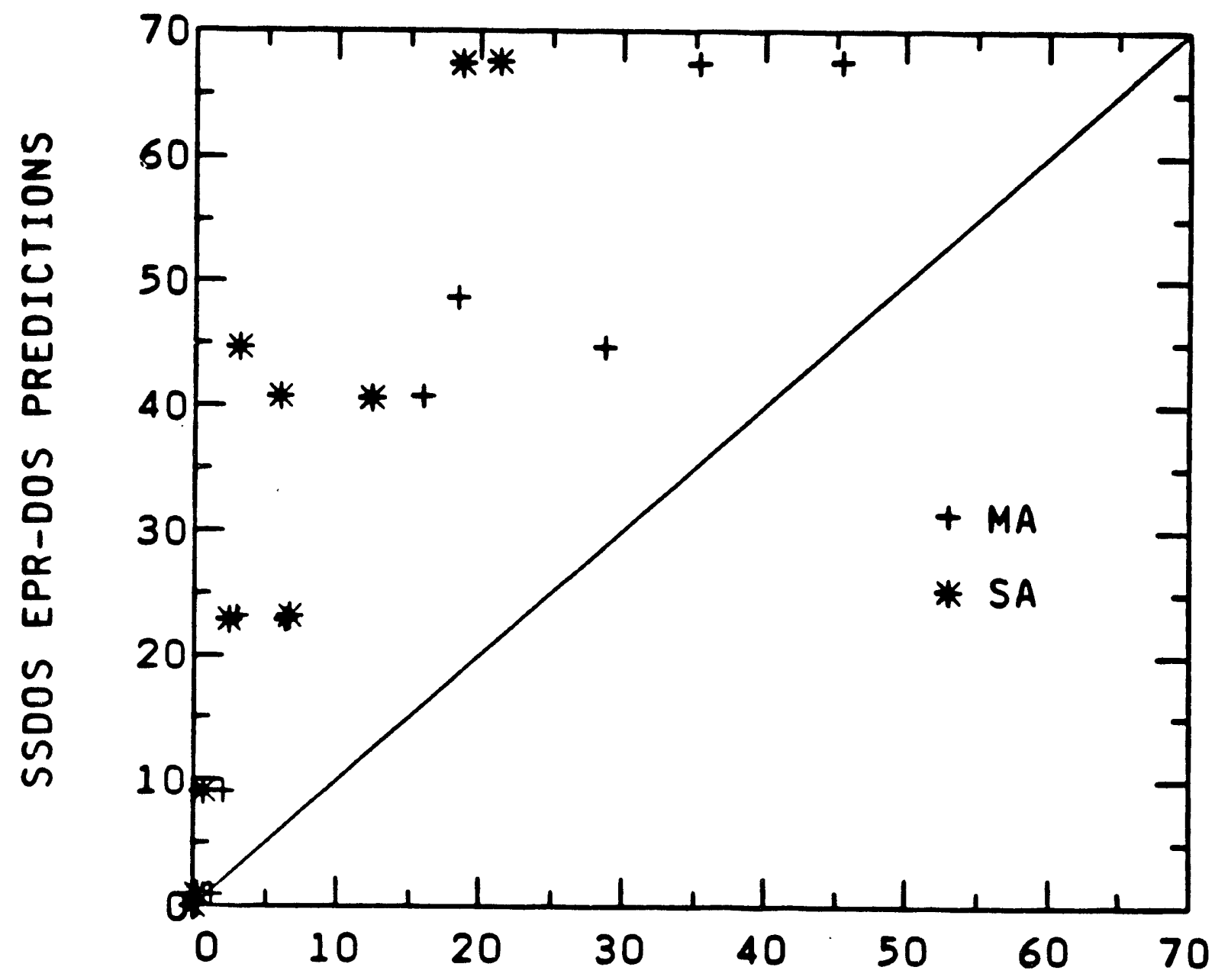

EXPERIMENTAL EPR-DOS

Figure 41. Comparisons, on a One-To-One Correlation Basis, of SMA SSDOS Predictions with Experimental CCS Results for MA and SA Materials from Heat SS-16

\subsubsection{Heat SS-17}

Statistically most accurate SSDOS model predictions for CCS of the as-received and pre-strained MA materials (test matrices of Tables 3 and 5) are compared on a one-to-one correlation basis to the experimentally determined EPR-DOS values in Figure 42. The results of these, along with conservative predictions, are also presented in tabulated from in Appendix B.

Degree of sensitization values for the MA and pre-strained MA samples were consistently overpredicted, similar to the results obtained for heat SS-16. The model overpredicted values for the $0 \%$ strain MA samples by about the same amount as for pre-strained materials. 


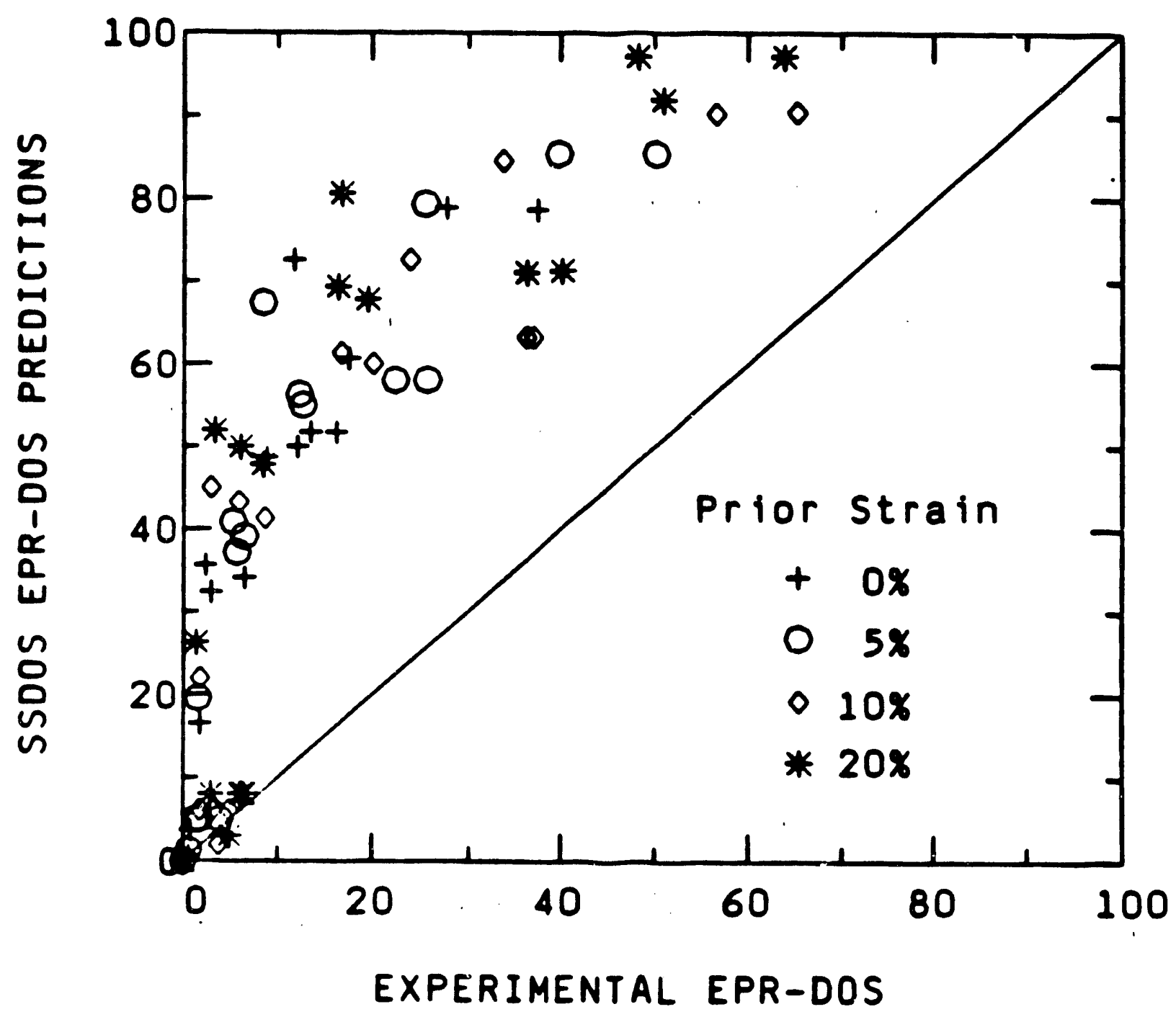

Figure 42. Comparisons, on a One-To-One Correlation Basis, of SMA SSDOS Predictions with Experimental CCS Results for MA and Pre-Strained MA Materials from Heat SS-17

Predictions of the strain effects on CCS development in the pre-strained MA materials seem to be more reasonable than the initial starting point, prediction of CCS development in the MA material (Figure 42). This is very important from a modeling point of view because predictions of strain effects on increasing sensitization development are close to experimental observations. The problem appears to lie primarily in predicting CCS development of the initial MA material.

Continuous cooling sensitization development in the HO samples was also overpredicted by the SSDOS model (Figures 43a and 44a). The SMA predictions were higher than the experimental results at all temperatures below $850^{\circ} \mathrm{C}$ for both the MA and $10 \%$ pre-strained MA samples heated to a peak cycle temperature of $950^{\circ} \mathrm{C}$. 


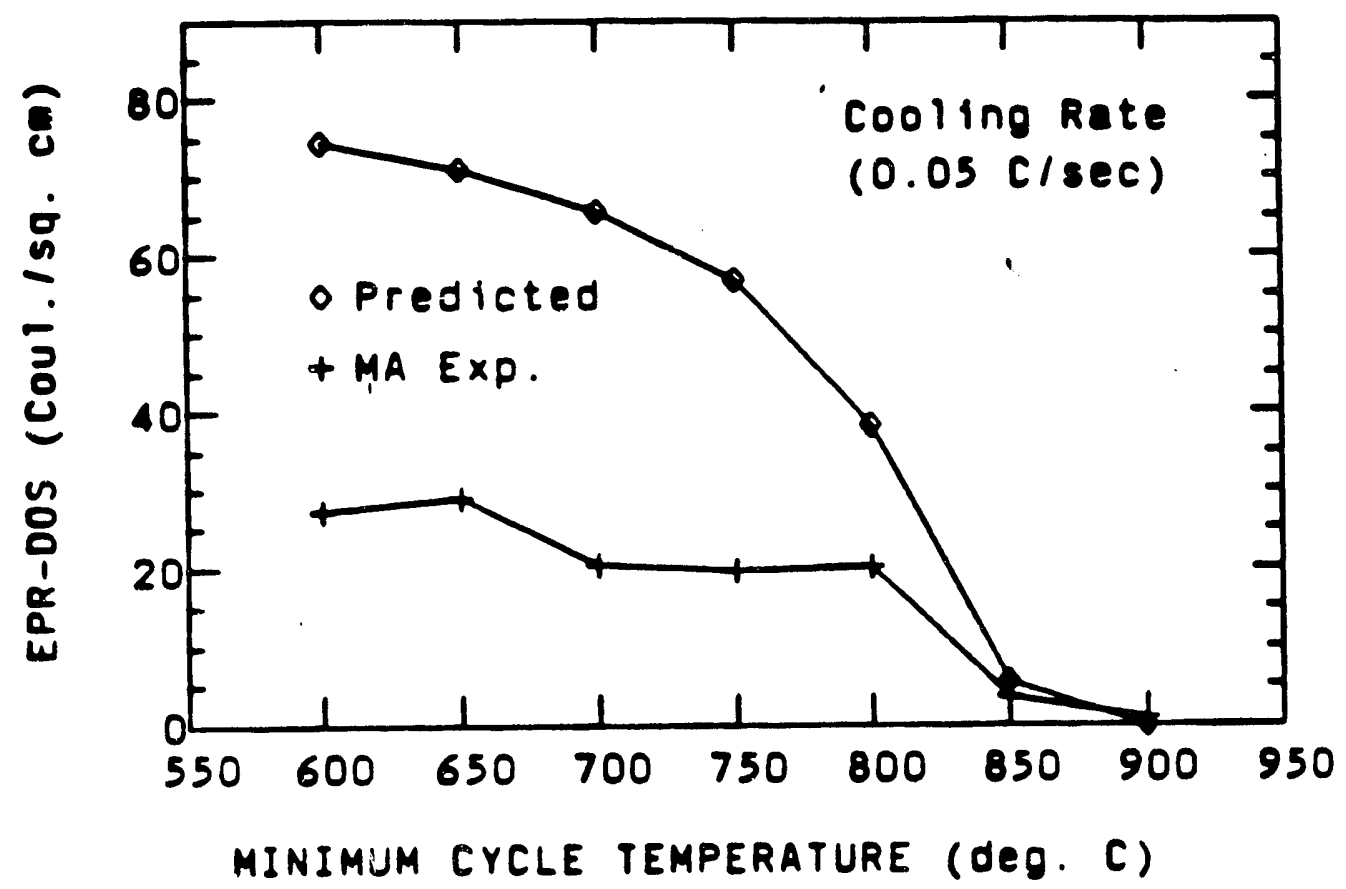

(a)

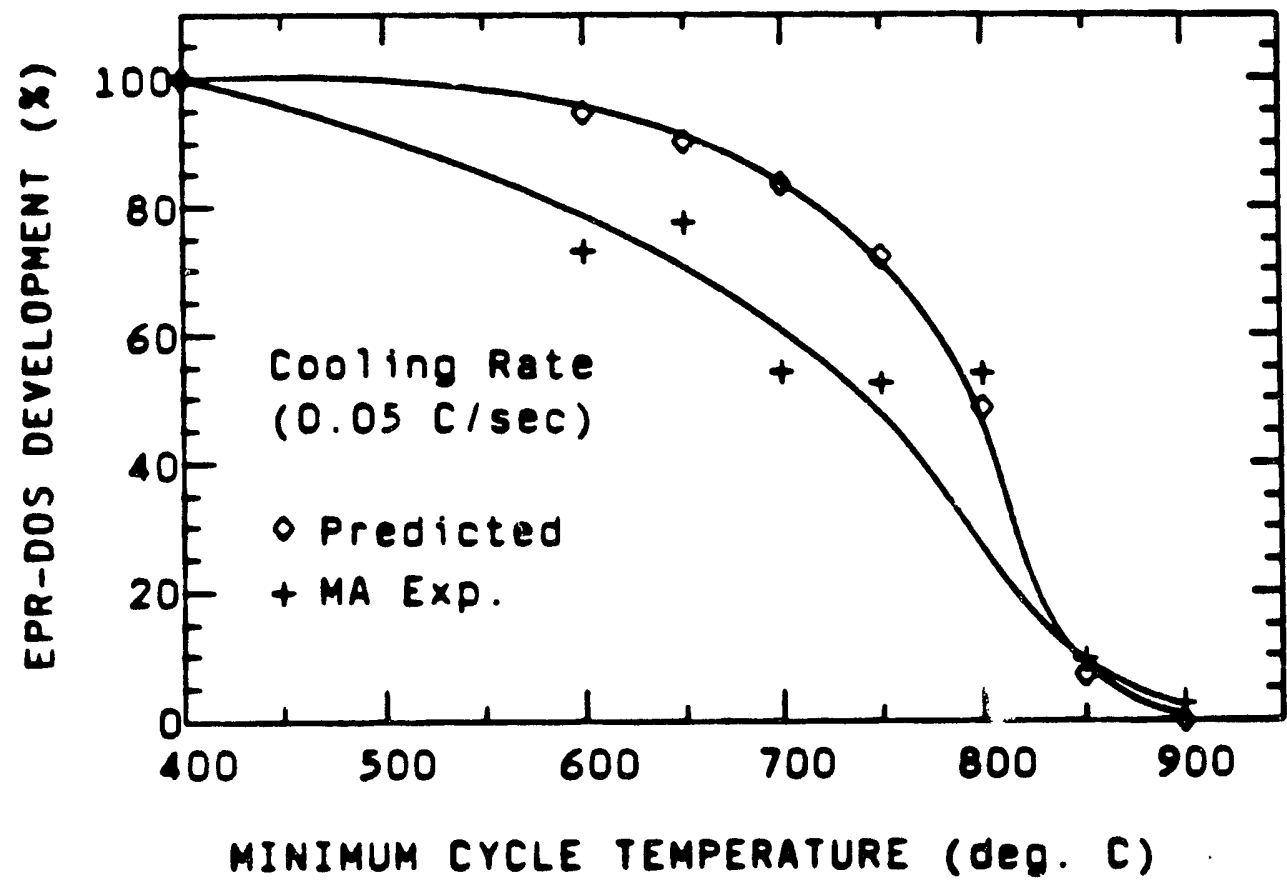

(b)

Figure 43. Comparisons of SMA SSDOS Predictions and HO Results for Heat SS-17 MA Materials (Paak Tamparatura of $950^{\circ} \mathrm{C}$ ) as a Function of Minimum Cycle Temporature and (a) EPR-DOS, and (b) Percentage EPR-DOS Development 


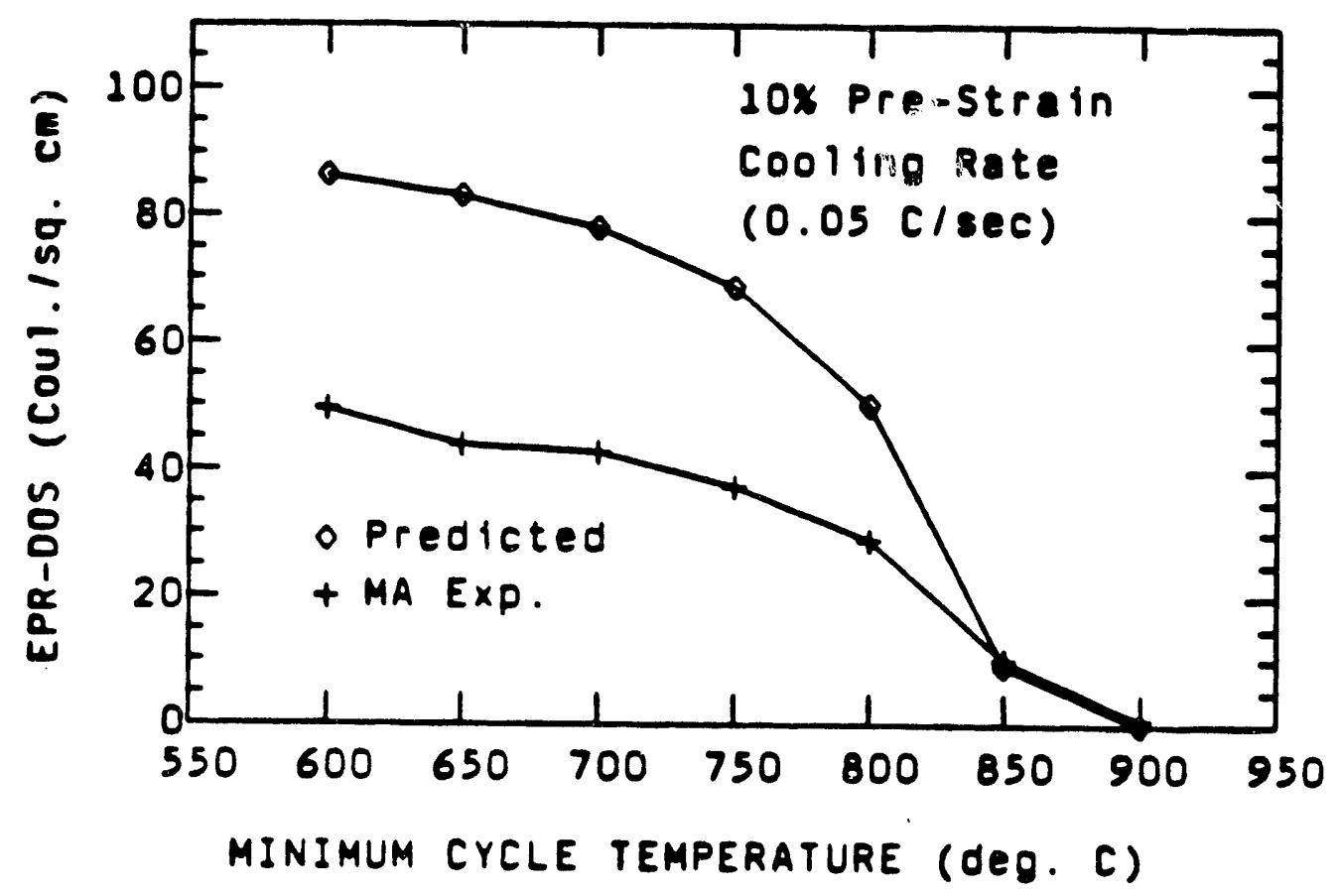

(a)

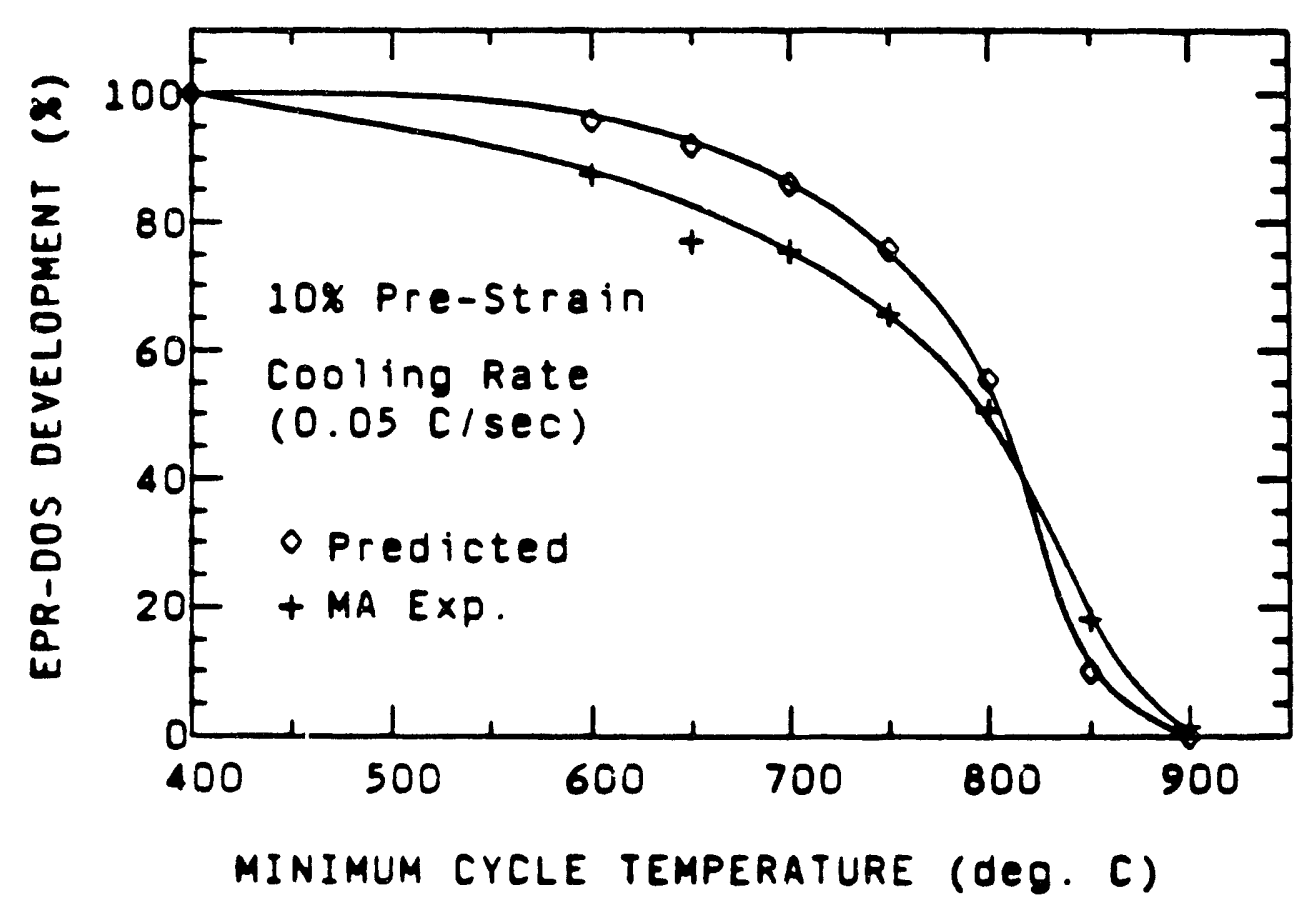

(b)

Fioure 44. Comparisons of SMA SSDOS Predictions and HO Results for Heat SS-17 Materials with 10\% PS (Peak Temperature of $950^{\circ} \mathrm{C}$ ) as a Function of Minimum Cycle Temperature and (a) EPR-DOS, and (b) Percentage EPR-DOS Development 
The rate of change of sensitization development appears to be different for the predicted and experimental results. This is shown in Figures $43 a$ and $44 a$ and indicates that $\mathrm{Cr}$-diffusion kinetics are probably not accurately predicted in the SSDOS model. Figures $43 \mathrm{~b}$ and $44 \mathrm{~b}$ show the percentage of EPR-DOS development during cooling for predicted and experimental results. These values were calculated using the final EPR-DOS of samples cooled to $400^{\circ} \mathrm{C}$ as the fully developed $100 \%$ sensitization value. The values for the other minimum temperatures were calculated as a percentage of the final EPR-DOS value at $400^{\circ} \mathrm{C}$. These results indicate that the general trends for sensitization development were accurately predicted (i.e. that nearly all of the EPR-DOS value is developed by $700^{\circ} \mathrm{C}$ during cooling, for this material).

\subsubsection{Comparisons with Other CCS Investigations}

Bruemmer ${ }^{(8)}$ and Cedeno ${ }^{(56)}$ both generated experimental EPR-DOS data for the CCS of MA materials from heats SS-16 and SS-17. This data is compared to the current CCS work (Simmons) and with SSDOS predictions in the graphs of Figures 45-47.

The CC thermal cycles used in the work by Bruemmer and Cedeno were obtained by furnace heating specimens to specific peak temperatures and allowing them to continuously cool with the furnace door open. These procedures result in non-linear heating and cooling cycles (similar to the cycle shown in Figure 6 ) in contrast to the present work. Also, heating rates obtained in the furnace were much slower than those used for Gleeble simulation. It is expected that heating rates almost an order of magnitude less than those used in the current work were obtained. Cooling rates obtained by Bruemmer and Cedeno were measured using a linear fit to the temperature decrease with time from 800 to $550^{\circ} \mathrm{C}$. Cooling rates were reported to vary somewhat depending on the peak cycle temperature, but cooling rates of 0.05 and $0.56^{\circ} \mathrm{C} / \mathrm{sec}$ were reported for the work presented here.

Cedeno also tested samples from heat SS-16 in a Gleeble thermal simulator using basically the saine procedures as Simmons. This Gleeble data is also compared to the present work and SSDOS predictions.

Comparison of Bruemmer's experimental data with the current work and SSDOS predictions for CCS of MA materials from heat SS-16 are presented in Figure 45. SSDOS o /erpredicted the CCS results of Bruemmer and Simmons by about the same amount. The current work (SimmonsGleeble) had EPR-DOS values very close to those of Bruemmer's furnace treated specimens. The exception to this is that a critical peak temperature of $1000^{\circ} \mathrm{C}$ is indicated for the data of Bruemmer compared to $950^{\circ} \mathrm{C}$ for the current work.

As discussed earlier, with the thermal cycles performed, the exact critical peak temperature for CCS of the MA material for this specific cooling rate could have been anywhere between 900 and $1000^{\circ} \mathrm{C}$ for the current work (apparently 900 to $1050^{\circ} \mathrm{C}$ for Bruemmer's data). Some of the explanations set forth in an earlier discussion, such as small temperature measurement discrepancies, or slow heating rates obtained in the furnace could have been responsible for this variation of critical peak temperature. The resuits of Advani ${ }^{(66)}$ indicate it is likely that carbides formed during heating in the furnace would not have dissolved for peak temperatures up to $1000^{\circ} \mathrm{C}$ and the cooling rates used by Bruemmer. 


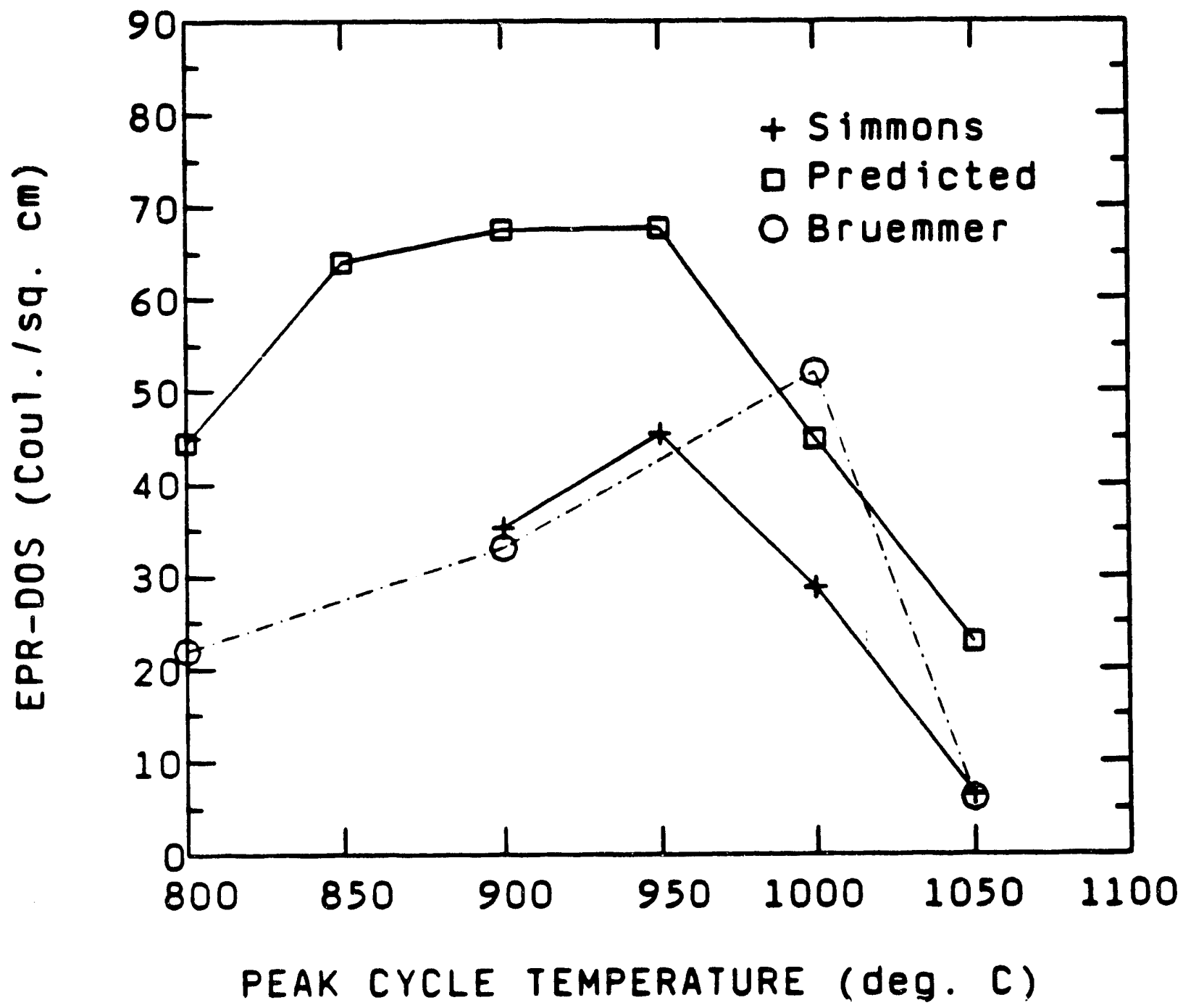

Figure 45. Comparisons of SMA SSDOS Predictions for CCS of Heat SS-16 MA Materials with Experimental Results of Simmons and Bruemmer ${ }^{(8)}$ for a Cooling Rate of $0.05^{\circ} \mathrm{C} / \mathrm{sec}$ Bruemmer's Results are for Furnace Cooled Specimens. 


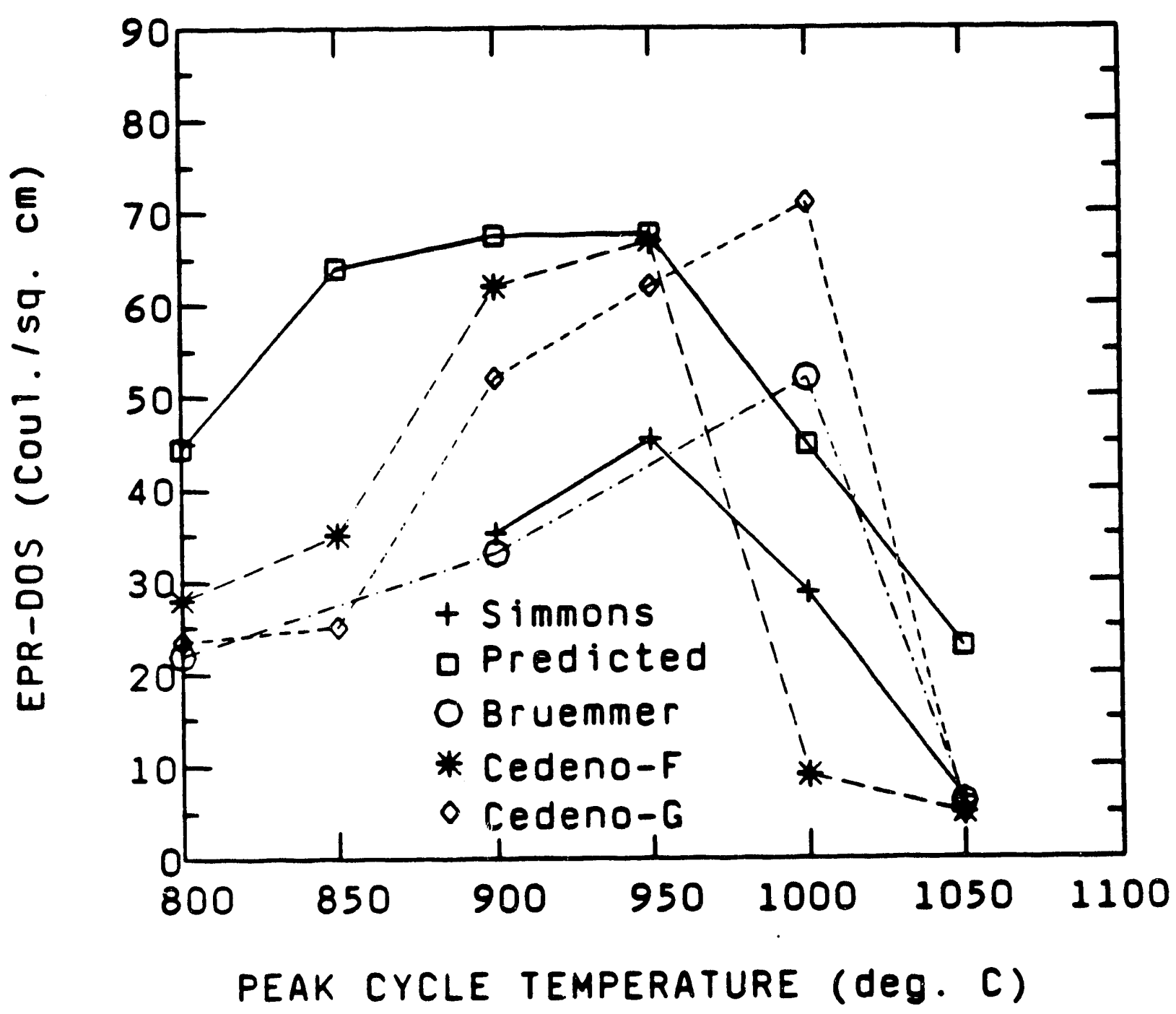

Figure 46. Same Comparisons of SMA SSDOS Predictions with Experimental Results for CCS of Heat SS-16 MA Materials as Figure 45 with Cedeno's ${ }^{(56)}$ Gleeble and Furnace Cooled Results Added 


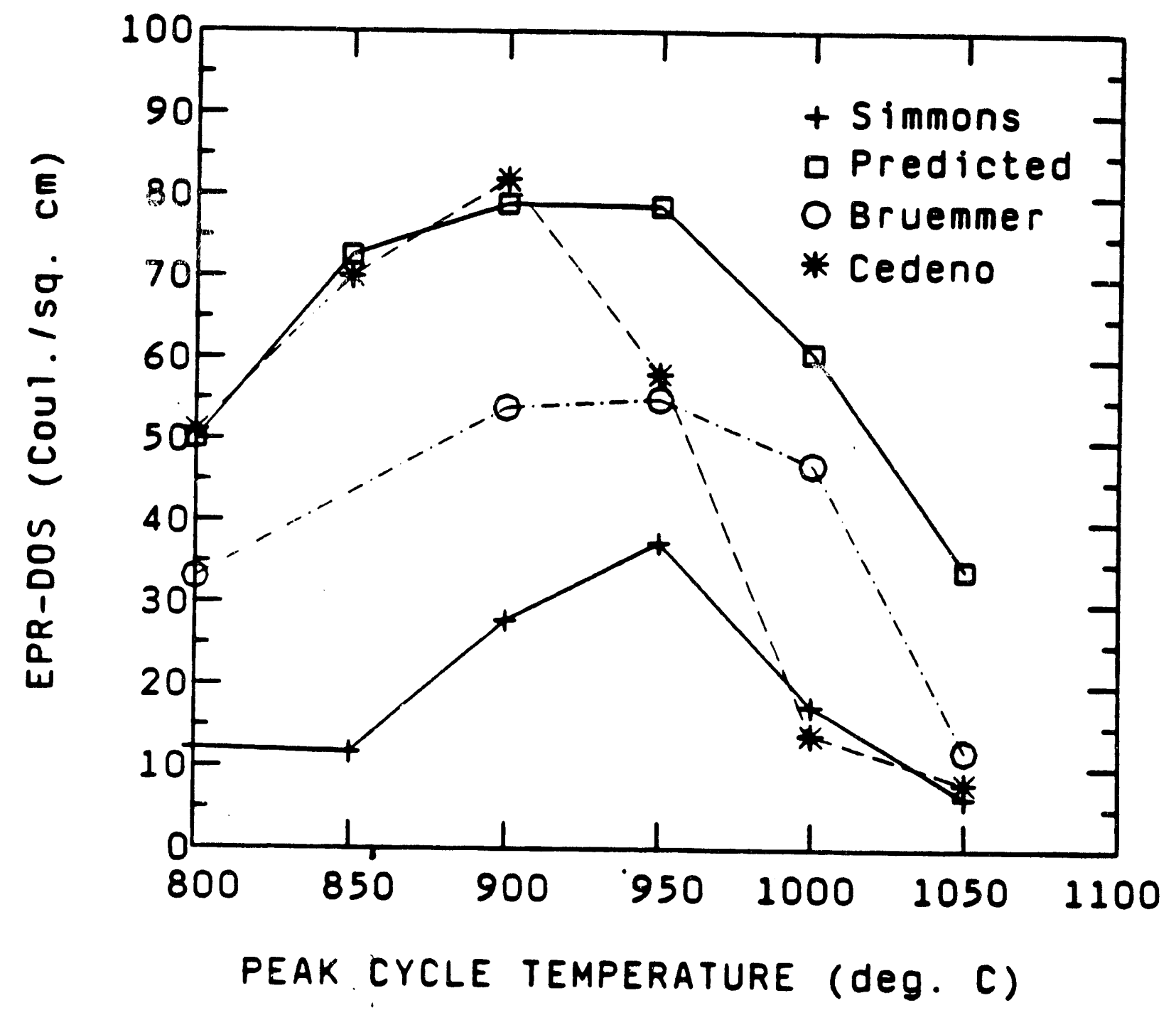

Figure 47. Comparisons of SMA SSDOS Predictions for CCS of Heat SS-17 MA Materials with Experimental Results of Simmons, Bruemmer, ${ }^{(8)}$ and Cedeno ${ }^{(56)}$ for a Cooling Rate of $0.05^{\circ} \mathrm{C} / \mathrm{sec}$. Bruemmer's and Cedeno's Results are for Furnace Cooled Specimens

There are many experimental differences between furnace and Gleeble testing. Furnace treatments result in; (1) non-linear heating and cooling rates, (2) slow heating rates, and (3) variations from Gleeble simulations in the amount of time spent near the peak temperature and within the actual temperature regime itself for "equal" peak cycle temperatures and cooling rates. The current work done with heat and quench testing indicated that a significant amount of sensitization development occurred in the high carbon $316 \mathrm{SS}$ heats at temperatures above $800^{\circ} \mathrm{C}$ (for peak cycle temperatures equal to, or less than, $950^{\circ} \mathrm{C}$ ). The cooling rates for furnace cooled specimens within this critical temperature range is undocumented.

Cedeno's data (for CCS experimentation using the furnace and Gleeble) was added to the comparisons of Figure 45 and this is illustrated in the graph of Figure 46. The EPR-DOS results for 
Cedeno's work are much higher than those presented for Simmons and Bruemmer and compare more favorably to SSDOS predictions. The critical peak temperature indicated for Cedeno's Gleeble and furnace work are not equal, but are 1000 and $950^{\circ} \mathrm{C}$, respectively. The reason for the differences in the magnitude of the EPR-DOS values for Cedeno's work compared with that of Simmons and Bruemmer is unknown.

Comparisons of experimental data from Bruemmer and Cedeno with the current work and SSDOS predictions for CCS of MA materials from Heat SS-17 are presented in Figure 47. SSDOS overpredicted the CCS reisults of Bruemmer for this heat also, but EPR-DOS values for the current work (Simmons-Gleeble) are not consistent with Bruemmer's furnace CCS data as was the case for heat SS-16. Sensitization values from Bruemmer lie in-between those of Simmons and SSDOS predictions. Sensitization (EPR-DOS) values reported by Cedeno for peak temperatures below $950^{\circ} \mathrm{C}$ are again much higher than those of Simmons and Bruemmer. A critical peak temperature of $950^{\circ} \mathrm{C}$ is indicated for the data of Simmons and Bruemmer, and $900^{\circ} \mathrm{C}$ for Cedeno. For peak temperatures below $950^{\circ} \mathrm{C}$ the experimental data of Cedeno agrees well with SSDOS predictions.

For both heats of material, the experimental results of Simmons and Bruemmer are in general agreement while those for Cedeno are consistently much higher. SSDOS overpredicted the results of Simmons and Bruemmer and compared more favorably with the results of Cedeno. Keeping previous discussions in mind, direct comparisons of EPR-DOS values obtained from different investigators for "equal" CCS studies (peak cycle temperatures and cooling rates), even using the same materials, must be viewed with caution.

For both heats of material, the SSDOS model generally predicted the critical peak temperature effect for CCS correctly. However, the way this is handled in the model is fundamentally incorrect since adjustments are made to the $\mathrm{Cr}$ diffusivity to slow down sensitization development for peak temperatures above certain values. Slowing down sensitization development at higher temperatures by reducing $\mathrm{Cr}$-diffusivity values is not consistent with the way diffusivity actually changes with temperature. Instead, it is suggested that carbide solubility, changes in GB and matrix structures, and carbide nucleation become the decerminate factors in reducing sensitization development for higher peak temperatures. The retardation of carbide nucleation and subsequent sensitization development during CC thermal treatments for temperatures above the critical peak temperature has been demonstrated. The results indicate that carbide nucleation characteristics are important in CCS and should be considered for sensitization modeling.

Although overprediction of sensitization development is more conservative and therefore more desirable than underprediction, the differences noted in the current work between SSDOS predictions and experimentally determined EPR-DOS values are unacceptable. The reason for the overprediction of the EPR-DOS values obtained in the current work, and the CCS values determined by the model's developer, is not known at this point and should be determined before the model is applied further to CCS applications. However, this in-depth analysis of the SSDOS model is beyond the scope of the present work.

\subsection{Variations in Test Results}

Some inconsistencies were noted in the quantitative EPR-DOS test results and single samples had sensitization responses which did not fit general trends. It is postulated that some of these 
variations can be attributed to the fact that the bulk of CCS thermal treatments were carried out on as-received mill-annealed materials. Wall thicknesses of the as-received pipes varied considerably [from about 0.56 to $0.64 \mathrm{~cm}$ ] and grain size variations were also observed in the as-received materials. These observations indicate that thermomechanical working of the material varied within the pipes and resulted in microstructural differences from one area to another.

Sample-to-sample variations in sensitization response is considered to be partially due to microstructural variations present throughout the pipe materials. The inconsistencies in sensitization response from sample-to-sample and variations between MA and SA materials of the same composition signify the importance of prior thermomechanical treatments on sensitization development.

Due to variations within EPR test results themselves, differences in EPR-DOS values of $10 \%$ (relative to the given value) or less cannot be considered to be very significant. For EPR-DOS values less than about $2 \mathrm{C} / \mathrm{cm}^{2}$, the relative difference expected can rise to about $50 \%$. Additional errors may arise since data points were determined from only one Gleeble sample and many interrelated factors are involved in determining the DOS of a particular sample. Slight variations present within the as-received MA material itself, such as degree of deformation, grain size, or chemical segregation, could alter the results from one specimen to another or cause anomalous results for a single sample.

It is also possible that anomalies can occur during Gleeble thermal cycling itself. Simall variations in thermocouple positioning or placement (i.e. bead geometry effects and position of the wires above the bead) can cause the peak temperature within the isothermal zone to be higher than the measured values. This would result in sensitization response within the sample to be different than expected. 


\section{CONCLUSIONS}

The CCS behavior of high-carbon 316 SS materials has been characterized as a function of peak cycle temperature, cooling rate, and initial material condition. Degree of sensitization measurements during the cooling cycles themselves resulted in definition of the critical temperature range for CCS development. The effects of strain on CCS development in a 316 SS have been characterized.

The CCS data base developed in the current work has been compared to, and provides the information necessary for the future development of, a computer-based sensitization prediction model (SSDOS) developed by Bruemmer. $(8,10)$

The primary conclusions and observations resulting from the current work on CCS are listed below:

(1) A critical peak temperature for continuous cooling sensitization was observed. Peak cycle temperatures either above or below this critical peak temperature result in lower EPR-DOS values.

(2) Continuous cooling sensitization development increased with decreasing cooling rates and occurred primarily in the critical range between about 900 and $750^{\circ} \mathrm{C}$.

(3) Peak cycle temperatures of 1000 and $1050^{\circ} \mathrm{C}$ suppressed carbide nucleation and sensitization development to lower temperatures during continuous cooling.

(4) Quenching from, and reheating to, the critical peak temperature nullified the effects of an elevated temperature exposure $\left(1050^{\circ} \mathrm{C}\right)$ on retarding sensitization development during continuous cooling.

(5) Prior deformation significantly enhanced the rate of CCS development. The degree of sensitization was generally found to increase with increasing amounts of prior strain.

(6) Limited transgranular carbide precipitation was observed in $20 \%$ prior strain samples heated to peak temperatures of 800,850 , and $900^{\circ} \mathrm{C}$ for cooling rates of 0.10 and $0.05^{\circ} \mathrm{C} / \mathrm{sec}$, but was not a significant factor in the present work.

(7) Strain recovery at elevated temperatures played an important role in reducing the effectiveness of deformation in accelerating sensitization developinent for particular peak cycle temperatures and cooling rates.

(8) Due to the effects of recovery, in certain cases, prior strain values of $20 \%$ were only as effective as $10 \%$ in enhancing sensitization development.

(9) The SSDOS model consistently overpredicted the CCS development in both heats of 316 SS, regardless of material condition (i.e. mill-annealed, solution- annealed, and pre-strained materials). 


\section{FUTURE WORK RECOMMENDATIONS}

The present work has characterized the effects of deformation at ambient temperature on the CCS of 316 SS as a first step in quantitatively understanding the complicated phenomena of weldinduced sensitization. High peak temperatures, above a critical peak temperature, have been shown to retard CCS development compared to lower temperatures and also reduce the effects of deformation in enhancing sensitization development. It is evident that more microstructural evaluation, using STEM, of the CCS work completed up to this point is needed to obtain a better understanding of the effects of strain on carbide nucleation and growth characteristics, and especially the recovery phenomena occurring at elevated temperatures.

The results also indicate the necessity for research which examines the effects of high temperature deformation (simultaneous strain) on CCS which correlates better to what actually occurs in weldments. The application of deformation at elevated temperatures and sensitization development under these dynamic circumstances is expected to vary somewhat from the effects of prior deformation. Simultaneous strain at elevated temperatures may result in dislocation structures and carbide nucleation and growth characteristics which differ from what occurs in materials deformed at ambient temperature.

Studying simultaneous strain effects at elevated temperatures on CCS would hopefully lead to the simulation of weld HAZ thermal and strain cycles and comparison of the resulting DOS values with those of actual weldments.

Analytical electron microscopy has proven a valuable tool in studying $\mathrm{Cr}$-depletion characteristics of SSs and should be applied more thoroughly to study the effects of strain recovery during CC thermal treatments, and the effects of strain on GB, twin, and matrix structures. These structures affect the nucleation and growth characteristics of carbides and are important in determining the effects of strain on carbide nucleation and growth kinetics as well as Cr-depletion zone development.

The present results can be used to help modify the SSDOS model to correlate better to CCS on a more theoretical basis by taking into account the effects of elevated temperature exposures, deformation, and recovery on carbide nucleation and sensitization development. 


\section{REFERENCES}

1. M. Fox, "An Overview of Intergranular Stress Corrosion Cracking in BWRs," Proceedings: Seminar on Countermeasures for Pipe Cracking in BWRs, Vol. 1, EPRI WS-79-174, Electric Power Regearch Institute, Palo Alto, California (1980).

2. C.G. Schmidt, R.D. Caligiuri, et al., Met. Trans. A, Vol. 18A, August, p. 1483 (1987).

3. A. Taboada, L. Frank, "Intergranular Corrosion in Nuclear Systems," Intergranular Corrosion of Stainless Alloys, ASTM STP 656, R. F. Steigerwald, Ed., ASTM, pp. 85-98 (1978).

4. H. Hanninen, I. Aho-Mantila, "Effect of Sensitization and Cold Work on Stress Corrosion Susceptibility of Austenitic Stainless Steels in BWR and PWR Conditions, Technical Research Center of Finland (1981).

5. E.C. Bain, R.H. Aborn, Trans. Amer. Soc. Steel Treat., Vol. 18, p.837 (1930).

6. C. Stawstrom, M. Hillert, J. Iron Steel Inst., p. 77, January (1969).

7. C.S. Tedmon, Jr., D.A. Vermilyea, J.H. Rosolowski, J. Electrochem. Soc., Vul. 118, No. 2, p. 192 (1971).

8. S.M. Bruemmer, PhD Dissertation, "Quantitative Measurement and Modeling of Sensitization Development in Stainless Steels," Oregon Graduate Institute of Science and Technology (OGI) [Formerly the Oregon Graduate Center], Beaverton, May (1988).

9. H.D. Solomon, Corrosion, Vol. 34, No. 6, p. 183 (1978).

10. S.M. Bruemmer, Corrosion/89, Paper No. 561, National Association of Corrosion Engineers (1989).

11. M. Deighton, J. Iron Steel Inst., p. 1012, November (1970).

12. B. Weiss, R. Stickler, Met. Trans., Vol. 3, p. 851, April (1972).

13. J.K.L. Lai, Mat. Sci. \& Eng., Vol. 61, p. 101 (1983).

14. J.K.L. Lai, Mat. Sci. \& Eng., Vol. 58, p. 19 (1983).

15. E.A. Lorià, Corrosion, Vol. 40, No. 8, p. 441, August (1984).

16. C. DaCasa, V.B. Nileshwar, D.A. Melford, J. Iron Steel Inst., p. 1325, October (1969).

17. E.L. Hall, C.L. Briant, Met. Trans. A, Vol. 15A, p. 793, May (1984).

18. R.L. Fullman, Acta Metall., Vol. 30, p. 1407 (1982).

19. C.L. Briant, E.L. Hall, Corrosion, Vol. 42, No. 9, p. 523, September (1986). 
20. S.M. Bruemmer, L.A. Charlot, Scripta Metall., Vol. 20, p. 1019 (1986).

21. D.G. Atteridge, S.M. Bruemmer, "Evaluation of Wolded and Repair Welded Stainless Steel for LWR Service," U.S. Nuclear Regulatory Commission Report: NUREG/CR-3613, Vol. 3, No. 2 (1986).

22. K. Arioka, M. Hourai, S. Noguchi, and K. Onimura, CORROSION/83, Paper No. 134, National Association of Corrosion Engineers (1983).

23. C.L. Briant, R.A. Mullford, E.L. Hall, Corrosion, Vol. 38, No. 9, p. 468, September (1982).

24. Metals Handbook, 9th Ed., Vol. 3, "Properties and Selection: Stainless Steels, Tool Materials and Special-Purpose Metals," American Society for Metals, Metals Park, Ohio (1980).

25. D. Peckner, I.M. Bernstein, "Handbook of Stainless Steөls," McGraw-Hill Book Co., New York (1977).

26. S.M. Bruemmer, L.A. Charlot, D.G. Atteridge, "Evaluation of Welded and Repair Welded Stainless Steel for LWR Service," U.S. Nuclear Regulatory Commission Report: NUREG/CR3618 (1984).

27. S. Hertzman, Met. Trans. A, Vol. 18A, p. 1767, October (1987).

28. E.A. Loria, J. Metals, p. 137, June (1979).

29. W.L. Clarke, R.L. Cowan, W.L. Walker, "Comparative Methods for Measuring Degree of Sensitization in Stainless Steel," Intergranular Corrosion of Stainless Alloys, ASTM STP 656, R.F. Steigerwald, Ed., ASTM, pp. 99-132 (1978).

30. W.L. Clàrke, V.M. Romero, J.C. Danko, CORROSION/77, Paper No. 180, National Association of Corrrssion Engineers (1977).

31. W.L. Clarke, "The EPR Method for the Detection of Sensitization in Stainless Steels," NUREG0251-1, U.S. Nuclear Regulatory Commission (1976).

32. E.A. Loria, J. Metals, p. 16, October (1982).

33. E.A. Loria, Corrosion, Vol. 37, No. 8, p. 481, August (1981).

34. ASTM Book of Standards, A 262, ASTM, Philadelphia, Pennsylvania, Vol. 10, p. 1 (1978).

35. ASTM Committee G-1 - Corrosion of Metals, Subcommittee G01.08 - Corrosion of Nuclear Materials, "Test Method for Electrochemical Potentiokinetic Reactivation (EPR) Method for Detecting Sensitization of AISI-304 and 304L Stainless Steels," ASTM.

36. A. Mignone, A. Borello, A. La Barbera, Corrosion, Vol. 38, No. 7, p. 391, July (1982).

37. S.M. Bruemmer, Corrosion, Vol. 42, No. 1, p. 27, January (1986).

38. J.B. Lee, Corrosion, Vol. 42, No. 2, p. 106, February (1986). 
39. C.L. Briant, A.M. Ritter, Met. Trans. A, Vol. 11A, p. 2010, December (1980).

40. P.L. Andresen, H.D. Solomon, D.F. Taylor, "Basic Studies on the Variabilities of FabricationRelated Sensitization Phenomena in Stainless Steels," NP-1823, Electric Power Research Institute (1981).

41. H.D. Solomon, "Variables Influencing Weld Sensitization of Austenitic Stainless Steel," Technical Information Series, No. 79CRD037, General Electric Co., Schenectady, New York, February (1979).

42. H.D. Solomon, D.C. Lord, Corrosion, Vol. 36, No. 8, p. 395, August (1980).

43. J.W. Christian, "The Theory of Transformations in Metals and Alloys, Part I - Equilibrium and General Kinetic Theory," Pergamon Press Ltd., 2nd ed. (1975).

44. M.H. Lewis, B. Hattersley, Acta Metall., Vol. 13, p. 1159 , November (1965).

45. L.K. Singhal, J.W. Martin, Trans. Met. Soc. AlME, Vol. 242, p. 814, May (1968).

46. D.A. Porter, K.E. Easterling, "Phase Transformations in Metals and Alloys", Van Nostrand Reinhold Co. Ltd., (1981).

47. J.P. Adamson, J.W. Martin, Acta Metall., Vol. 19, p. 1015, October (1971).

48. E.W. Hart, Acta Metall., Vol. 5, p. 597, October (1957).

49. F.A. Huntley, F.W. Willoughby, J. Electrochem. Soc., Vol. 120, No. 3, p. 415, March (1973).

50. J.M. Hill, Scripta Metall., Vol. 13, No. 11, p. 1027 (1979).

51. R.W. Ballufii, Phys. Stat. Sol., Vol. 42, p. 11 (1970).

52. A.L. Ruoff, R.W. Balluffi, J. Applied Phys., Vol. 34, No. 7, p. 1848, July (1963).

53. A.H. Advani, D.G. Atteridge, S.M. Bruemmer, "Effects of Prior and Simultaneous Deformation on the Sensitization of Austenitic Stainless Steels," ASM International World Congress Precipitation Phenomena: Deformation Aging, Chicago, Illinois (1988).

54. A.H. Advani, D.G. Atteridge, L.E. Murr, S.M. Bruemmer, "Effects of Prior Deformation on the Sensitization of Type 316 Austenitic Stainless Steel I: Isothermal Sensitization," ASM Trends in Welding Research Conference, Gatlinburg, Tennessee, ASM International (1989).

55. C.L. Briant, A.M. Ritter, Scripta Metall., Vol. 13, No. 3, p. 177 (1979).

56. Cesar Cedeno, Work Completed in Pursuit of MS Degree, "Thermal Cycle Effects orl Stainless Steel Sensitization", Oregon Graduate Institute of Science and Technology (OGI) (Formerly the Oregon Graduate Center], Beaverton (1989).

57. V. Cihal, "Intergranular Corrosion of Steels and Alloys," Materials Science Monograph No. 18, Elsevier Publishing Co., New York (1984). 
58. J.E. Spruiell, J.A. Scott, C.S. Ary, and R.L. Hardin, Met. Trans., Vol. 4, p. 1533, June (1973).

59. H.D. Solomon, Corrosion, Vol. 36, No. 7, p. 357, July (1980).

60. H.D. Solomon, Corrosion, Vol. 41, No. 9, p. 513, September (1985).

61. D.J. Widgery, "Weld Thermal Simulators: A Review," Proceedings of the Conference on Weld Thermal Simulators for Research and Problem Solving, The Welding Institute, Cambridge, England, April (1972).

62. D.W. Walsh, M.J. Cieslak, W.F. Savage, Welding Journal, p. 184-s, July (1986).

63. I.M. Kilpatrick, R.C. Allan, R. Main, Paper No. 5, Proceedings of the Conference on Weld Thermal Simulators for Research and Problem Solving, The Welding Institute, Cambridge, England, p. 25, April (1972).

64. ASTM Book of Standards, Vol. 2.01, E 112-85, ASTM, Philadelphia, Pennsylvania, p. 815 (1988).

65. H.D. Solomon, Corrosion, Vol. 40, No. 2, p. 51, February (1984).

66. A.H. Advani, Work Completed in Pursuit of PhD Degree, "Deformation Effects on Grain Boundary Cr-Depietion (Sensitization) Development in Type 316 Stainless Steels," Oregon Graduate Institute of Science and Technology (OGI) [Formerly the Oregon Graduate Center], Beaverton (1989).

67. D.G. Morris, D.R. Harries, J. Mat. Sci., Vol. 14, p. 2625 (1979).

68. H. Ikawa, Y. Nakao, K. Nishimoto, "Study of Weld Decay in SUS 304 Precipitation Phenomena of $\mathrm{M}_{23} \mathrm{C}_{6}$ During Thermal Cycles", Technical Reports of Osaka University, No. 1434, p. 369 (1978). 
APPENDIX A

EPR-DOS Results for Heat SS-16 Materials

89 


\begin{tabular}{|c|c|c|c|c|c|}
\hline$S / N$ & $\begin{array}{l}\text { Maximum } \\
\text { Tomp. }\left({ }^{\circ} \mathrm{C}\right) \\
\end{array}$ & $\begin{array}{c}\text { Cooling Rate } \\
\left({ }^{\circ} \mathrm{C} / \mathrm{sec}\right)\end{array}$ & $\begin{array}{l}\text { "SMA" Pred. } \\
\left(\mathrm{C} / \mathrm{cm}^{2}\right)\end{array}$ & $\begin{array}{l}\text { "Cons." Pred. } \\
\left(\mathrm{C} / \mathrm{cm}^{2}\right)\end{array}$ & $\begin{array}{c}P a \\
\left(C / \mathrm{cm}^{2}\right)\end{array}$ \\
\hline- & 800 & 0.05 & 44.5 & 56.6 & --- \\
\hline- & 850 & 0.05 & 64.0 & 82.9 & --- \\
\hline MA50 & 900 & 0.05 & 67.4 & 95.7 & 35.3 \\
\hline MA51 & 950 & 0.05 & 67.6 & 95.9 & 45.4 \\
\hline MA52 & 1000 & 0.05 & 44.8 & 76.8 & 28.7 \\
\hline MA53 & 1050 & 0.05 & 22.9 & 51.0 & 6.4 \\
\hline$\cdots$ & 800 & 0.10 & 27.3 & 37.6 & $\cdots$ \\
\hline$\cdots$ & 850 & 0.10 & 39.7 & 59.4 & -.-- \\
\hline MA58 & 900 & 0.10 & 40.8 & 69.8 & 16.0 \\
\hline MA59 & 950 & 0.10 & 40.7 & 69.8 & 18.5 \\
\hline MA60 & 1000 & 0.10 & 23.1 & 48.6 & 3.0 \\
\hline MA61 & 1050 & 0.10 & 9.2 & 27.2 & 2.0 \\
\hline$-\cdots$ & 800 & 1.0 & 0.7 & 4.1 & $\cdots$ \\
\hline--- & 850 & 1.0 & 0.9 & 7.6 & $\cdots$ \\
\hline MA54 & 900 & 1.0 & 0.9 & 7.7 & 0.7 \\
\hline MA55 & 950 & 1.0 & 0.9 & 7.7 & 1.2 \\
\hline MA56 & 1000 & 1.0 & 0 & 2.2 & 0.3 \\
\hline MA57 & 1050 & 1.0 & 0 & 0 & 0 \\
\hline
\end{tabular}

The predicted values from the SSDOS model were obtained by two methods, the first was the "statistically most accurate" ("SMA"), and the second the "Conservative" ("Cons.") method. The results listed above in Table A1 correspond to the test matrix of Table 2 for the MA material. 
Table A2 EPR-DOS Results for Heat 88-16 8A Material

\begin{tabular}{|c|c|c|c|c|c|}
\hline S/N & $\begin{array}{l}\text { Maximum } \\
\left.\text { Tomp. }^{\circ} \mathrm{C}\right)\end{array}$ & $\begin{array}{c}\text { Cooling Rate } \\
\left({ }^{\circ} \mathrm{C} / \mathrm{sec}\right)\end{array}$ & $\begin{array}{l}\text { "SMA" Pred. } \\
\left(\mathrm{C} / \mathrm{cm}^{2}\right)\end{array}$ & $\begin{array}{l}\text { "Cons." Pred. } \\
\left(\mathrm{C} / \mathrm{cm}^{2}\right)\end{array}$ & $\mathrm{Pa}\left(\mathrm{C} / \mathrm{cm}^{2}\right)$ \\
\hline$\ldots$ & 800 & 0.05 & 44.5 & 56.6 & $\cdots$ \\
\hline$-\infty$ & 850 & 0.05 & 64.0 & 82.9 & --- \\
\hline SA1 & 900 & 0.05 & 67.4 & 95.7 & 18.7 \\
\hline SA3 & 950 & 0.05 & 67.6 & 95.9 & 21.4 \\
\hline SA4 & 1000 & 0.05 & 44.8 & 76.8 & 3.1 \\
\hline SA5 & 1050 & 0.05 & 22.9 & 51.0 & 2.5 \\
\hline -.- & 800 & 0.10 & 27.3 & 37.6 & ---- \\
\hline--- & 850 & 0.10 & 39.7 & 59.4 & --- \\
\hline SA11 & 900 & 0.10 & 40.8 & 69.8 & 6.1 \\
\hline SA12 & 950 & 0.10 & 40.7 & 69.8 & 12.4 \\
\hline SA13 & 1000 & 0.10 & 23.1 & 48.6 & 6.7 \\
\hline SA14 & 1050 & 0.10 & 9.2 & 27.2 & 0.7 \\
\hline--- & 800 & 1.0 & 0.7 & 4.1 & ---- \\
\hline -.- & 850 & 1.0 & 0.9 & 7.6 & $-\cdots$ \\
\hline SA7 & 900 & 1.0 & 0.9 & 7.7 & 0.2 \\
\hline SA8 & 950 & 1.0 & 0.9 & 7.7 & 0.3 \\
\hline SA9 & 1000 & 1.0 & 0 & 2.2 & 0 \\
\hline SA10 & 1050 & 1.0 & 0 & 0 & 0 \\
\hline
\end{tabular}

The predicted values from the SSDOS model were obtained by two methods, the first was the "statisticaliy most accurate" ("SMA"), and the second the "Conservative" ("Cons.") method. The results listed above in Table A2 correspond to the test matrix of Table 2 for the SA material. 


\section{APPENDIX B}

EPR-DOS Results for Heat SS-17 Materials 


\begin{tabular}{cccccc}
\hline \multicolumn{5}{c}{ Table B1 EPR-DOS Results for Heat SS-17 MA Material } \\
\hline S/N & $\begin{array}{c}\text { Maximum } \\
\text { Temp. }\left(^{\circ} \mathrm{C}\right)\end{array}$ & $\begin{array}{c}\text { Cooling Rate } \\
\left({ }^{\circ} \mathrm{C} / \mathrm{seC}\right)\end{array}$ & $\begin{array}{c}\text { "SMA" Pred. } \\
\left(\mathrm{C} / \mathrm{cm}^{2}\right)\end{array}$ & $\begin{array}{c}\text { "Cons." Pred. } \\
\left(\mathrm{C} / \mathrm{cm}^{2}\right)\end{array}$ & $\begin{array}{c}\text { Pa } \\
\left({\left.\mathrm{C} / \mathrm{cm}^{2}\right)}^{2}\right.\end{array}$ \\
\hline MA62 & 800 & 0.05 & 50.1 & 62.8 & 12.1 \\
MA63 & 850 & 0.05 & 72.6 & 90.4 & 11.7 \\
MA70 & 900 & 0.05 & 78.8 & 103 & 27.8 \\
MA71 & 950 & 0.05 & 78.7 & 104 & 37.5 \\
MA72 & 1000 & 0.05 & 60.7 & 94.6 & 17.5 \\
MA73 & 1050 & 0.05 & 34.1 & 70.4 & 6.4
\end{tabular}

$\begin{array}{cccccc}\text { MA64 } & 800 & 0.10 & 32.3 & 43.6 & 3.0 \\ \text { MA65 } & 850 & 0.10 & 48.8 & 68.9 & 8.7 \\ \text { MA78 } & 900 & 0.10 & 51.8 & 84.4 & 16.2 \\ \text { MA79 } & 950 & 0.10 & 51.7 & 84.8 & 13.5 \\ \text { MA80 } & 1000 & 0.10 & 35.7 & 68.9 & 2.3 \\ \text { MA81 } & 1050 & 0.10 & 16.5 & 43.4 & 1.8 \\ & & & & & \\ \cdots-- & 800 & 1.0 & 2.6 & 6.8 & \cdots \\ \text { MA74 } & 850 & 1.0 & 3.8 & 13.4 & \cdots \\ \text { MA75 } & 950 & 1.0 & 3.8 & 15.1 & 0.7 \\ \text { MA76 } & 1000 & 1.0 & 3.8 & 15.0 & 0.8 \\ \text { MA77 } & 1050 & 1.0 & 0.6 & 8.3 & 0.5\end{array}$

The predicted values from the SSDOS model were obtained by two methods, the first was the "statistically most accurate" ("SMA"), and the second the "Conservative" ("Cons.") method. The results listed above in Table $B 1$ correspond to the test matrix of Table 3 for the MA material with $0 \%$ prior strain. 


\begin{tabular}{|c|c|c|c|c|c|}
\hline S/N & $\begin{array}{l}\text { Maximum } \\
\text { Tomp. }\left(^{\circ} \mathrm{C}\right)\end{array}$ & $\begin{array}{c}\text { Cooling Rate } \\
\left({ }^{\circ} \mathrm{C} / \sec ^{\prime}\right)\end{array}$ & $\begin{array}{l}\text { "SMA" Pred. } \\
\left(\mathrm{C} / \mathrm{cm}^{2}\right)\end{array}$ & $\begin{array}{l}\text { "Cons." Prod. } \\
\left(\mathrm{C} / \mathrm{cm}^{2}\right)\end{array}$ & $\mathrm{Pa}\left(\mathrm{C} / \mathrm{cm}^{2}\right)$ \\
\hline 516 & 800 & 0.05 & 56.3 & 69.7 & 12.2 \\
\hline 501 & 850 & 0.05 & 79.4 & 96.2 & 25.5 \\
\hline 502 & 900 & 0.05 & 85.5 & 106 & 39.8 \\
\hline 503 & 950 & 0.05 & 85.4 & 107 & 50.3 \\
\hline 504 & 1000 & 0.05 & 67.4 & 99.8 & 8.3 \\
\hline 505 & 1050 & 0.05 & 39.1 & 77.2 & 6.4 \\
\hline 517 & 800 & 0.10 & 37.2 & 49.5 & 5.7 \\
\hline 506 & 850 & 0.10 & 54.9 & 75.7 & 12.7 \\
\hline 507 & 900 & 0.10 & 58.1 & 90.8 & 22.4 \\
\hline 508 & 950 & 0.10 & 58.0 & 91.1 & 25.8 \\
\hline 509 & 1000 & 0.10 & 40.9 & 75.7 & 5.2 \\
\hline 510 & 1050 & 0.10 & 19.5 & 49.2 & 1.6 \\
\hline--- & 800 & 1.0 & 3.7 & 8.6 & $\cdots$ \\
\hline 511 & 850 & 1.0 & 5.1 & 16.7 & 1.4 \\
\hline 512 & 900 & 1.0 & 5.1 & 18.0 & 1.8 \\
\hline 513 & 950 & 1.0 & 5.1 & 17.9 & 3.8 \\
\hline 514 & 1000 & 1.0 & 1.3 & 10.3 & 0.6 \\
\hline 515 & 1050 & 1.0 & 0 & 2.6 & 0 \\
\hline
\end{tabular}

The predicted values from the SSDOS model were obtained by two methods, the first was the "statistically most accurate" ("SMA"), and the second the "Conservative" ("Cons.") method. The results listed above in Table B2 correspond to the test matrix of Table 5 for the MA material with $5 \%$ prior strain. 


\begin{tabular}{|c|c|c|c|c|c|}
\hline $8 / N$ & $\begin{array}{l}\text { Moximum } \\
\text { Tomp. }\left(^{\circ} \mathrm{C}\right) \\
\end{array}$ & $\begin{array}{c}\text { Cooling Rate } \\
\left({ }^{\circ} \mathrm{C} / \mathrm{sec}\right)\end{array}$ & $\begin{array}{l}\text { "SMA" Pred. } \\
\left(\mathrm{C} / \mathrm{cm}^{2}\right)\end{array}$ & $\begin{array}{l}\text { "Cons." Pred. } \\
\left(\mathrm{C} / \mathrm{sm}^{2}\right)\end{array}$ & $P_{D}\left(C / \mathrm{cm}^{2}\right)$ \\
\hline 1016 & 800 & 0.05 & 61.4 & 75.0 & 16.7 \\
\hline 1001 & 850 & 0.05 & 84.6 & 100 & 33.8 \\
\hline 1002 & 900 & 0.05 & 90.4 & 109 & 65.2 \\
\hline 1003 & 950 & 0.05 & 90.3 & 110 & 56.7 \\
\hline 1004 & 1000 & 0.05 & 72.7 & 103 & 24.1 \\
\hline 1005 & 1050 & 0.05 & 43.2 & 82.4 & 5.8 \\
\hline 1017 & 800 & 0.10 & 41.3 & 54.3 & 8.6 \\
\hline 1006 & 850 & 0.10 & 59.9 & 81.0 & 20.2 \\
\hline 1007 & 900 & 0.10 & 63.3 & 95.3 & 36.3 \\
\hline 1008 & 950 & 0.10 & 63.2 & 95.7 & 37.1 \\
\hline 1009 & 1000 & 0.10 & 45.1 & 81.0 & 3.0 \\
\hline 1010 & 1050 & 0.10 & 22.0 & 53.9 & 1.8 \\
\hline --- & 800 & 1.0 & 4.7 & 10.2 & $\cdots$ \\
\hline 1011 & 850 & 1.0 & 6.2 & 18.4 & 1.7 \\
\hline 1012 & 900 & 1.0 & 6.2 & 20.5 & 3.2 \\
\hline 1013 & 950 & 1.0 & 6.2 & 20.4 & 4.8 \\
\hline 1014 & 1000 & 1.0 & 1.9 & 12.0 & 3.7 \\
\hline 1015 & 1050 & 1.0 & 0 & 3.4 & 0 \\
\hline
\end{tabular}

The predicted values from the SSDOS model were obtained by two methods, the first was the "statistically most accurate" ("SMA"), and the second the "Conservative" ("Cons.") mothod. The results listed above in Table $\mathrm{B} 3$ correspond to the test matrix of Table 5 for the MA material with $10 \%$ prior strain. 


\begin{tabular}{|c|c|c|c|c|c|}
\hline S/N & $\begin{array}{l}\text { Maximum } \\
\text { Temp. }\left(^{\circ} \mathrm{C}\right)\end{array}$ & $\begin{array}{c}\text { Cooling Rate } \\
\left({ }^{\circ} \mathrm{C} / \mathrm{sec}\right)\end{array}$ & $\begin{array}{l}\text { "SMA" Pred. } \\
\left(\mathrm{C} / \mathrm{cm}^{2}\right)\end{array}$ & $\begin{array}{l}\text { "Cons." Pred. } \\
\left.\text { (C/cm }{ }^{2}\right)\end{array}$ & $\mathrm{Pa}\left(\mathrm{C} / \mathrm{cm}^{2}\right)$ \\
\hline 2016 & 800 & 0.05 & 69.3 & 83.0 & 16.5 \\
\hline 2001 & 850 & 0.05 & 92.0 & 104 & 51.0 \\
\hline 2002 & 900 & 0.05 & 97.2 & 114 & 63.9 \\
\hline 2003 & 950 & 0.05 & 97.1 & 115 & 48.3 \\
\hline 2004 & 1000 & 0.05 & 80.6 & 107 & 16.7 \\
\hline 2005 & 1050 & 0.05 & 49.9 & 90.0 & 6.0 \\
\hline 2017 & 800 & 0.10 & 47.9 & 62.0 & 8.4 \\
\hline 2006 & 850 & 0.10 & 67.8 & 88.7 & 19.6 \\
\hline 2007 & 900 & 0.10 & 71.2 & 101 & 40.3 \\
\hline 2008 & 950 & 0.10 & 71.1 & 101 & 36.3 \\
\hline 2009 & 1000 & 0.10 & 52.0 & 88.7 & 3.3 \\
\hline 2010 & 1050 & 0.10 & 26.3 & 61.5 & 1.4 \\
\hline -.. & 800 & 1.0 & 6.4 & 12.8 & -.- \\
\hline 2011 & 850 & 1.0 & 8.1 & 22.4 & 3.0 \\
\hline 2012 & 900 & 1.0 & 8.1 & 24.7 & 6.0 \\
\hline 2013 & 950 & 1.0 & 8.1 & 24.6 & 6.5 \\
\hline 2014 & 1000 & 1.0 & 3.0 & 14.9 & 4.9 \\
\hline 2015 & 1050 & 1.0 & 0 & 4.8 & 0 \\
\hline
\end{tabular}

The predicted values from the SSDOS model were obtained by two methods, the first was the "statistically most accurate" ("SMA"), and the second the "Conservative" ("Cons.") method. The results listed above in Table $\mathbf{B 4}$ correspond to the test matrix of Table 5 for the MA material with $20 \%$ prior strain. 


\section{Table B5 EPR-DOS for Heat SS-17 Heat and Quench Matrix}

\begin{tabular}{|c|c|c|c|c|c|}
\hline $\mathbf{S} / \mathbf{N}$ & Prior Strain $(\%)$ & $\begin{array}{l}\text { Maximum } \\
\text { Tamp. }\left(^{\circ} \mathrm{C}\right) \\
\end{array}$ & $\begin{array}{c}\text { Cooling Rate } \\
\left({ }^{\circ} \mathrm{C} / \mathrm{sec}\right)\end{array}$ & $\begin{array}{c}\text { Maximum } \\
\text { Tomp. }\left(1^{\circ} \mathrm{C}\right) \\
\end{array}$ & $\mathrm{Pa}\left(\mathrm{C} / \mathrm{cm}^{2}\right)$ \\
\hline HO92 & 0 & 850 & 0.05 & 800 & 6.6 \\
\hline H093 & 0 & 850 & 0.05 & 750 & 9.9 \\
\hline HO94 & 0 & 850 & 0.05 & 700 & 11.1 \\
\hline H095 & 0 & 850 & 0.05 & 650 & 11.8 \\
\hline HO96 & 0 & 850 & 0.05 & 600 & 15.4 \\
\hline MA63 & 0 & 850 & 0.05 & 400 & 11.7 \\
\hline HO101 & 0 & 950 & 0.05 & 900 & 1.0 \\
\hline HQ102 & 0 & 950 & 0.05 & 850 & 3.6 \\
\hline HQ103 & 0 & 950 & 0.05 & 800 & 20.3 \\
\hline HQ104 & 0 & 950 & 0.05 & 750 & 19.7 \\
\hline H0105 & 0 & 950 & 0.05 & 700 & 20.4 \\
\hline HQ106 & 0 & 950 & 0.05 & 650 & 29.1 \\
\hline Ho107 & 0 & 950 & 0.05 & 600 & 27.4 \\
\hline MA71 & 0 & 950 & 0.05 & 400 & 37.5 \\
\hline HO110 & 10 & 950 & 0.05 & 900 & 0.8 \\
\hline Ho111 & 10 & 950 & 0.05 & 850 & 10.2 \\
\hline HO112 & 10 & 950 & 0.05 & 800 & 28.8 \\
\hline Ho113 & 10 & 950 & 0.05 & 750 & 37.3 \\
\hline HO114 & 10 & 950 & 0.05 & 700 & 42.8 \\
\hline HQ115 & 10 & 950 & 0.05 & 650 & 43.7 \\
\hline HO116 & 10 & 950 & 0.05 & 600 & 49.6 \\
\hline 1003 & 10 & 950 & 0.05 & 400 & 56.7 \\
\hline H086 & 0 & 1050 & 0.05 & 950 & 0 \\
\hline HO87 & 0 & 1050 & 0.05 & 900 & 0 \\
\hline H088 & 0 & 1050 & 0.05 & 850 & 0 \\
\hline HO89 & 0 & 1050 & 0.05 & 800 & 0 \\
\hline HQ9O & 0 & 1050 & 0.05 & 750 & 1.9 \\
\hline HQ97 & 0 & 1050 & 0.05 & 700 & 5.2 \\
\hline HO98 & 0 & 1050 & 0.05 & 600 & 7.8 \\
\hline HO99 & 0 & 1050 & 0.05 & 600 & 6.5 \\
\hline MA73 & 0 & 1050 & 0.05 & 600 & 6.4 \\
\hline
\end{tabular}




\begin{tabular}{|c|c|c|c|c|}
\hline $\mathbf{S} / \mathbf{N}$ & $\begin{array}{c}\text { Prior Strain } \\
\text { (\%) }\end{array}$ & $\begin{array}{l}\text { "SMA" Pred. } \\
\left(\mathrm{C} / \mathrm{cm}^{2}\right)\end{array}$ & $\begin{array}{l}\text { "Cons." Pred. } \\
\left(\mathrm{C} / \mathrm{cm}^{2}\right)\end{array}$ & $\mathrm{Pa}\left(\mathrm{C} / \mathrm{cm}^{2}\right)$ \\
\hline HO92 & 0 & 31.7 & 59.6 & 6.6 \\
\hline H093 & 0 & 51.4 & 73.4 & 8.9 \\
\hline HO94 & 0 & 60.0 & 80.8 & 11.1 \\
\hline HO95 & 0 & 65.1 & 84.7 & 11.8 \\
\hline HQ96 & 0 & 68.5 & 87.3 & 15.4 \\
\hline HQ101 & 0 & 0 & 2.3 & 1.0 \\
\hline HQ102 & 0 & 5.6 & 56.6 & 3.6 \\
\hline HQ103 & 0 & 38.3 & 82.4 & 20.3 \\
\hline HQ104 & 0 & 56.9 & 93.2 & 19.7 \\
\hline HQ105 & 0 & 65.7 & 98.2 & 20.4 \\
\hline HQ106 & 0 & 71.1 & 101 & 29.1 \\
\hline HQ107 & 0 & 74.5 & 103 & 27.4 \\
\hline HQ110 & 10 & 0 & 4.0 & 0.8 \\
\hline HQ111 & 10 & 9.1 & 68.1 & 10.2 \\
\hline HQ112 & 10 & 50.2 & 93.5 & 28.8 \\
\hline HQ113 & 10 & 68.5 & 102 & 37.3 \\
\hline HO114 & 10 & 77.8 & 105 & 42.8 \\
\hline HO115 & 10 & 83.1 & 107 & 43.7 \\
\hline HO116 & 10 & 86.4 & 108 & 49.6 \\
\hline H086 & 0 & 0 & 0 & 0 \\
\hline H087 & 0 & 0 & 0 & 0 \\
\hline H088 & 0 & 0 & 3.3 & 0 \\
\hline HQ89 & 0 & 1.1 & 29.4 & 0 \\
\hline HO9O & 0 & 8.5 & 48.7 & 1.9 \\
\hline H097 & 0 & 16.2 & 57.2 & 5.2 \\
\hline HO98 & 0 & 21.6 & 62.4 & 7.8 \\
\hline Ho99 & 0 & 25.3 & 65.9 & 6.5 \\
\hline
\end{tabular}

The results listed in Tables B5 and B6 correspond to the test matrix of Table 7 for heat and quench testing of the MA material from heat SS-17. 


\begin{tabular}{|c|c|}
\hline $\begin{array}{l}\text { U.S. NUCLEAA REGULATORY COMMISSION } \\
\text { BIBLIOGRAPHIC DATA SHEET } \\
\text { (SEm instructions on the roverso) }\end{array}$ & $\begin{array}{l}\text { 1. REPOAT NUMBER } \\
\text { NUREG/GR-0003 }\end{array}$ \\
\hline \multirow{4}{*}{$\begin{array}{l}\text { 2. TITLE AND SUDTITLE } \\
\text { Effect of Prior Deformation on Sensitization Development } \\
\text { in Stainless Steel During Continuous Cooling }\end{array}$} & \\
\hline & 3. DATE REPORT PUBLISHED \\
\hline & \\
\hline & $\begin{array}{l}\text { 4. FIN OR GAANT NUMBEA } \\
\text { G1107 }\end{array}$ \\
\hline \multirow{2}{*}{$\begin{array}{l}\text { 5. AUTHOR(S) } \\
\text { J. W. Simmons } \\
\text { Contributing Authors } \\
\text { D. G. Atteridge, S. M. Bruemmer }\end{array}$} & 6. TYPE OF REPORT \\
\hline & 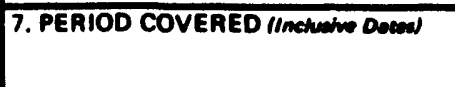 \\
\hline \multicolumn{2}{|c|}{ 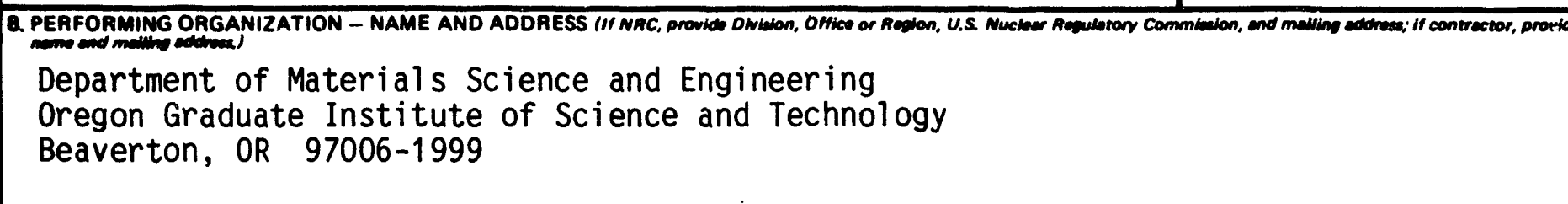 } \\
\hline \multicolumn{2}{|c|}{ 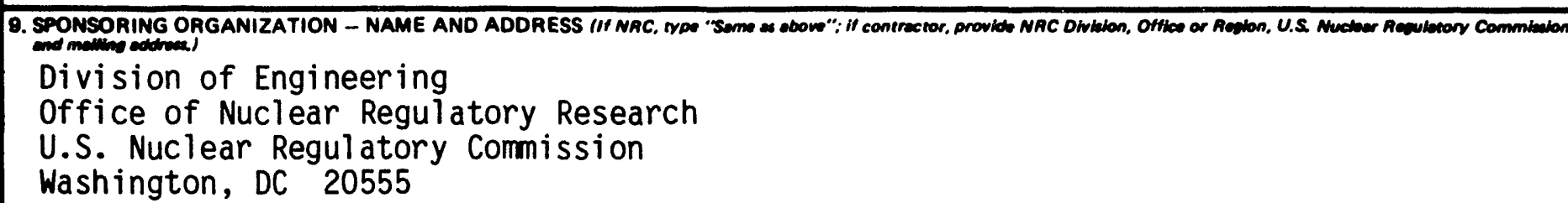 } \\
\hline
\end{tabular}

10. SUPPLEMENTARY NOTES

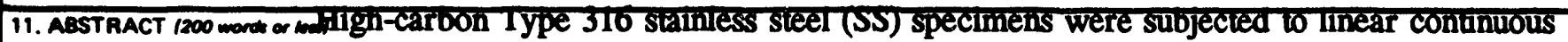
cooling in a computer-controlled Gleeble thermal simulator. The degree of sensitization (DOS) was quantitatively measured using the electrochemical potentiokinetic reactivation (EPR) test.

Sensitization values for the thermal cycles employed in the investigation were predicted using Bruemmer's SSDOS sensitization prediction model.

Prior deformation significantly enhanced the rate of DOS development in the Type 316 SS material. The DOS increased with increasing amounts of prior strain and decreasing cooling rates. Sensitization response was also sensitive to peak cycle temperatures. Continuous cooling sensitization development occurred primarily in the critical temperature range between about 900 and $750^{\circ} \mathrm{C}$. Peak cycle temperatures above 1000 retarded sensitization development during subsequent continuous cooling. Strain recovery at elevated temperatures played an important role in reducing the effectiveness of prior deformation in accelerating seisitization kinetics. Due to the effects of recovery, in certain cases, prior strain values of $20 \%$ were only as effective as $10 \%$ in increasing the rate of sensitization development. Limited transgranular carbide precipitation was observed in 20\% prior strain samples but was not a significant factor in the present work. The SSDOS model consistently over predicted DOS development regardless of material condition.

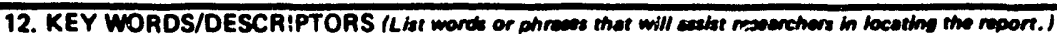

austenitic, stainless steel, carbide precipitation, chromium depletion, sensitization, continuous cooling, electrochemical potentiokinetic reactivation test, sensitization modeling, deformation effects

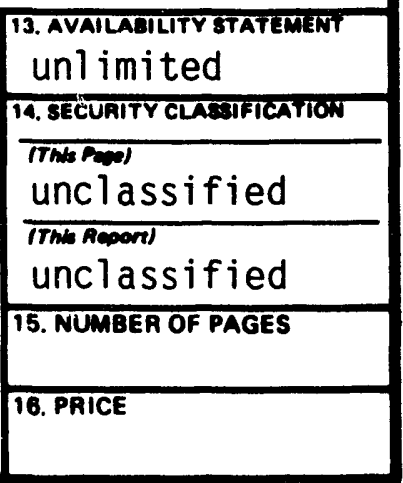



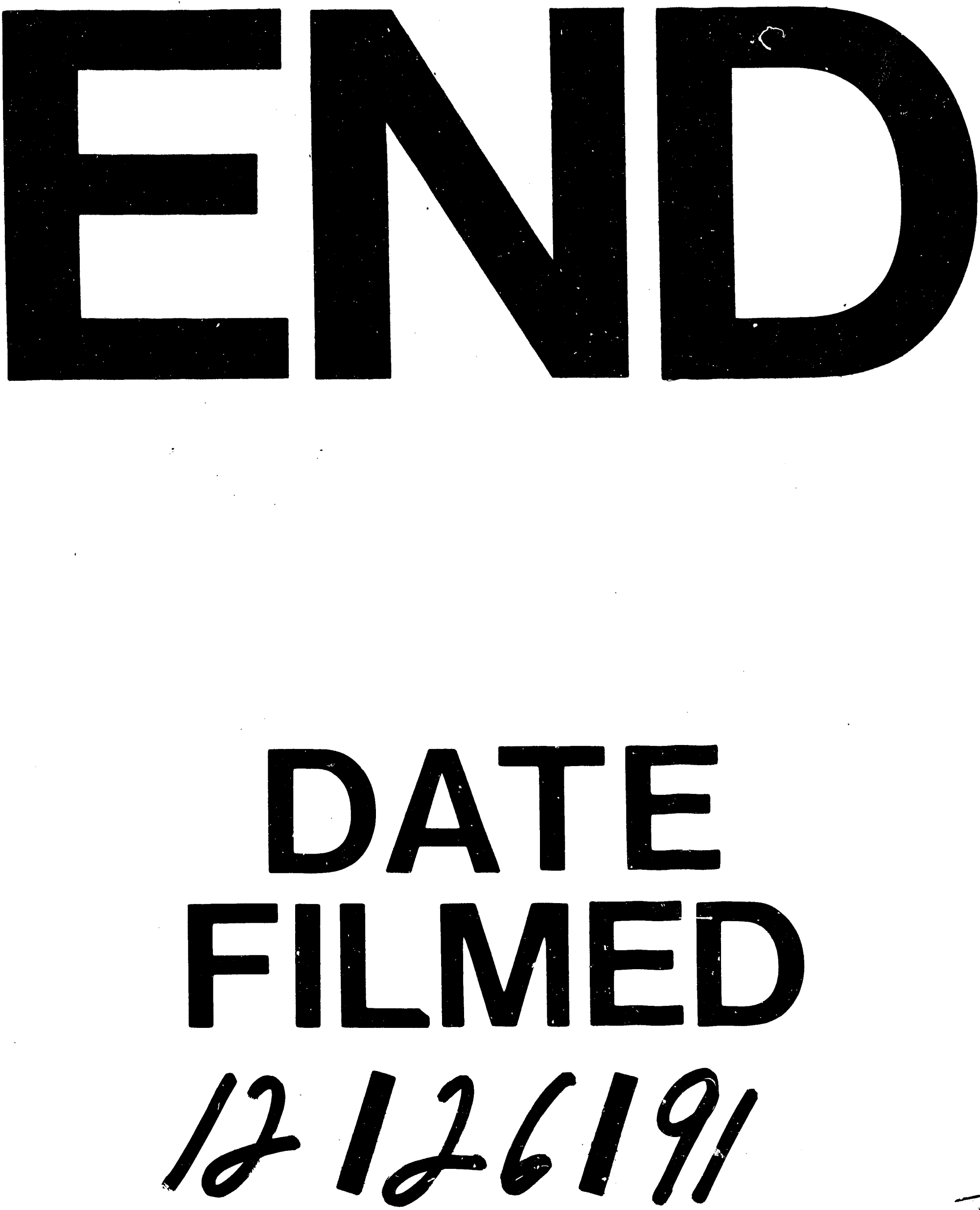